\title{
A Paleoclimate Reconstruction of the Little Ice Age to Modern Era Climate Conditions in the Eastern Ross Sea, Antarctica as captured in the RICE Ice Core
}

\author{
By \\ Hannah Jane Brightley
}

A thesis submitted to Victoria University of Wellington in partial fulfilment of the requirements for the degree of Master of Science in Geology 2017

School of Geography, Environmental and Earth Sciences Victoria University of Wellington 


\begin{abstract}
$\underline{\text { Abstract }}$
The Little Ice Age (LIA) (1400-1850 AD) represents one of the most significant climatic shifts over the past 5000 years. Previous studies from Antarctica indicate generally cooler and stormier conditions during this period, but this pattern shows distinct spatial and temporal variability. The Roosevelt Island Climate Evolution (RICE) ice core provides a new opportunity to study the drivers behind this variability at annual/seasonal resolution, in a relatively under-sampled and climatically sensitive region in the eastern Ross Sea. Contrary to previous studies, isotope measurements suggest warm conditions during the LIA at Roosevelt Island.
\end{abstract}

This study presents analysis of eight major ions $\left(\mathrm{Na}^{+}, \mathrm{Mg}^{2+}, \mathrm{Ca}^{2+}, \mathrm{K}^{+}, \mathrm{MS}^{-}, \mathrm{Cl}^{-}, \mathrm{NO}_{3}{ }^{-}, \mathrm{SO}_{4}{ }^{2-}\right.$ ) using both Ion Chromatograph and ICP-MS data, in order to reconstruct the atmospheric circulation pattern, sea ice extent and marine primary productivity across this LIA to Modern Era (ME) at Roosevelt Island. The dataset is tied to a robust age model allowing annual dating and the opportunity to accurately reconstruct rates of change during this ME-LIA. Challenges revolving around the calibration of the lon Chromatograph are also discussed. The major ion record determines whether the lack of cooling in the Roosevelt Island core implied by the stable isotopes represents a true temperature anomaly or whether the atmospheric circulation pattern caused an isotopic enrichment that masks an underlying cooling.

It was determined that Roosevelt Island experienced during the LIA (i) an increase in marine air mass intrusions along with weaker katabatic winds compared to the 200 years prior, (ii) decreased biological productivity and (iii) increased sea ice. From the 1850-1880s to $1992 A D$, there is a shift to reduced marine winds, increased katabatics, increased biological productivity and decreased sea ice until 1992. In the wider Ross Sea context, this suggests an east-west divide in terms of the dominance of katabatics versus marine wind influence. This divide is attributed with the warming signal seen in the RICE record in the Eastern Ross Sea and the cooling in the Western Ross Sea records. It is also likely linked to the influence of climate indices on the depth/position of the Amundsen Sea Low. 


\section{Acknowledgements}

I would like to say a big thank you to my supervisors Nancy Bertler and Lionel Carter for giving me the opportunity to work on this project and for their continued support and enthusiasm. Thank you in particular to Nancy, for encouraging me to take every opportunity to develop my knowledge and further my academic career.

A huge thank you also goes to Rebecca Pyne for her never ending support, not only in the technical aspects of the ice core laboratory but also as a friend, I couldn't have done this without you. I would also like to thank Jérôme Leveneur and Liz Keller for always putting aside time to help me with my statistical analysis. Thank you also to the RICE project team for their work that I have included in this thesis.

To my parents and Jarra, thank you for your love and unwavering encouragement throughout the last two years. To my friends, in particularly my JB office crew, for enduring the struggles together and my past/current flatmates, for creating a home to look forward to return to after a day at university. Finally, thank you to the ARC/SGEES and GNS Science staff and students who I have studied, worked with or been taught by over the last two years.

This work is a contribution to the Roosevelt Island Climate Evolution (RICE) Program, funded by national contributions from New Zealand, Australia, Denmark, Germany, Italy, the People's Republic of China, Sweden, UK, and USA. The main logistics support was provided by Antarctica New Zealand (Event K049) and the US Antarctic Program. Funding for this project was provided by the New Zealand Ministry of Business, Innovation, and Employment Grants through Victoria University of Wellington (RDFVUW-1103, 15-VUW-131) and GNS Science (540GCT32), and Antarctica New Zealand (K049). 


\section{Table of Contents}

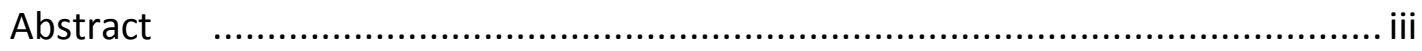

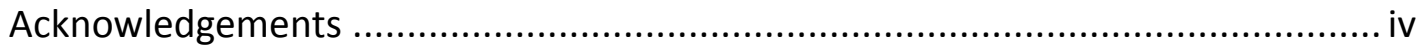

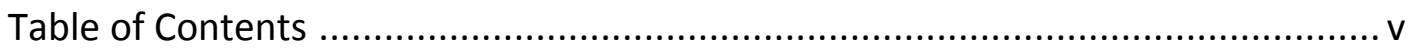

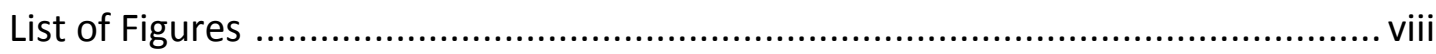

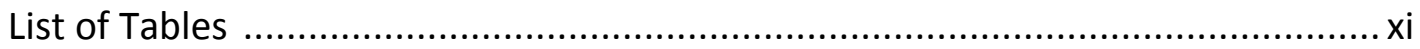

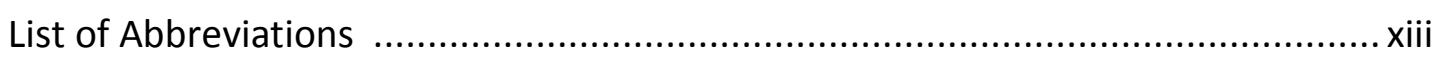

Chapter 1: Introduction ................................................................................ 1

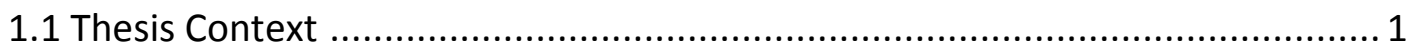

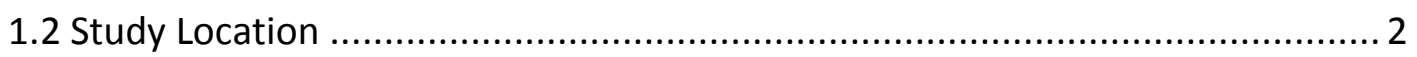

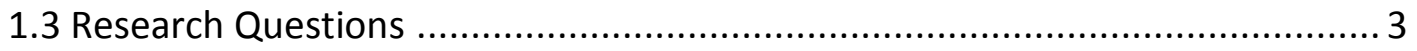

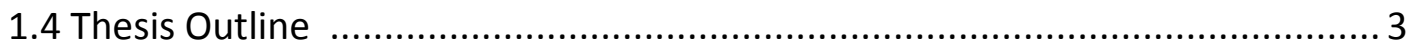

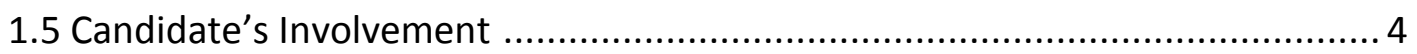

Chapter 2: Background ................................................................................... 5

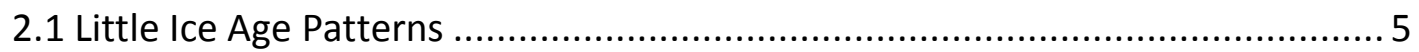

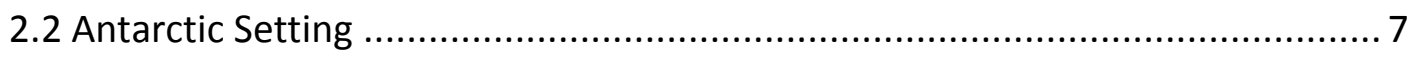

2.2.1 General Antarctic Circulation .................................................. 7

2.2.2 El Niño Southern Oscillation ......................................................... 8

2.2.3 Pacific Decadal Oscillation ............................................................ 9

2.2.4 Southern Annular Mode ............................................................. 10

2.3 Ice Core Paleoclimatology and Major Ion Analysis ......................................... 11

2.3.1 Ice Core Paleoclimatology .......................................................... 11

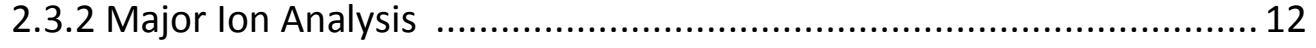

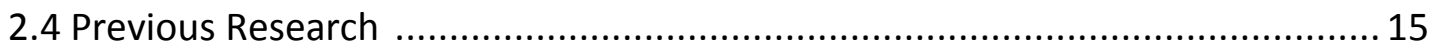

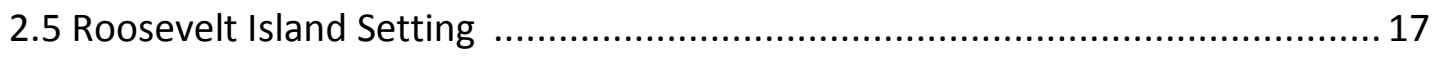

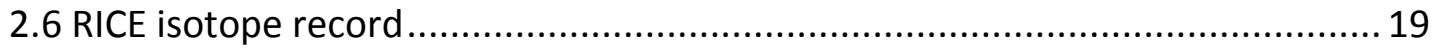

Chapter 3: Methodology and data .......................................................... 21

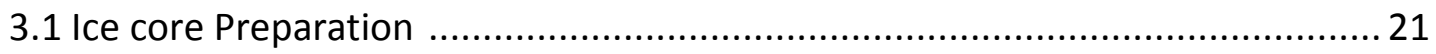

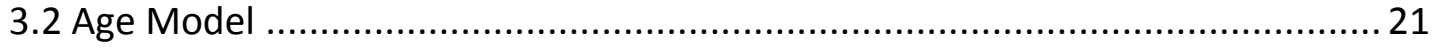

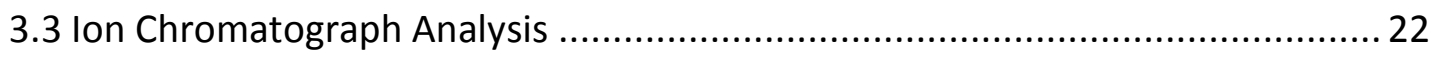

3.3.1 Dionex Ion Chromatograph ICS-5000 Capillary System Methodology. 23

3.3.2 Dionex Ion Chromatograph ICS-5000 2 mm Analytical System

Methodology 


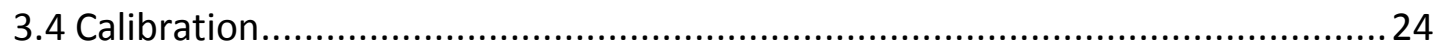

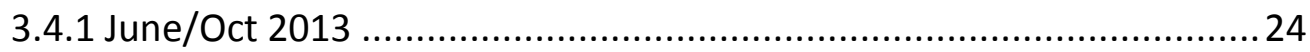

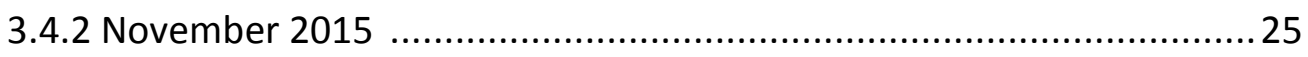

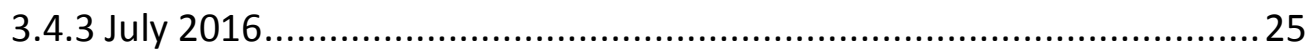

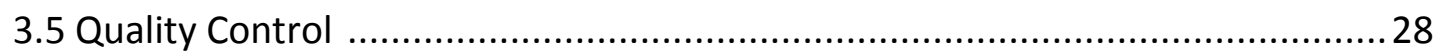

3.5.1 June/Oct 2013 ........................................................................ 30

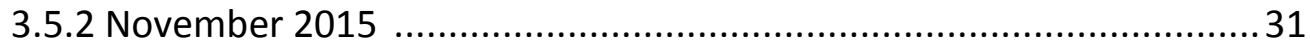

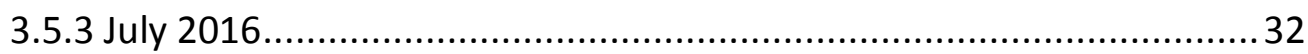

3.5.4 Data Quality Summary ........................................................... 33

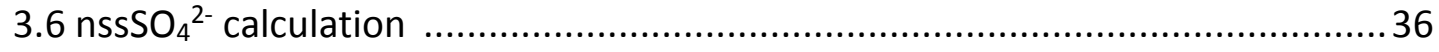

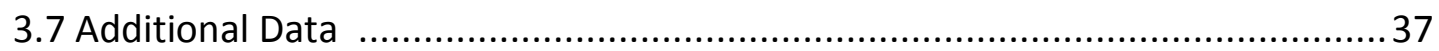

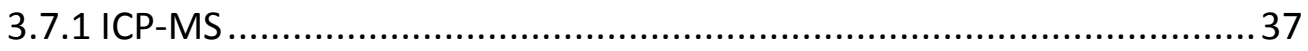

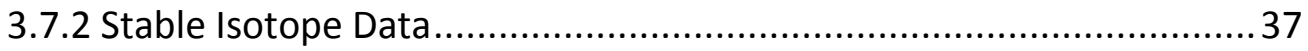

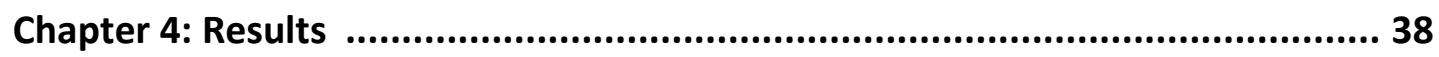

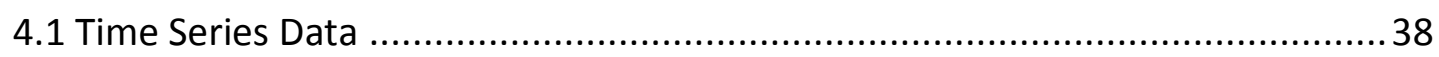

4.1.1 Long-term trend (1200-1992 AD) of 4 yearly resolved ICP-MS data.... 38

4.1.2 Modern Era Trends of IC and ICP-MS annually resolved data (1850-

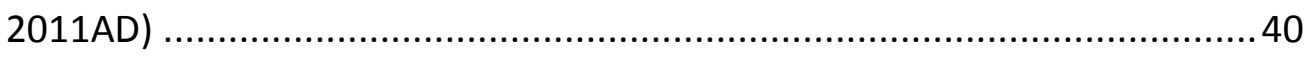

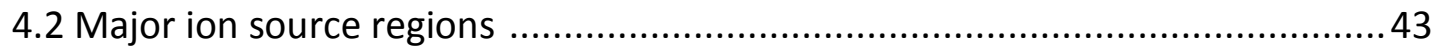

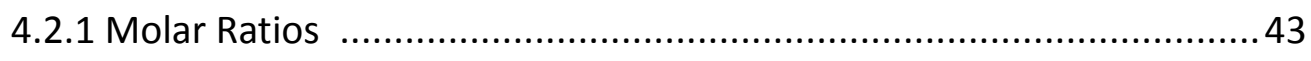

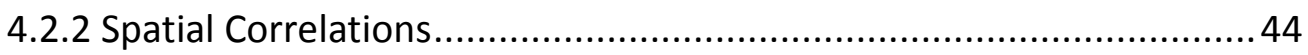

4.2.3 Sea salt source and timing .................................................... 47

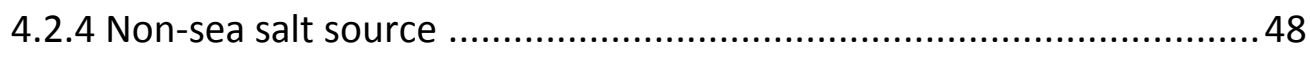

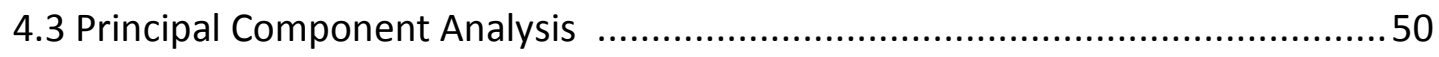

4.4 Investigation of Important Climate Indices .................................................53

4.4.1 First Principal Component ...................................................... 53

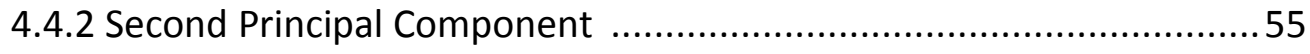

4.4.3 Summary of PC/Climate Indice comparison ..................................57

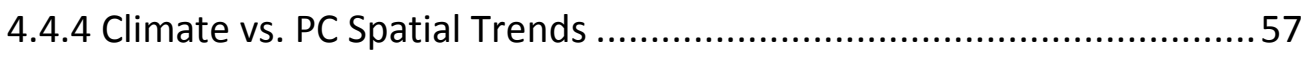

4.5 Time Series Cyclicity/Spectral Analysis ...................................................60

4.5.1 First Principal Component ..........................................................61

4.5.2 Second Principal Component ......................................................62

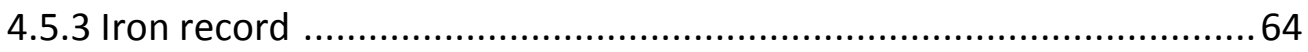




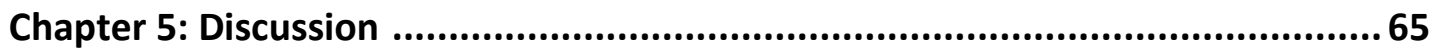

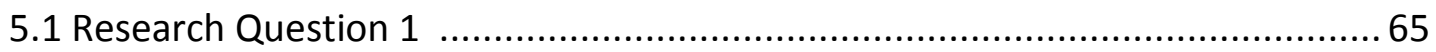

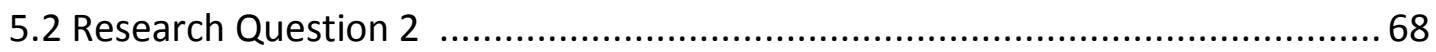

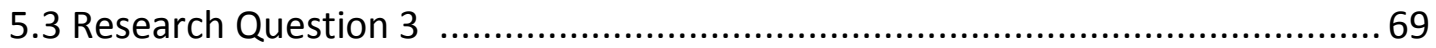

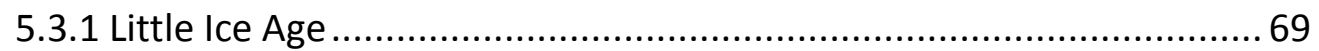

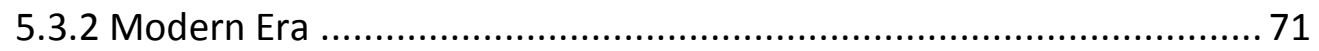

5.3.3 Explanation for Trends in LIA …................................................. 72

Chapter 6: Conclusions and Future Work ..................................................... 75

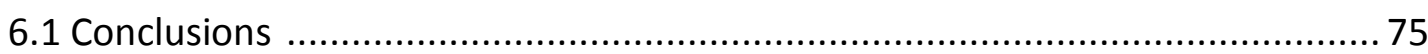

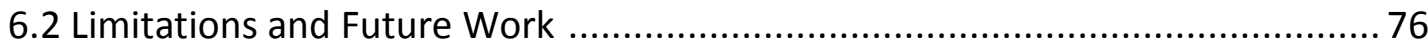

6.2.1 Ion Chromatograph Calibration Improvements ............................... 76

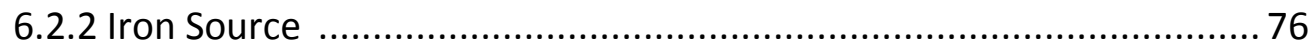

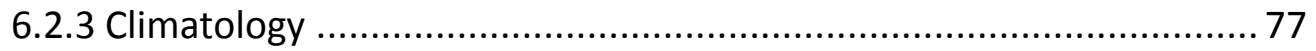

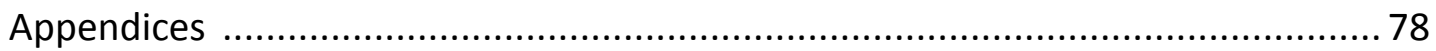

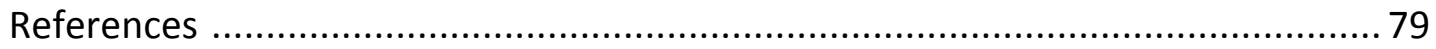




\section{List of Figures}

\section{Chapter 1}

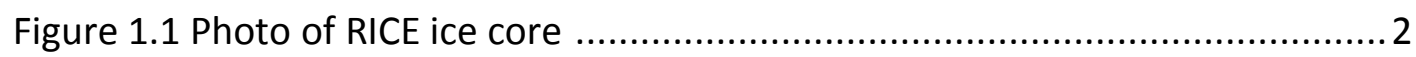

Figure 1.2. Photo of RICE ice core preparation in Antarctica ..............................2

Figure 1.3: Map showing location of Roosevelt Island .....................................2

\section{Chapter 2}

Figure 2.1: Summary of Little Ice Age spatial and temporal signatures ..................5

Figure 2.2: Summary of suggested causes of the LIA and their timing ..................6

Figure 2.3: Diagram of oceanic and atmospheric patterns during ENSO modes .....9

Figure 2.4: Diagram of Southern Annular Mode atmospheric pattern ...................10

Figure 2.5: Map of Antarctica showing LIA ice core site locations ........................15

Figure 2.6: Schematic diagram showing oceanic/atmospheric processes affecting

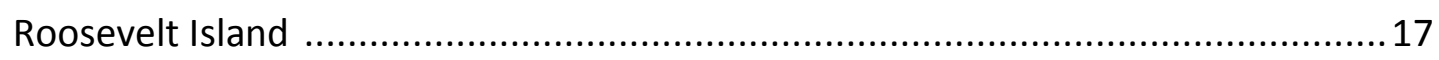

Figure 2.7: RICE $\delta D$ isotope record between 1200-2012 AD ..............................20

\section{Chapter 3:}

Figure 3.1: Photo showing continuous melter system ....................................... 21

Figure 3.2: Age/Depth graph for the past 2000 years of the RICE core ..................22

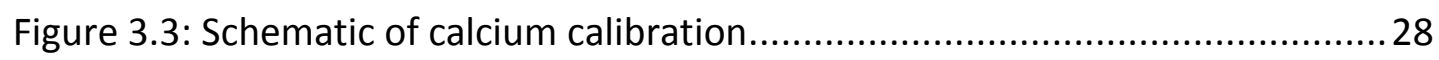

Figure 3.4: Cation stacked time series comparing all raw data from the four

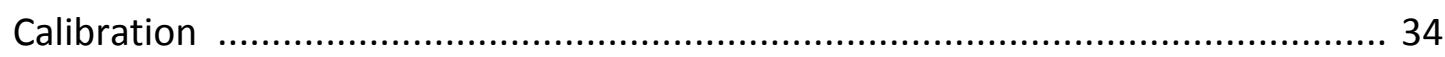

Figure 3.5: Anion stacked time series comparing all raw data from the four

Calibration

\section{Chapter 4:}

Figure 4.1: ICP-MS 4yr resolved time series spanning 1204-1992 AD for seven major ions

Figure 4.2: ICP-MS and IC annually resolved time series for the modern era (18502011AD)

Figure 4.3: Spatial correlation pattern of ERA-interim summer meridional surface winds with relevant major ions .44

Figure 4.4: Spatial correlation pattern of ERA-interim summer zonal surface winds with relevant major ions . .45

Figure 4.5: Spatial correlation pattern of ERA-interim summer mean sea level pressure with relevant major ions 46 
Figure 4.6: Spatial correlation pattern of ERA-interim annual sea ice concentration ICPMS annual nssSO4 over 1979-2011 AD

Figure 4.7: Time series comparing $\mathrm{MS}^{-}$and $\mathrm{Na}^{+}$peaks over 20 years 48

Figure 4.8: Time series comparing $\mathrm{nsSO}_{4}{ }^{2-} \mathrm{IC}$ record with sea ice extent in the Ross Sea 49

Figure 4.9: Comparison of VLG, EPICA and RICE nssSO4 to determine coinciding volcanic peaks 50

Figure 4.10: Time series comparing the SOI index with PC1 53

Figure 4.11: Time series comparing annual SAM index with the IC annual PC1 between 1729-1991 AD 54

Figure 4.12: Time series comparing the PDO index and the annual IC PC1 between 1854-1992 AD 54

Figure 4.13: Time series comparing the SAM index between 1200-1992 AD with 4yr resolved PC1 55

Figure 4.14: Time series comparing the SOI index with PC2 56

Figure 4.15: Time series comparing the PDO index and the annual IC PC2 between 1854-1992AD 56

Figure 4.16: Time series comparing the SAM index between 1200-1992 AD with 4yr resolved PC2 57

Figure 4.17: Spatial correlation pattern of ERA-interim annual meridional winds with PC1 and PC2 between 1979-2015 AD 58

Figure 4.18: Spatial correlation pattern of ERA-interim annual zonal winds with PC1 and PC2 between 1979-2015 AD 59

Figure 4.19: Spatial correlation pattern of ERA-interim annual mean sea level pressure with PC1 and PC2 between 1979-2015 AD 60

Figure 4.20: Spectral analysis with REDFIT of the annual PC1 data 61

Figure 4.21: Wavelet analysis with of the annual PC1 data 62

Figure 4.22: Spectral analysis with REDFIT of the annual PC2 data 63

Figure 4.23: Wavelet analysis with of the annual PC2 data 63

Figure 4.24: Spectral analysis with REDFIT of the 4yr resolved Fe data 64

\section{Chapter 5:}

Figure 5.1: Time series of RICE deuterium isotope record and accumulation between 
Figure 5.2: Time series of PC1/marine wind proxy 66

Figure 5.3: Time series of PC2/biological proxy 67

Figure 5.4: Time series of Fe/Katabatic wind proxy 68

Figure 5.5: Time series comparing deuterium isotope records of RICE, VLG and MES 69

Figure 5.6: Schematic diagram showing Little Ice Age conditions in the Ross Sea......70 Figure 5.7: Schematic diagram showing Modern Era conditions in the Ross Sea ......71 Figure 5.8: Map showing reconstructed katabatic streamlines that influence the Ross Sea ice core sites 72 


\section{List of Tables}

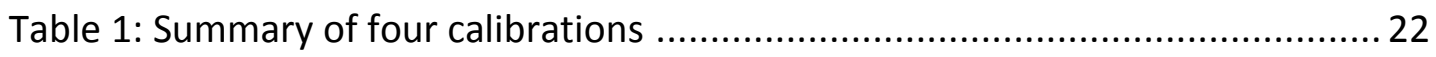

Table 2: Chromeleon calibration information for June 2013 calibration ................ 24

Table 3: Chromeleon calibration information for October 2013 calibration ........... 25

Table 4: Chromeleon calibration information for November 2015 calibration ....... 25

Table 5: Chromeleon calibration information for July 2016 calibration ................ 26

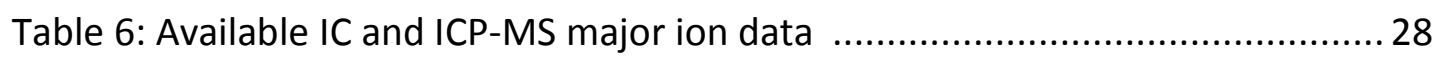

Table 7: Summary of RICE sample data medians and range ............................... 29

Tables 8: Comparing the external quality control certified values for Big Moose to measured concentrations during June 2013 calibrations .................................... 30

Tables 9: Comparing the external quality control certified values for Big Moose to measured concentrations during October 2013 calibrations ............................. 30

Table 10: Comparing the external quality control certified values for AES to

measured concentrations during November 2015 calibration

Table 11: Comparing the external quality control certified values for Big Moose to measured concentrations during November 2015 calibration

Tables 12: Comparing weight estimated concentrations for Levels 3 with measured concentrations during November 2015 calibration 32

Tables 13: Comparing weight estimated concentrations for levels 7 with measured concentrations during November 2015 calibration 32

Tables 14: Comparing weight estimated concentrations for Level 11 with measured concentrations during November 2015 calibration

Table 15: Comparing AES external quality control certified values with measured concentrations during July 2016 calibration 32

Tables 16: Comparing weight estimated concentrations for level 1.5 with measured concentrations during July 2016 calibration 33

Tables 17: Comparing weight estimated concentrations for levels 3 with measured concentrations during July 2016 calibration

Tables 18: Comparing weight estimated concentrations for level 7 with measured concentrations during July 2016 calibration

Tables 19: Comparing weight estimated concentrations for level 11 with measured concentrations during July 2016 calibration .33 
Table 20: Summary of two-sample t-test results conducted on ICP-MS 4yr resolved data 38

Tables 21: Statistical testing for modern era trend significance for cations 42

Tables 22: Statistical testing for modern era trend significance for anions 42

Table 23: Comparison of expected molar ratios in seawater with and measured Ratios

Table 24: Comparison of seawater/frost flower $\mathrm{SO}_{4}{ }^{2-} / \mathrm{Na}^{+}$molar ratios with measured ratios

Table 25: Principal component analysis results from IC 1729-1991 AD annual data..51 Table 26: Principal component analysis results from ICP-MS 1204-1992 AD 4year resolved data 52

Table 27: Statistical relationship between IC annually resolved PC1 with the SAM, SOI and PDO index 53

Table 28: Statistical analysis between ICP-MS PC1 and the SAM index 55

Table 29: statistical relationship between IC annually resolved PC2 with the SAM, SOI and PDO index 56

Table 30: statistical analysis between ICP-MS PC2 and the SAM index 57 


\section{List of Abbreviations}

ASL : Amundsen Sea Low

CFA: Continuous Flow Analysis

DEM: Digital Elevation Model

ENSO : El Niño Southern Oscillation

IC : Ion Chromatograph

ICP-MS : Induced Coupled Plasma Mass Spectrometry

LIA : Little Ice Age ( 1400-1850 AD)

ME : Modern Era ( 1850-1992 AD)

MES : Mount Erebus Saddle (ice core)

MSLP: Mean Sea Level Pressure

PC: Principal Component (from Principal Component Analysis)

PPB: parts per billion

PDO : Pacific Decadal Oscillation

QC: Quality Control standard

RICE : Roosevelt Island Climate Evolution (ice core)

SAM : Southern Annular Mode

SIE : Sea ice extent

SOI : Southern Oscillation Index

VLG : Victoria Lower Glacier (ice core)

WAIS: West Antarctic Ice Sheet (ice core) 



\section{Chapter 1: Introduction}

\subsection{Thesis Context}

With carbon dioxide concentrations continuing to rise, the importance of determining Antarctica's atmospheric and oceanic behaviour in a warming world is imperative. In order to assess that behaviour we consult paleoclimate records. The past 2000 years allow records of rapid climate change in the recent past to be studied at high resolution and thus track change through the transition from a natural to a human influenced climate. However, Antarctica's record of climate change and the impact on the atmospheric/oceanic conditions over the last 2000 years is relatively sparse, due to poor spatial and temporal coverage of high (annual/seasonal) resolution paleoclimate records (Rahaman et al., 2016).

The Little Ice Age (LIA) is of particular significance as current atmospheric and oceanic conditions observed in Antarctica may have been occurring in a similar way in the LIA, despite warmer temperatures (Bertler et al., 2011). Clear spatial variability exists in the temperature signal of the LIA, with the majority of records indicating a cooling (Bertler et al., 2011; Kreutz et al., 2000; Orsi et al., 2012; Rhodes et al., 2012), whereas Siple Station records a warming (Mosley-Thompson \& Thompson, 1990). The eastern Ross Sea is relatively under sampled during this time and is located in a sensitive region that could contribute to better understanding this spatial variability and the causal processes occurring in the Ross Sea region. 


\subsection{Study location}

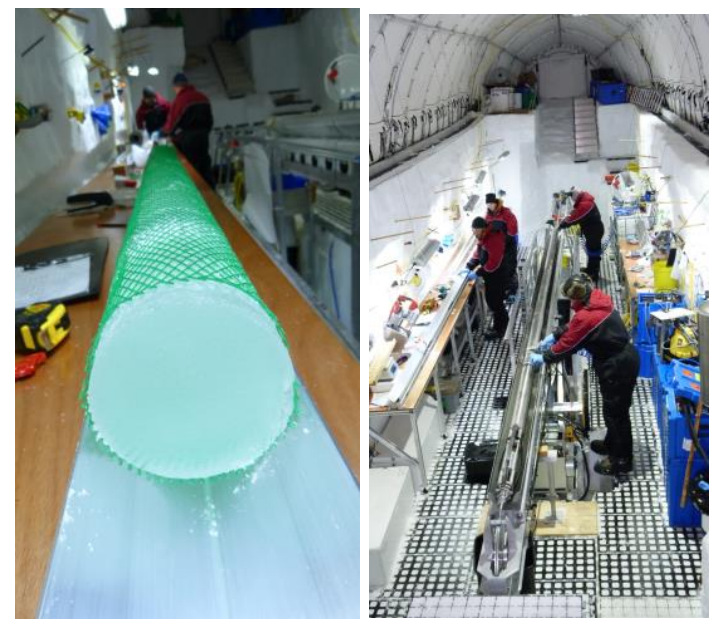

Figure 1.1 (left): Photo of RICE ice core.

Figure 1.2. (right): Photo of RICE ice core preparation in Antarctica.

Photos courtesy of Nancy Bertler.

The highly resolved Roosevelt Island Climate Evolution (RICE) ice core provides a new opportunity to study this relatively under sampled area in the eastern Ross Sea during the LIA. The RICE project is an international collaboration comprising 9 nations and 21 institutions, aimed at determining the stability of the Ross Ice Shelf in a warmer world. The RICE ice core is a $763 \mathrm{~m}$ core and was recovered from Roosevelt Island over the 2011/2012 and 2012/2013 field seasons (Figures $1.2 \& 1.2$ ).

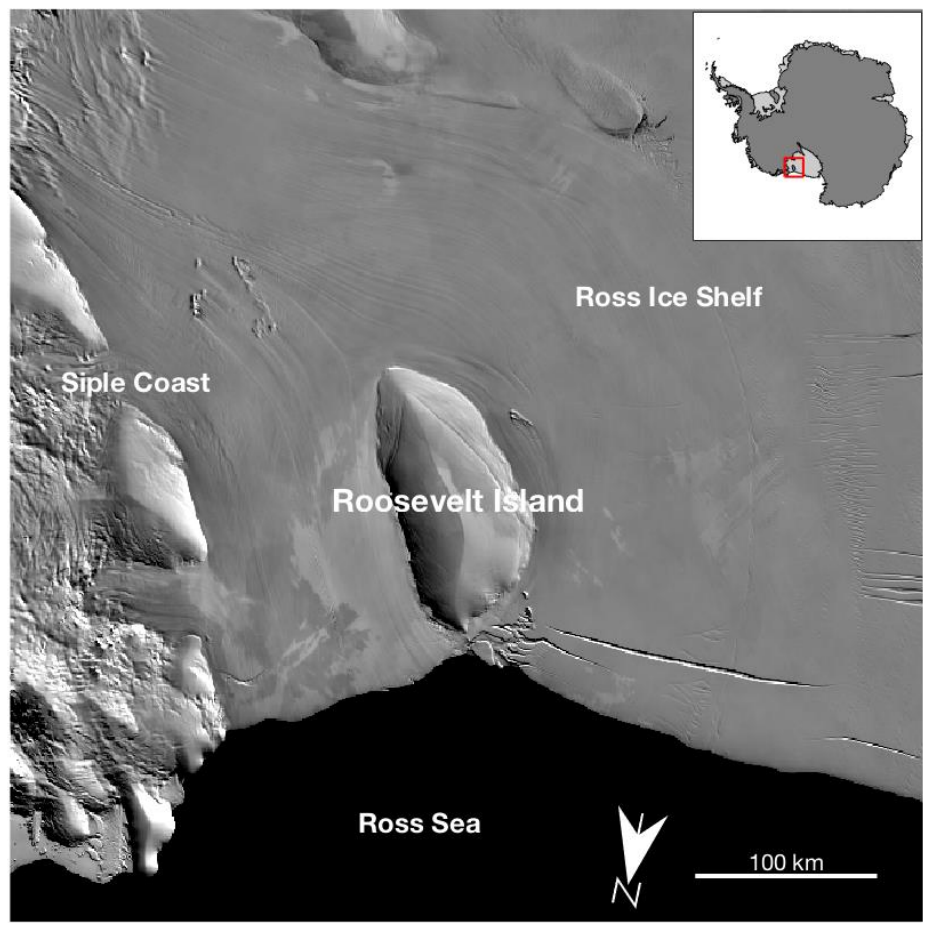

Figure 1.3: Location of Roosevelt Island. 
Roosevelt Island is an independent ice rise located on the north-eastern edge of the Ross Ice Shelf $\left(79.36398^{\circ} \mathrm{S}, 161.70645^{\circ} \mathrm{W}, 550 \mathrm{~m}\right.$ above sea level) (Figures 1.3). The RICE ice core provides an excellent opportunity to assess the atmospheric and oceanic processes occurring in Antarctica during the Little Ice Age to Modern Era (ME) transition, as it sits in a region that is known to be very sensitive to changes in climate drivers (Emanuelson, 2016). These drivers include the El Niño-Southern Oscillation (ENSO), Southern Annular Mode (SAM) and Pacific Decadal Oscillation (PDO), which interact with teleconnections in the tropics through the Amundsen Sea Low (ASL) and with the mid-latitudes through the position and strength of the Westerly winds.

\subsection{Research Questions}

This thesis will further our knowledge of the Little Ice Age-Modern Era conditions in Antarctica, as well as contribute to the wider Roosevelt Island Climate Evolution (RICE) project database. The thesis presented here focuses on 3 research questions:

1) What were the atmospheric and climatic conditions experienced at Roosevelt Island during the LIA/ME and over this transition?

2) What climate drivers can be linked to the processes we observe at Roosevelt Island during the LIA/ME and over this transition?

3) How do the climate conditions at Roosevelt Island fit in the context of the wider Ross Sea setting during the LIA/ME and over this transition?

\subsection{Outline}

This thesis comprises six chapters. Chapter 1 describes the context behind this research and the three research questions. Chapter 2 provides a background to the Little Ice Age, the Antarctic and the Ross Sea climatic/atmospheric setting and how major ion analyses in ice cores are used to reconstruct past environmental conditions. Chapter 3 will describe the methodology undertaken to analyse the major ion 
chemistry of the RICE ice core. Chapter 4 presents the results of time series and the associated statistical analyses. Chapter 5 provides a discussion on the 3 research questions. Finally, Chapter 6 details the main conclusions and the implications for future work.

\subsection{Candidate's Involvement}

This thesis contributes to the large amount of work that has already been conducted on the RICE ice core by the international RICE team. My contribution involved independently (following an induction) analysising 1020 ice core samples for 8 major ions during July 2016 on the Ion Chromatograph at the NZ National Ice Core Laboratory. Aided by Nancy Bertler and Rebecca Pyne, I developed a calibration for this data set which allowed the analysis of both ultra low and high ion concentrations required for studying a coastal ice core site. I subsequently processed previously run data from June/October 2013 and November 2015, that used alternative calibrations and in the former's case, a different IC machine. I pieced this older data with my data to form a longer IC timeseries (1558-1991 AD). This time series was then compared to the longer ICP-MS record measured by Andrea Tuohy and Peter Neff (1202-2011 AD). I was then guided on the data analysis techniques, but was responsible for their implementation. I completed the data interpretation and implications for past climate with the help of Nancy Bertler and Lionel Carter. 


\section{Chapter 2: Background}

\section{$\underline{2.1 \text { Little Ice Age Patterns }}$}

The LIA represents one of the most significant climatic shifts over the past 5000 years (Kreutz et al., 1997; Mayewski \& Maasch, 2006). The LIA phenomenon was initially used to describe the period between approximately 1400-1850s, when the Northern Hemisphere experienced exceptionally cold temperatures, subsequent glacial advances and mountain snow lines dropped to approximately $100 \mathrm{~m}$ below their current position (Figure 2.1) (Bond et al., 1999; Broecker et al., 1999; Grove, 1988). Broecker et al. (1999) reported that European summertime temperatures were relatively cold during the $17^{\text {th }}$ and early $19^{\text {th }}$ century (Figure 2.1 ). In North America, low summer temperatures were recorded from 1580 to 1730 AD and 1815 to 1870 AD (Broecker et al., 1999). However, the cooling was not synchronous across the whole of the Northern Hemisphere, with many regions recording warm temperatures similar to today, including areas in the Middle East, central North Atlantic, Africa, parts of the United States, tropical Eurasia and the extratropical Pacific Ocean (Mann et al., 2009).

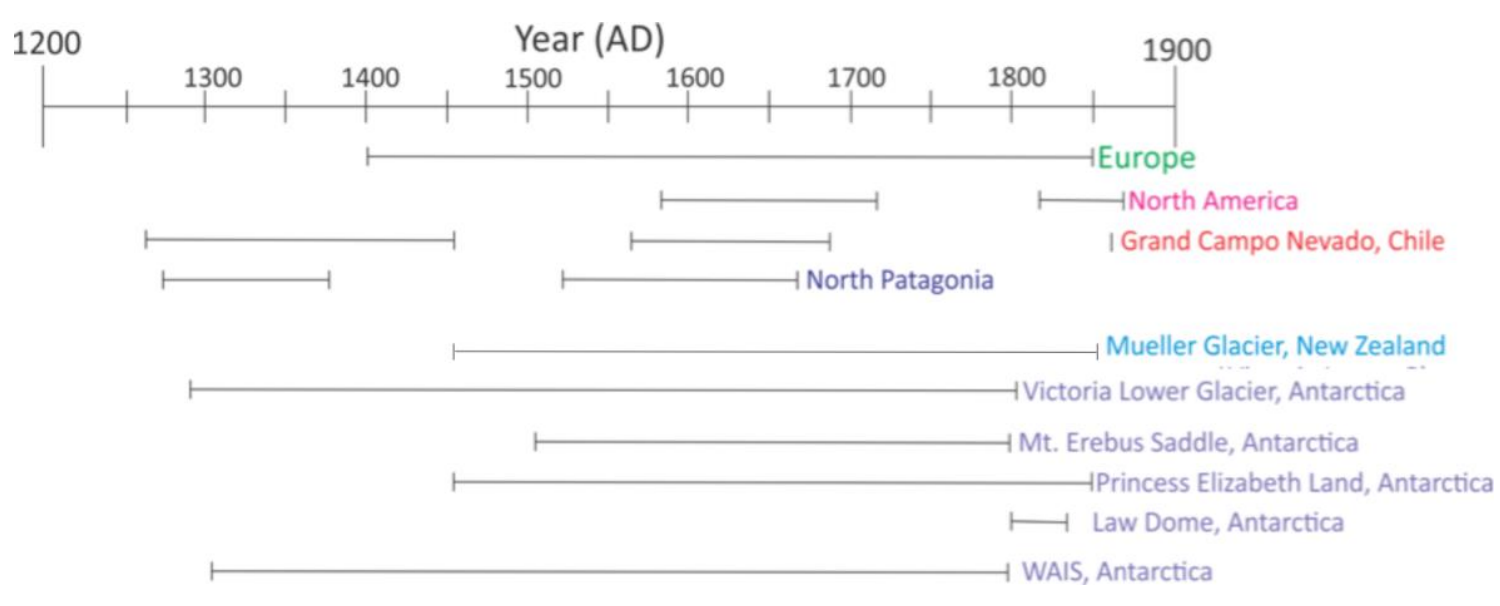

Figure 2.1: Summary of LIA cold signatures and their timing. Europe (Grove, 1988), North America (Broecker et al., 1999), Gran Campo Nevado (Koch \& Kilian, 2005), North Patagonia glacial advances (Villalba, 1994), Mueller Glacier, NZ (Schaefer et al., 2009). Victoria Lower Glacier (Bertler et al., 2011), Mt. Erebus Saddle (Rhodes et al., 2012), Princess Elizabeth Land (Li et al., 2009), Law Dome (Morgan, 1997), WAIS (Orsi et al., 2012).

However, contrary to previous understanding, the LIA signature has also been recorded in the Southern Hemisphere (Figure 2.1). Records from South America, 
including Chile and Patagonia, also show a cooler, wetter interval with glacial advances that coincide with the LIA (Koch \& Kilian, 2005; Villalba, 1994).

Mount Cook glacial records $\left({ }^{10} \mathrm{Be}\right)$ in New Zealand show broad similarities with the Northern Hemisphere over the past 700 years, with several advances followed by a termination during the mid to late $19^{\text {th }}$ century (Schaefer et al., 2009). However, Northern hemisphere glacier terminal moraine records show a LIA-maximum less than 400 years old, whereas Mueller Glacier's (Mt. Cook region) most prominent moraine from the past millennium is older, at $\sim 570$ years old (Schaefer et al., 2009). Putnam et al. (2012) linked the difference in timing to a southward shift in the Intertropical Convergence Zone (ITCZ) 500-400 years ago, which coincided with the Northern Hemisphere's (New Zealand) glacial advance (retreat).

Previous research has also confirmed a coincidence between the timing of the LIA and a generally cooler signature in Antarctic ice core and borehole records (Bertler et al., 2011; Li et al., 2009; Morgan, 1997; Orsi et al., 2012; Rhodes et al., 2012).

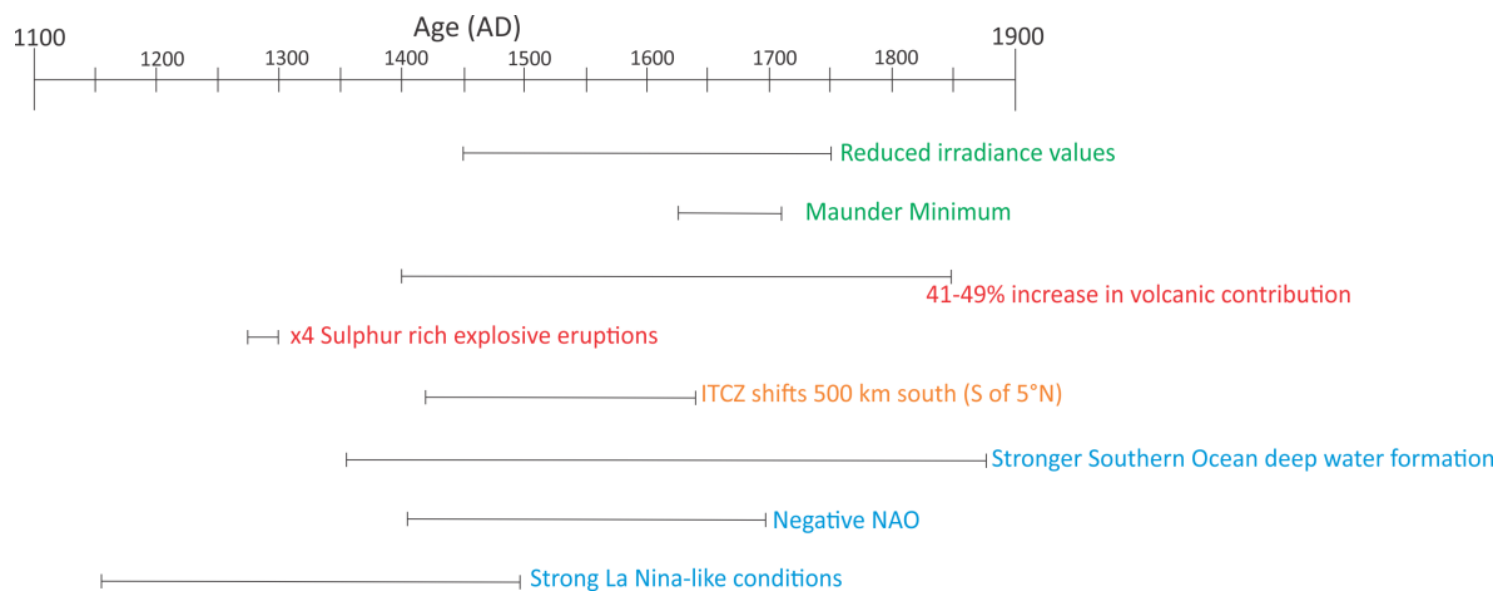

Figure 2.2: Summary of the suggested causes of the LIA and their respective estimated timings. Green shows solar irradiance impacts (Orsi et al., 2012). Red represents volcanic impacts (Crowley, 2000; Miller et al., 2012). Orange refers to climatological impacts (Sachs et al., 2009). Blue relates to oceanic/climate impacts (Broecker et al., 1999; Mann et al., 2009; Rustic et al., 2015).

Causes of this climatic phenomenon have ranged (Figure 2.2) from differences in deepwater formation in the Artic vs. Antarctic (Broecker, 2000), decreased solar irradiance (Bard et al., 2000; Orsi et al., 2012), volcanism (Crowley, 2000; Miller et al., 2012; Orsi et al., 2012), changes in the North Atlantic Oscillation (NAO) (Bradwell et al., 2006; 
Mann et al., 2009; Trouet et al., 2009) and El Niño Southern Oscillation (ENSO) (Oppo et al., 2009; Rustic et al., 2015) or movements in the Intertropical Convergence Zone (Haug et al., 2001; Newton et al., 2006; Putnam et al., 2012; Rouillard et al., 2016; Rustic et al., 2015; Sachs et al., 2009).

\section{$\underline{2.2 \text { Antarctic Setting }}$}

\subsubsection{General Antarctic circulation}

Antarctica is the highest, driest, coldest and windiest place on Earth (Bertler \& Barrett, 2010). The continent is comprised of the $10.35 \times 10^{6} \mathrm{~km}^{2}$ East Antarctic Ice sheet (EAIS) and the smaller West Antarctic Ice Sheet (WAIS) $\left(1.97 \times 10^{6} \mathrm{~km}^{2}\right)$, which are separated by the Transantarctic Mountains that stretch 3,500 km from the Ross to the Weddell Sea (Bertler \& Barrett, 2010; King \& Turner, 1997). Antarctica's thermal isolation is mainly due to the eastwards-flowing Antarctic Circumpolar Current (ACC), stretching between $40-65^{\circ}$ latitude. The ACC is the largest current in the world, the only current to connect all ocean basins, and is driven by the strong mid-latitude westerly winds (King \& Turner, 1997) .

Antarctica is surrounded by a belt of sea ice. During winter the sea ice covers up to $18 \times 10^{6} \mathrm{~km}^{2}$ of ocean but by the end of summer, it reduces to approximately $3 \times 10^{6} \mathrm{~km}^{2}$ (NSIDC, 2016). Unlike in the Arctic, the majority of Antarctic sea ice melts each summer, resulting in most sea ice being thin $1^{\text {st }}$ year ice.

The Antarctic atmospheric circulation is comprised of three main features; a weak surface anticyclone over the continent, the circumpolar trough and three climatologically low pressure centres (King \& Turner, 1997). The weak anti-cyclonic vortex over the continent is observed at the $500 \mathrm{hPa}$ pressure surface, and is displaced slightly off the South Pole towards the Ross Ice Shelf (King \& Turner, 1997). Whereas at the $300 \mathrm{hPa}$ surface the vortex is stronger and more symmetrical about the South Pole (King \& Turner, 1997). The circumpolar trough is a belt of low pressure that extends around Antarctica at roughly $66^{\circ} \mathrm{S}$, driven by a high concentration of cyclonic activity 
around the continent. Due to the asymmetry in the Antarctic continent three distinct climatological low-pressure centres occur within the Antarctic Circumpolar Trough. The most significant of these low pressures is the Amundsen Sea Low (ASL).

On average the ASL exists roughly between $60-70^{\circ} \mathrm{S}, 170-290^{\circ} \mathrm{E}$, just north of Marie Byrd Land in the Ross/Amundsen Seas. From this location it controls much of the meridional precipitation that reaches the Ross Sea through the formation of synoptic scale cyclones (Bertler et al., 2006; Neff \& Bertler, 2015). The ASL's depth shows a semi-annual oscillation, experiencing its lowest pressures in autumn and spring and its highest in summer and winter (Turner et al., 2013). It also exhibits a zonal and meridional climatological seasonal progression, often reaching its farthest easterly position in summer and farthest westerly (and southerly) position in winter (Fogt et al., 2012; Turner et al., 2013). The ASL is sensitive to the influence of the El Niño Southern Oscillation (ENSO), Pacific Decadal Oscillation (PDO) and the Southern Annular Mode (SAM).

\subsubsection{El Niño Southern Oscillation}

ENSO is the Earth's dominant mode of inter-annual variability. It describes the interaction between the ocean and atmosphere in the central Pacific (Walker Circulation) that oscillates on 2-7 year periodicity between the anomalously cold (La Niña) and anomalously warm (El Niño) sea surface temperatures off South America (Figure 2.3) (Collins et al., 2010). It is responsible for temperature and precipitation changes across the Pacific and other parts of the world including Antarctica through teleconnections (Liu et al., 2014). The Southern Oscillation Index (SOI) measures the difference in observed sea level pressure between Tahiti and Darwin; this can be used to reflect shifts from the La Niña (positive SOI) to El Niño (negative SOI) to normal phases (neutral SOI).

It also has been suggested that ENSO influences the zonal position of the ASL; during an El Niño the ASL moved $1400 \mathrm{~km}$ to the east off Marie Byrd Land between 1980-1990 AD (Bromwich et al., 2000; Cullather et al., 1996). However, it has been suggested that although the ASL does occupy a slightly westerly (easterly) position during La Niña (EI 
Niño) this difference in position is not statistically significant (Turner et al., 2013). Despite this, ENSO does show a statistically significant relationship in affecting the ASL's intensity, with an El Niño (La Niña) seeing higher (lower) mean sea level pressure (MSLP) (Turner et al., 2013). This impact on the ASL is greatest during winter (Turner et al., 2013).

Redacted figure due to copyright. Please refer to hard copy.

Figure 2.3: the oceanic and atmospheric patterns associated with the Walker circulation cell during normal conditions (La Niña conditions are just these patterns accelerated) and El Niño. Taken from Collins et al. (2010).

\subsubsection{Pacific Decadal Oscillation}

The Pacific Decadal Oscillation (PDO) is one of the main drivers of multi-decadal variability in sea surface temperatures in the extratropical North Pacific (MacDonald, 2005). It is often described as a long-lived El Niño-like pattern in terms of the Pacific climate variability (NOAA-NCDC, 2016). Like the ENSO pattern, the phases of the PDO are marked by either warm or cool phases, based on the ocean temperature anomalies in the northeast and tropical Pacific Ocean (NOAA-NCDC, 2016). For the $20^{\text {th }}$ century, the PDO appears to fluctuate on two general periodicities; 15 -to-25 years and 50-to-70 years (Mantua \& Hare, 2002). Over the past century, two full PDO cycles have occurred; a "cool" phase between 1890 to 1924 and 1947-1976 and a "warm" phase between 1925-1946 and 1977 until the mid-1990s (at least)(Mantua \& Hare, 2002). This periodicity appears to fluctuate through time, between 1600 and 1800 AD there is very little variability within the 50 to 100 year frequency range and yet this remerges between 1300 and 1500 AD and 1000 to 1200 AD(MacDonald, 2005). The PDO's influence has been recorded in Antarctica. The Vostok ice core's (central Antarctica) $\delta D$ 
and snow accumulation records show a 50-year cycle that significantly correlates with the PDO, suggesting a climatic teleconnection between central Antarctica and the tropical Pacific on a decadal scale (Ekaykin et al., 2004)

\subsubsection{Southern Annular Mode}

The SAM is the dominant mode of climatic variability in the Southern Hemisphere (Marshall, 2003). It describes a zonally symmetric pattern of opposing geopotential height perturbations, with one node over Antarctica and the other over the midlatitudes around $45^{\circ} \mathrm{S}$ (Gillett et al., 2006). The 'sign' of the SAM oscillates between a positive phase and negative phase. In the positive phase, a geopotential low anomaly develops over Antarctica as the pressure increases over the mid-latitudes (Figure 2.4), which strengthens the storm track and forces it polewards (Gillett et al., 2006). In the negative phase, the opposite is observed. This process represents the shift in the position and intensity of the westerly winds (Meredith et al., 2008). The poleward shift of the storm tracks is strongest in the austral summer, when the Southern Hemisphere jet is further towards Antarctica and relatively separated from the Hadley cell (Kushner et al., 2001). The SAM changes state on a week by week basis, however since the $15^{\text {th }}$ century it has seen a gradual shift to its positive phase, causing a cooling over the Antarctic continent, but a warming on the Antarctic Peninsula (Abram et al., 2014; Renwick \& Thompson, 2006)

\section{Redacted figure due to copyright. Please refer to hard copy.}

Figure 2.4: Diagram showing the position of the geopotential high (red) over the midlatitudes and the geopotential low (blue) over Antarctica, during a positive SAM event. The opposite pattern occurs in the negative phase (Renwick \& Thompson, 2006). 
The phase of SAM exerts a strong control on the meridional position of the ASL. During the negative phase of SAM, the ASL mean position occurs at roughly $68.72^{\circ} \mathrm{S} \pm 6.67^{\circ}$ and in positive mode the ASL is situated at $70.43^{\circ} \mathrm{S} \pm 6.10^{\circ}$ (Turner et al., 2013). However, the SAM appears to show no statistically significant relationship to the ASL'S zonal location, with its mean longitudinal position in the positive phase recording $128.76^{\circ} \mathrm{W} \pm 58.53^{\circ}$ and the negative phase occurring at $130.94^{\circ} \mathrm{W} \pm 66.20^{\circ}$ (Turner et al., 2013). The SAM positive phase also tends to lead to an overall lower circumpolar trough MSLP including the ASL, intensifying its circulation (Turner et al., 2013). According to Fogt and Bromwich (2011) the expression of the ENSO in the South Pacific teleconnection is detectable when they occur with a weak SAM or when an El Niño (La Niña) events occur with a negative (positive) SAM phase.

Past occurrences of these climate modes can be recorded in paleoclimate records including ice cores.

\section{$\underline{2.3 \text { Ice core paleoclimatology and major ion analysis }}$}

\subsubsection{Ice Core Paleoclimatology}

Ice cores are an invaluable paleoenvironmental proxy, providing a near instrumentalquality record of past temperature, changes in atmospheric circulation, dust loading, volcanic eruptions, biological processes and human influence on the environment as evinced by isotopic, major ion and trace element proxies (Brook, 2007). At sites with high snow accumulation rates, they allow continuous reconstructions as far back as 850,000 years ago, with some seasonally resolving the past $\sim 30,000-40,000$ years (Bertler \& Barrett, 2010). This is particularly important in areas in Antarctica as instrumental data are sparse and short in duration (Jouzel \& Merlivat, 1984). Major ion analysis can track the input of elements from sources including continental dust, volcanic eruptions, sea salt and biological processes (Brook, 2007). These records can be used to reconstruct past atmospheric circulation processes, sea ice extent, wind direction, primary productivity and aridity across the globe. 


\subsubsection{Major Ion Analysis}

This study presents eight major ions; four cations; $\mathrm{Na}^{+}, \mathrm{Ca}^{2+}, \mathrm{K}^{+}, \mathrm{Mg}^{2+}$, and three anions; $\mathrm{NO}_{3}{ }^{-}, \mathrm{MS}^{-}, \mathrm{SO}_{4}{ }^{2-}$, as well as non-sea salt sulphate $\left(\mathrm{nssSO}_{4}{ }^{2-}\right)$, which is calculated using the $\mathrm{Na}^{+}$and $\mathrm{SO}_{4}{ }^{2-}$. Together, these ions are used to reconstruct the marine/katabatic wind influence, primary productivity and sea ice extent at Roosevelt Island and surrounding region.

\section{$\mathrm{Na}^{+} \& \mathrm{Cl}^{-}$}

$\mathrm{Na}^{+}$provides an indicator of sea salt and can therefore act as a sensitive recorder of marine-sourced winds (Kreutz et al., 2000; Legrand \& Mayewski, 1997). Legrand and Mayewski (1997) confirm the use of $\mathrm{Na}^{+}$and $\mathrm{Cl}^{-}$as a proxy for marine air masses as their molar ratios show a similar value to the bulk seawater reference value (1.17).

\section{$\mathrm{SO}_{4}{ }^{2-}$ and $\mathrm{nsSSO}_{4}{ }^{2-}$}

Sea salt $\mathrm{SO}_{4}{ }^{2-}\left(\mathrm{SS} \mathrm{SO}_{4}{ }^{2-}\right)$ tends to be sourced from polynyas, cyclonic activity, bubble bursting and frost flowers, which generally reach Antarctica almost exclusively through the lower troposphere (Dixon et al., 2005). Typically $\mathrm{SO}_{4}{ }^{2-}$ peaks in summer and reaches its minimum during winter (Legrand \& Delmas, 1984).

Non-sea salt sulfate (nss $\mathrm{SO}_{4}{ }^{2-}$ ) is calculated by subtracting the proportional sea salt sulfate ( $\mathrm{ss} \mathrm{SO}_{4}{ }^{2-}$ ) from total sulphate. Non-sea salt $\mathrm{SO}_{4}{ }^{2-}$ (nss $\mathrm{SO}_{4}{ }^{2-}$ ) can reach sites from volcanic eruptions (minor apart from large eruptions) and biological reactions occurring in local polynyas (Dixon et al., 2005). Phytoplankton produce non-sea salt sulphate when dimethylsulphoniopropionate (DMSP) is converted to dimethyl-sulfide (DMS), which becomes oxidised to form MS $^{-}$and sulphate (Abram et al., 2013; Sinclair et al., 2014).

\section{$\mathrm{Ca}^{2+}$}

Most studies use $\mathrm{Ca}^{2+}$ as evidence of terrestrial dust, sourced from fine-grained calcium carbonate, dolomite and gypsum deposits (Laj et al., 1997; Markle et al., 2012; McConnell et al., 2007; Wolff et al., 2006). In the Greenland Ice Core Project (GRIP), calcium was used as a proxy for continental dust, as it was assumed to be sourced 
from soluble carbonates from soils in the region (Delmonte et al., 2002). However, previous studies including McConnell et al. (2007) have hinted at the lack of reliability in using $\mathrm{Ca}^{2+}$ as a proxy for a terrestrial source because (particularly at coastal locations) up to $90 \%$ of total soluble calcium can come from seawater and could therefore reflect a marine influence. Sommer et al. (2000) has suggested that more than $60 \%$ of the calcium concentration between their three East Antarctic cores was likely derived from an ocean source. Recent research from the Danish group of the RICE team has confirmed this, as they determine the $\mathrm{Ca}^{2+}$ source at Roosevelt Island is likely to be marine (P.Vallelonga, pers. comms).

$\mathrm{K}^{+}$

Bertler (2004) highlighted that potassium has both marine and terrestrial sources. The marine influence is supported by Bertler et al. (2005), which shows the ion having a statistically significant inverse relationship with increasing altitude.

\section{$\mathrm{Mg}^{2+}$}

Legrand and Mayewski (1997) highlight the use of $\mathrm{Mg}^{2+}$ as evidence of terrestrial salts, which can therefore act as a proxy for the katabatic winds (Markle et al., 2012). Mg can also be used as a sea salt indicator (Legrand \& Delmas, 1984; Li et al., 2009). Rhodes et al. (2012) showed how $\mathrm{Na}^{+}, \mathrm{Mg}^{2+}$ and $\mathrm{Sr}$ were strongly correlated $\left(\mathrm{R}^{2}>0.92\right)$ and their concentration ratios correspond to seawater concentration ratios, indicating a marine source.

$\mathrm{NO}_{3}{ }^{-}$

$\mathrm{NO}_{3}{ }^{-}$is thought to form in the tropics through lightning and soil exhalation and then transported to Antarctica through the upper troposphere/lower stratosphere (Legrand \& Delmas, 1986). Following deposition on the polar plateaus, the $\mathrm{NO}_{3}{ }^{-}$signature can be transported to coastal sites through katabatic winds (Legrand \& Mayewski, 1997). Therefore $\mathrm{NO}_{3}{ }^{-}$is used as an indicator of polar stratospheric clouds and hence provides evidence of a stratospheric air mass contribution (Legrand \& Mayewski, 1997). 


\section{MSA}

Methanesulphonic acid (MSA) is another by product of the conversion of dimethylsulphoniopropionate (a gas produced by species of phytoplankton in the ocean) to dimethyl-sulfide (DMS), which becomes oxidised to form $\mathrm{MS}^{-}$and sulphate (Abram et al., 2013; Sinclair et al., 2014). In the ice core geochemistry we analyse MS-, the ion form of MSA. As primary productivity is closely linked to sea ice in the Antarctic, the $\mathrm{MS}^{-}$record can be used as a proxy for sea ice, however this relationship varies across Antarctica. At Newall Glacier and Law Dome, MS- shows a positive correlation with sea ice and is therefore used as a sea ice proxy (Curran et al., 2003; Welch et al., 1993). A positive correlation in the Indian Ocean sector of the East Antarctic coastline is supposedly due to MSA forming from sea-ice algae (Sinclair et al., 2014). Whereas $\mathrm{MS}^{-}$records from the Weddell Sea, Dolleman Island and Lambert Glacier, all showed a negative correlation with sea ice, with a decrease in MSA concentration occurring following a winter with increased sea ice (Abram et al., 2007; Pasteur et al., 1994; Sun et al., 2002). In the Ross Sea, Sinclair et al. (2014) and Rhodes et al. (2009) determined that MSA concentration shows a negative correlation with sea ice and therefore reflects the amount of open-ocean area in the Ross Sea Polynya $\left(R^{2}=\right.$ $0.903)$.

\section{$\mathrm{SO}_{4}{ }^{2-} / \mathrm{Na}^{+}$ratio indicator of frost flowers}

It was originally thought that bubble bursting and sea spray were the only source of marine aerosols/sea salts in ice core records. However, sea salt concentration peaks in winter, despite having to travel further from the ocean across expansive sea ice (Abram et al., 2007; Rankin et al., 2000; Rankin et al., 2004). Two hypotheses were put forward - that either more efficient transport occurred during winter or that $\mathrm{Na}^{+}$was formed locally on sea ice through frost flower formation. It was shown that samples depleted in $\mathrm{nss} \mathrm{SO}_{4}{ }^{2-}$ in relation to $\mathrm{Na}^{+}$indicate fractionation to frost flowers (Rankin et al., 2000), while enriched ratios suggest a more vigorous transport (Wolff et al., 2003). Frost flowers occur when sea ice forms rapidly under cold conditions, when the conditions are below $-8^{\circ} \mathrm{C}$ sodium sulphate in the form of mirabilite will precipitate from the developing brine (Kaspari et al., 2005). This process removes most of the sulphate and approximately $13 \%$ of the sodium from the solution, resulting in a fractionation between the two ions (Rankin et al., 2002). Following this, the surface 
brine evaporates and creates a water vapour layer in which enhanced crystal growth forms frost flowers (Martin et al., 1996). The onshore winds and synoptic cyclones subsequently transport this signature to the coastal sites. These winds need to be strong enough to incorporate the salt from the flowers, but not so powerful that the flowers are destroyed (Rankin et al., 2000). Frost flowers have been shown to contribute $40 \%$ to the $\mathrm{Na}^{+}$budget in Antarctic ice cores, and in locations where there is at least $300 \mathrm{~km}$ of sea ice they dominate over open-water production at coastal sites (Kaspari et al., 2005; Rankin et al., 2000). As a result nss $\mathrm{SO}_{4}{ }^{2-} / \mathrm{Na}^{+}$can be used to reconstruct sea ice extent through the ratio typical of frost flowers, thus providing an additional proxy for sea ice extent (Dixon et al., 2005; Rankin et al., 2000).

$\mathrm{Fe}$

Bertler (2004) highlight the use of Fe as a terrestrial dust source.

\subsection{Previous Research}

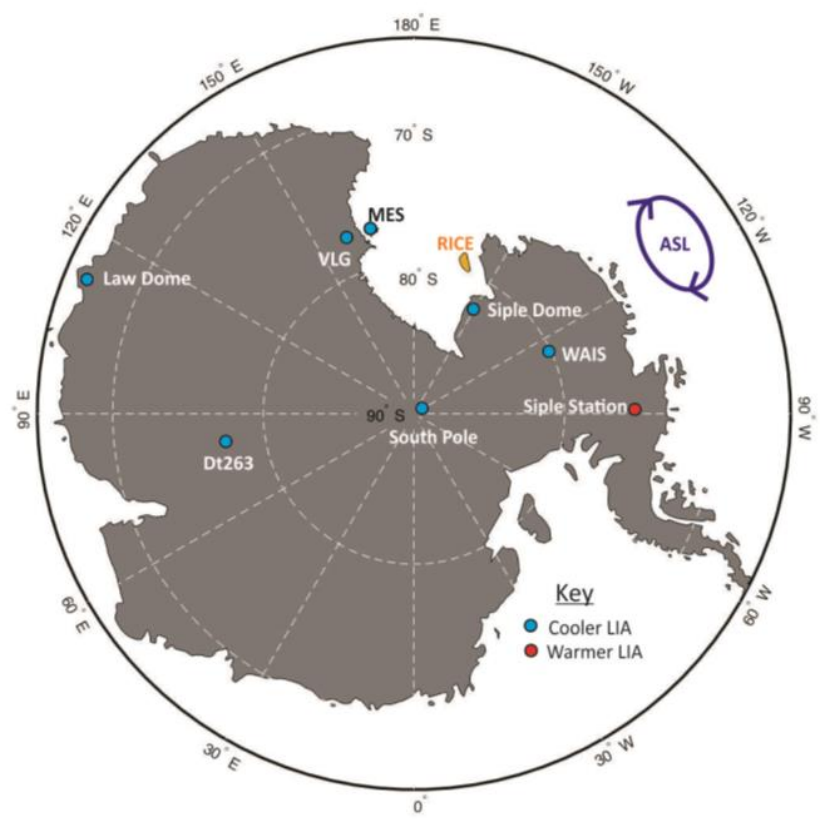

Figure 2.5: Map of Antarctica showing location of LIA ice core/borehole site locations (blue and red dots). ASL is the nominal location of the Amundsen Sea Low.

As previously mentioned, a LIA signature has been observed in several Antarctic ice core/bore hold records from across the continent (Figure 2.5). These records generally describe a period of colder temperatures, for instance, Bertler et al. (2011) reconstructed a $2{ }^{\circ} \mathrm{C}$ colder summer temperature from the Victoria Lower Glacier (VLG) 
ice core during the LIA time period. They determined Antarctica to be generally cooler, drier and stormier with stronger katabatic winds and snow accumulation decreasing by $67 \%$, which likely resulted in an increased sea-ice extent in the Ross Sea (Bertler et al., 2011). Rhodes et al. (2012) calculated a similar cooling in the Ross Sea Region of $1.6^{\circ} \mathrm{C}$ $\pm 1.4^{\circ} \mathrm{C}$ between 1500 and $1800 \mathrm{AD}$ from the Mt. Erebus Saddle ice core. They estimated that katabatic winds exceeded $57 \mathrm{~ms}^{-1}$, resulting in an enlarged Ross Sea polynya and a subsequent $80 \%$ increase in biological productivity in 1600-1875 AD. Li et al. (2009) also recorded colder, drier and reduced snow accumulation conditions in Princess Elizabeth Land (DT263), East Antarctica between 1450-1850 AD, coinciding with the LIA, conditions which they believe hold for the eastern Indian Ocean sector of East Antarctica. Morgan (1997) also suggested that summer month temperatures were relatively stable over the last 700 years at Law Dome (Dome Summit South ice core), however, the winters showed a cold period centred in the early 1800s. And most recently, Orsi et al. (2012) reconstructed that temperatures between 1300-1800 CE were $0.52^{\circ} \mathrm{C} \pm 0.28^{\circ} \mathrm{C}$ colder than the last 100 year average from the West Antarctic Ice Sheet (WAIS) Divide borehole temperature reconstruction.

Kreutz et al. (2000) recorded an increase in sea salt concentrations at Siple Dome from $1400 \mathrm{AD}$ until the $20^{\text {th }}$ century. They attributed this to a possible intensification and enhanced decadal variability in sea level pressure of the ASL. Thompson and MosleyThompson (1981) determined that concentrations of insoluble particles dramatically increased between 1450 and $1850 \mathrm{AD}$ at the South Pole ice core, a nearly two-fold increase in total particle concentration. This could potentially be attributed to a poleward shift in the westerlies, causing more meridional flow (Shulmeister et al., 2004). However, for the past 600 years there has been a negative correlation between the Law and Siple Dome ice core records, which is indicative of a more zonal westerly circulation in the southern Indian Ocean and southwest Pacific sectors during the LIA (Mayewski et al., 2004).

However, the LIA signature in Antarctica is temporally and spatially variable (Bertler et al., 2011). For example, Mosley-Thompson and Thompson (1990) reconstructed warmer and less dusty atmospheric conditions between 1600 and 1830 AD at Siple Station. The record suggests that it was not uncommon to observe a warming in the 
Ross Sea and a cooling in the Antarctic interior when the stronger zonal westerlies prevailed, highlighting the importance of understanding regional climate dynamics and feedbacks. These warmer conditions are potentially due to the influence of warm marine air masses travelling across West Antarctica during the LIA (Kreutz et al., 1997).

During this time period, $\mathrm{CO}_{2}$ levels also dropped by 6 and 10 ppmv between 1550 and $1880 \mathrm{AD}$ as recorded in the Law and Taylor Dome ice core records, respectively (Etheridge et al., 1996; Indermuhle et al., 1999).

\section{$\underline{2.5}$ Roosevelt Island Setting}

As a coastal location, Roosevelt Island sits at the confluence of the warm, meridional marine winds and the cold, dense katabatic winds (Figure 2.6). These are largely driven by the position of the ASL.

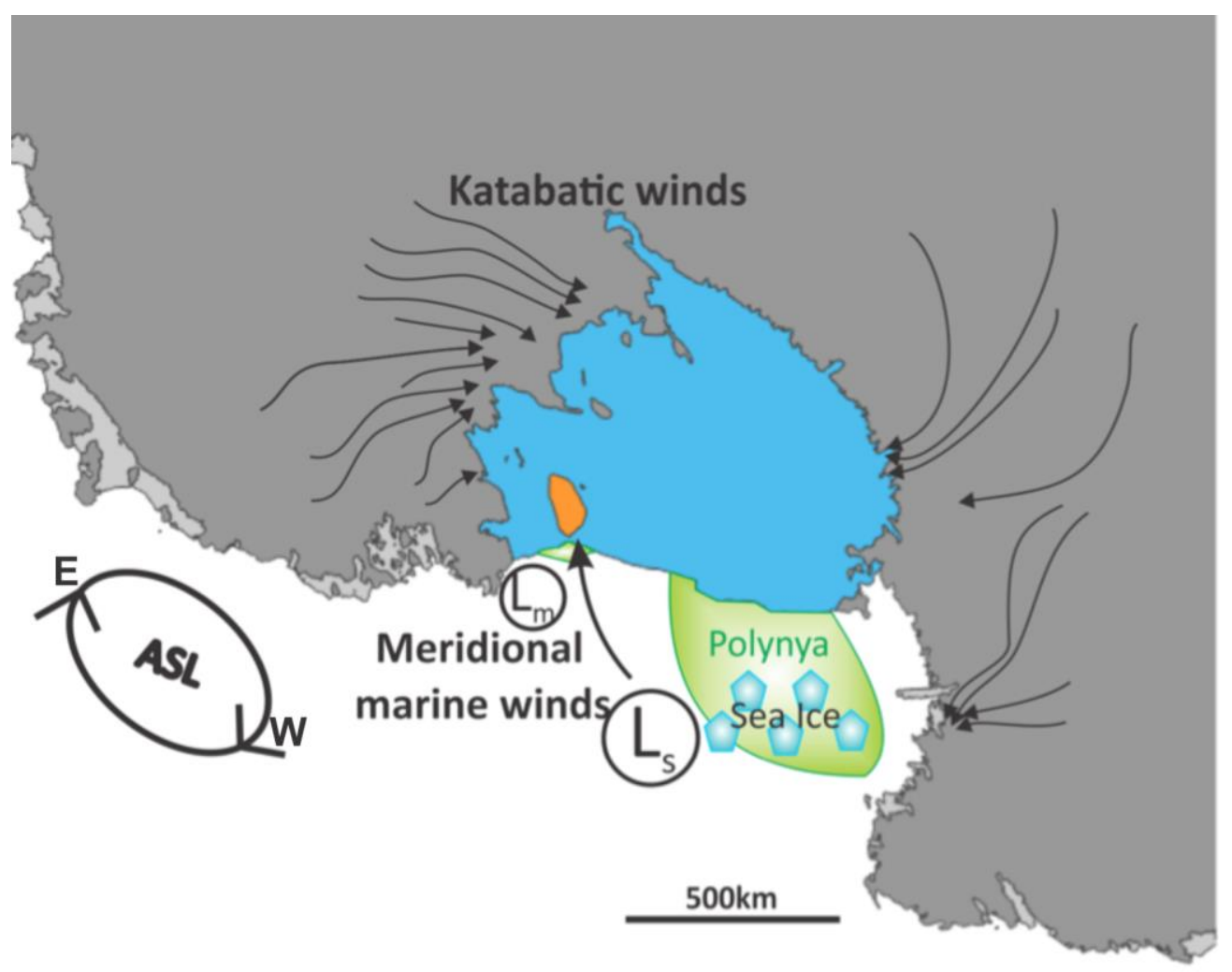

Figure 2.6: Schematic diagram showing oceanic and atmospheric processes affecting Roosevelt Island (orange) and Ross Ice Shelf (blue). ASL is the nominal location of the Amundsen Sea Low.

The marine winds arrive via the mesoscale and synoptic scale cyclones derived from the Ross/Amundsen Seas (Sinclair et al., 2010; Tuohy et al., 2015). Cyclones reaching 
Antarctica are mainly formed at the Polar Front, where the warm winds from the midlatitudes meet the cooler air bodies from the continent creating a major meridional temperature change in the troposphere (King \& Turner, 1997). Significant temperature gradients can also occur along Antarctica's coast, where cold continental air meets warm maritime air masses. This gradient can form mesoscale cyclones or small synoptic scale disturbances, which travel eastwards along the coast or north towards the Southern Ocean (King \& Turner, 1997). Mesoscale cyclones are typically less than $1000 \mathrm{~km}$ in horizontal diameter, averaging at approximately $100-500 \mathrm{~km}$, with surface speeds of over $15 \mathrm{~ms}^{-1}$, bringing strong winds and low surface pressures to the continent (Carrasco et al., 2003; King \& Turner, 1997). They are often located over icefree areas of ocean in southern airstreams to the west of synoptic lows (King \& Turner, 1997). Synoptic scale cyclones are those that exceed $1000 \mathrm{~km}$ diameter and travel in the circumpolar westerly flow around Antarctica providing high volumes of precipitation (Sinclair et al., 2010). It is the eastern branch of these low-pressure systems which bring warm, moist maritime air to the continent leading to precipitation (King \& Turner, 1997). The Ross Sea region's low elevation and proximity to the circumpolar trough makes it susceptible to frequent and intense cyclonic activity along the coast, causing stark contrasts with the inner plateau, which does not receive the same amount of accumulation (Sinclair et al., 2012).

The katabatic winds are gravity-driven atmospheric currents (Shulmeister et al., 2004). They form high on the Antarctic plateau, where net long-wave radiation losses cool the near-surface air. This dense air then drains outwards and downwards towards the coast (King \& Turner, 1997; Nylen \& Fountain, 2004). Katabatic winds are relatively slow in the continental interior due to the flat topography, however near the steep coastline their speeds increase (Nylen \& Fountain, 2004). These winds can also be enhanced by the movement of the aforementioned depressions moving eastwards along the coast, causing the cold katabatic air to travel far out over the ocean (Murphy \& Simmonds, 1993).

Roosevelt Island is also in the vicinity of the Ross Sea Polynya and a smaller polynya off its coast (N.Bertler, pers. comms). Polynyas are areas of reduced sea ice within the ice pack; their surface waters sustain high levels of biological productivity in spring and 
summer (Arrigo \& van Dijken, 2003). The Ross Sea Polynya is the largest consistently forming polynya on Earth and is the most biologically productive region in the Southern Ocean (Arrigo et al., 2008). The $\mathrm{MS}^{-}$and $\mathrm{nss} \mathrm{SO}_{4}{ }^{2-}$ concentrations recorded in the Roosevelt Island record are likely to reflect the dimethylsulphonionpropionate produced by the phytoplankton in this polynya. Both polynya are maintained through mechanical processes, therefore their sizes are largely dependent on the strength of the southerly winds, the ASL and the katabatic winds off the continent (Drucker et al., 2011).

\subsection{RICE Isotope Record}

Stable isotope records of $\delta O$ and $\delta D$ have been used in several ice core studies for paleothermometry (Barlow et al., 1993; Jouzel et al., 1996). The use of $\delta D$ as a paleoclimate indicator is based on the temperature-dependent fractionation of the two hydrogen isotopes during their movement through the hydrological cycle from the lower latitudes to the poles (Dansgaard, 1964). Due to the complex processes that affect the fractionation of these isotopes from the low latitudes to poles, $\delta D$ is not a direct link to surface temperature at an ice core site. Instead, $\delta D$ is determined by the difference in temperature between the site and its moisture source. According to Brook (2007), because the temperature changes at high latitudes are greater than at low latitudes, a relationship between $\delta D$ and surface temperature at the ice core site are assumed. Based on this proxy, the University of Copenhagen RICE team reconstructed the temperature at RICE for the last 2000 years using $\delta D$ as a proxy. However, contrary to previous Antarctic measurements during the LIA, the RICE deuterium isotope record shows an overall warming during this period (Figure 2.7). This could be attributed to a seasonal precipitation bias or the atmospheric circulation pattern has caused an isotopic enrichment which masks the underlying cooling. 


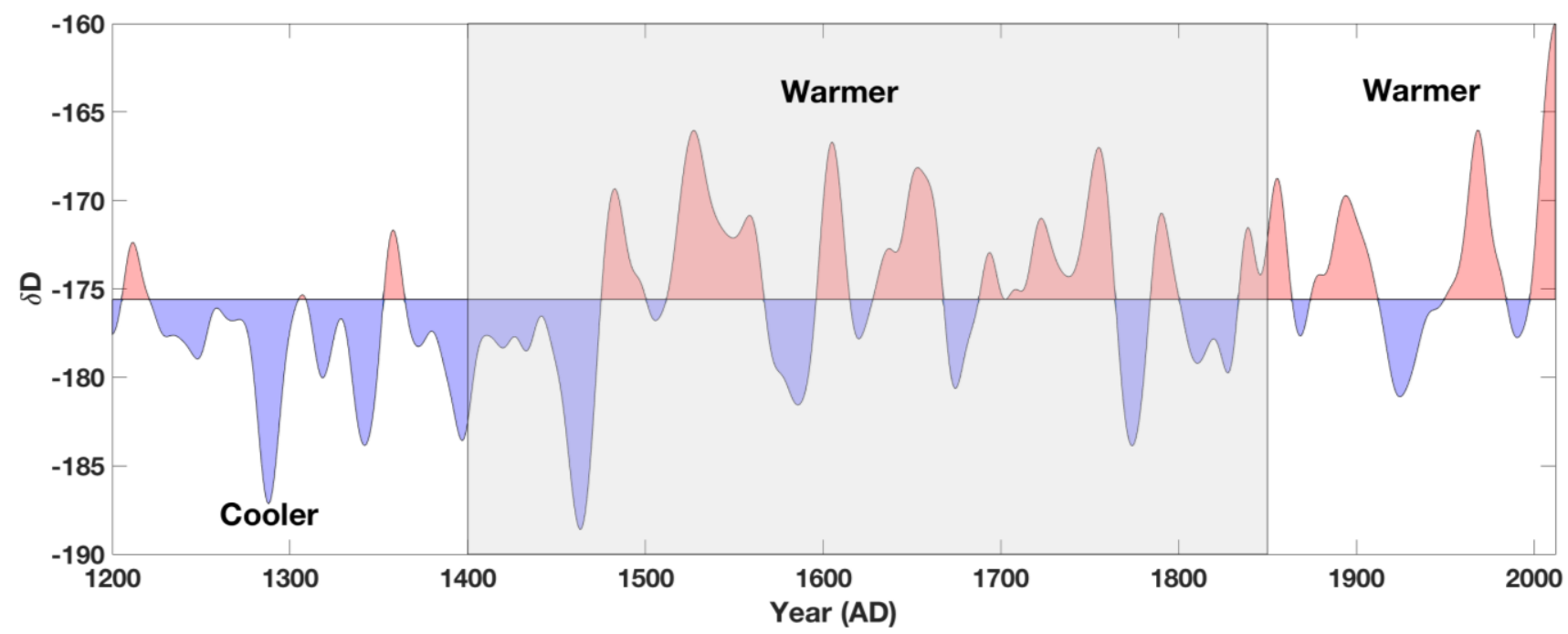

Figure 2.7: RICE SD isotope record from 1200-2012 AD. Grey box denotes Little Ice Age period. 


\subsection{Methodology}

\subsection{Ice core preparation}

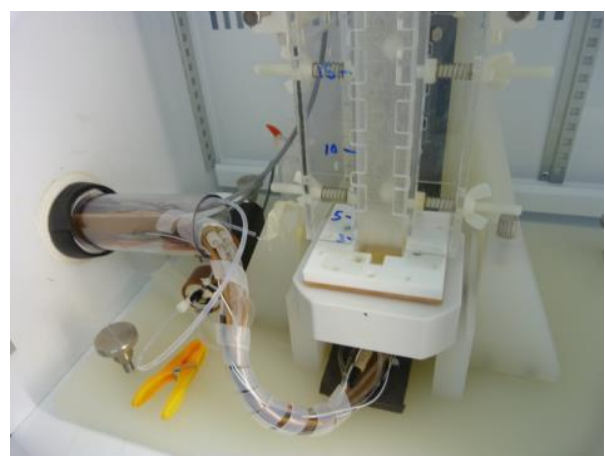

Figure 3.1: Photo showing continuous

melter system.

Photo courtesey of Nancy Bertler.

The RICE ice core was collected from Roosevelt Island $\left(79^{\circ} 21^{\prime} 46^{\prime \prime} \mathrm{S}, 161^{\circ} 42^{\prime} 3^{\prime \prime} \mathrm{W}\right.$, $560 \mathrm{~m}$ a.s.I) during the $2011 / 12$ and 2012/13 Antarctic field seasons by the RICE team. Following collection, the core was processed and melted over two core processing campaigns using a continuous melter system based on the design in Bigler et al. (2011) at the New Zealand Ice Core Laboratory, GNS Science in 2013 and 2014 (Figure 3.1). The stable isotope Continuous Flow Analysis (CFA) experimental setup is detailed in Emanuelsson et al. (2015). In addition to CFA analysis, 11,000 discrete ice core samples were collected in ultra-clean vials to cover the past 2000 years. These discrete samples were used for the ion analysis described in this thesis.

\subsection{Age model}

Roosevelt Island's coastal location and high snow accumulation allowed for sub-annual resolution through the LIA-ME section of the RICE IC data. The core was dated by the RICE team prior to the candidate's involvement (Figure 3.2) (Winstrup et al., In prep). The following techniques were used: annual layer counting of seasonally resolved proxies, methane concentration matched to the WAIS Divide ice core, tritium decay measurements, and volcanic eruptions as identified by tephras (N.Bertler, pers. comms). The 0-40 m section of the core was dated using a manual layer count (20121891 AD), whereas the 40-300 m (1891-0 AD) section was counted using an automated system. The counting made use of black carbon, calcium, conductivity, $\mathrm{pH}$ and stable isotopes. Thirteen geochemical signals of volcanic eruptions linked to the WAIS divide volcanic record and one tephra layer were used as discrete age benchmarks to constrain the age model. 
Ages for all samples in this thesis were determined using linearly interpolation of the age model at the sample mean depth.

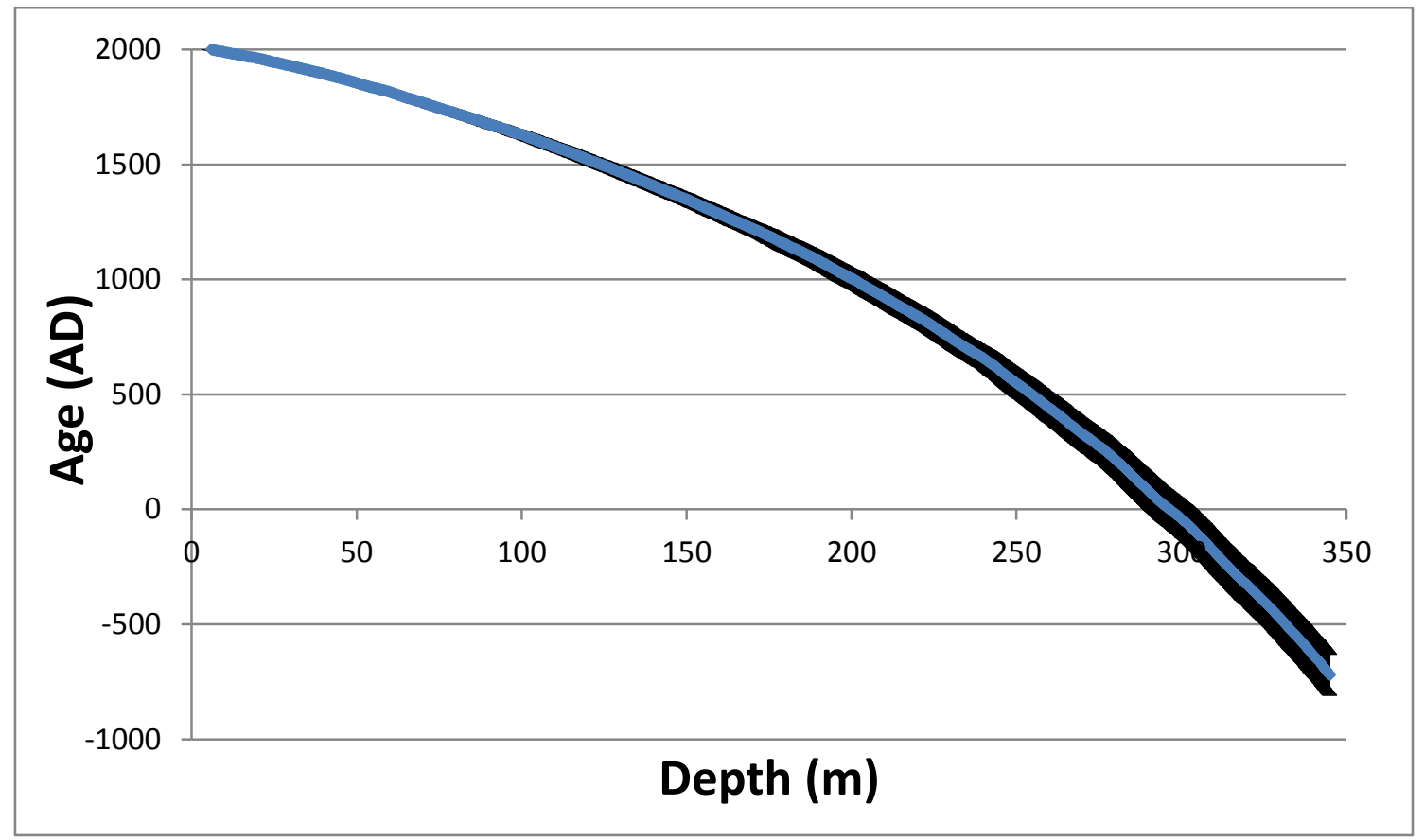

Figure 3.2: Age/depth plot for the last 2000 years for the RICE ice core. Blue line shows the age modelage, black shows the age uncertainty (Winstrup et al., In prep).

\section{$\underline{3.3 \text { Ion Chromatograph Analysis }}$}

Samples spanning the LIA-ME time period were measured at the NZ Ice Core Laboratory, GNS Science for 8 major ions: $\mathrm{Na}^{+}, \mathrm{Mg}^{2+}, \mathrm{Ca}^{2+}, \mathrm{K}^{+}, \mathrm{MS}^{-}, \mathrm{Cl}^{-}, \mathrm{NO}_{3}{ }^{-}$and $\mathrm{SO}_{4}{ }^{2-}$. This data was analysed over four different processing runs, using four different calibrations and on two different machines, detailed in Table 1. The bulk of the samples (1020) were measured by the candidate during the July 2016 processing run/calibration.

\begin{tabular}{|c|c|c|}
\hline Calibration & Time period & Machine \\
\hline Jun-13 & $1585-1613,1729-1755$ \& 1959-1991 AD & Capillary \\
\hline Oct-13 & $1900-1959$ AD & Capillary \\
\hline Nov-15 & $1558-1571 \& 1893-1900$ AD & 2 mm Analytical \\
\hline Jul-16 & $1571-1585 \& 1755-1893$ AD & 2 mm Analytical \\
\hline
\end{tabular}

Table 1: four calibrations used to measure major ion chromatograph data and the type of lon Chromatograph system used and the time period (years AD) this spanned, either the Capillary System or the $2 \mathrm{~mm}$ Analytical System. 


\subsubsection{Dionex Ion Chromatograph ICS-5000 Capillary System Methodology}

The June and October 2013 data was measured using the Dionex lon Chromatograph ICS-5000 Capillary System. Anions were measured using a Dionex IonPac AS-19 0.4 x $250 \mathrm{~mm}$ column with a Dionex IonPac AG19 $0.4 \times 50 \mathrm{~mm}$ guard column with a $\mathrm{KOH}$ eluent gradient concentration of 20-40 mM. Cations were measured using a Dionex IonPac CS-12A 0.4 x $250 \mathrm{~mm}$ column with a Dionex IonPac CG12A 0.4 × $50 \mathrm{~mm}$ guard column with a $20 \mathrm{mM}$ isocratic methane sulphonic acid eluent. Both cation and anion sides were fitted with a CCES $5002 \mathrm{ml}$ and ACES $5002 \mathrm{ml}$ anion suppressors, respectively.

This capillary system produced very broad peaks, which made it difficult to accurately determine ion concentrations (this will be further discussed in section 3.4.1). The system also had issues with carry over (when solution from the previous sample is included in second sample's measurement), therefore in 2015/2016 a new 2 mm Analytical System was used.

\subsubsection{Dionex Ion Chromatograph ICS-5000 2mm Analytical System Methodology}

The November 2015 and July 2016 data was measured using the Dionex Ion Chromatograph ICS-5000 2 mm Analytical System. Anions were measured using a Dionex lonPac AS-18 2 x 250 mm column with a Dionex lonPac AG18 2X 50 mm guard column and $250 \mu \mathrm{l}$ sample loop with a $\mathrm{KOH}$ eluent gradient concentration of 20-40 $\mathrm{mM}$. Cations were measured using a Dionex IonPac CS-12A 2 × $250 \mathrm{~mm}$ column with a Dionex lonPac CG12A $2 \times 50 \mathrm{~mm}$ guard column and a $100 \mu \mathrm{l}$ sample loop with $20 \mathrm{mM}$ isocratic methane sulphonic acid eluent. Both cation and anion sides were fitted with a CERS $5002 \mathrm{ml}$ and AERS $5002 \mathrm{ml}$ anion suppressors, respectively.

The sampling system was automated using an AS-HV autosampler. During preliminary tests, the autosampler was set to load $1 \mathrm{ml}$ of sample into the sample loop; however, this was insufficient to accurately measure the very low concentrations of ions. The loading method was then changed to load $2 \mathrm{ml}$ and this improved the results. The samples were introduced into the two sample loops through the separate isocratic 
pumps.

\section{$\underline{3.4 \text { Calibration }}$}

As listed in section 3.3 / Table 1, four calibrations were used to resolve the concentration of major ions in the samples during the LIA-ME time period. All ion chromatography (IC) data was analyzed using the Chromeleon software (version 7.2) ("Chromeleon 7.2 Chromatography Data System (CDS) Software," 2016). Every peak was manually checked to determine if the software had identified the correct peak and the area under the curve. If the software did not accurately select the peak, then the individual peak was manually integrated.

\subsubsection{June/Oct 2013}

During June and October 2013, a 9-point calibration was used (Tables 2 \& 3). Issues with the Capillary machine meant that several manual manipulations in Chromeleon were required to produce meaningful results. The $\mathrm{Ca}^{2+}$ and $\mathrm{Mg}^{2+}$ peaks were flat, broad and close together, making it harder to decipher where they start and end. The $\mathrm{NO}_{3}{ }^{-}$, $\mathrm{K}^{+}$and $\mathrm{MS}^{-}$peaks were also flat, broad peaks and hard to resolve. However, the $\mathrm{Na}^{+}, \mathrm{Cl}^{-}$ and $\mathrm{SO}_{4}{ }^{2-}$ analysis produced narrow and well-defined peaks. All ions were fitted with a linear calibration, apart from magnesium where a cubic curve was used (Table $2 \& 3$ ).

\begin{tabular}{|c|c|c|c|l|}
\hline Peak & Calibration Type & No. points & \multicolumn{1}{|c|}{$\mathbf{R}^{\mathbf{2}}$} & Range (ppb) \\
\hline $\mathbf{N a}^{+}$ & Linear with offset & 9 & 0.99986 & $10-2000$ \\
\hline $\mathbf{K}^{+}$ & Linear & 7 & 0.99969 & $10-750$ \\
\hline $\mathbf{M g}^{2+}$ & Cubic with offset & 6 & 0.99876 & $5-250$ \\
\hline $\mathbf{C a}^{2+}$ & Linear with offset & 6 & 0.99964 & $2.5-375$ \\
\hline $\mathbf{M S}^{-}$ & Linear with offset & 8 & 0.99979 & $2.5-375$ \\
\hline $\mathbf{C l}^{-}$ & Linear & 8 & 0.9999 & $10-1500$ \\
\hline $\mathbf{N O}_{3}{ }^{-}$ & Linear with offset & 6 & 0.99942 & $5-250$ \\
\hline $\mathbf{S O}_{4}{ }^{2-}$ & Linear with offset & 8 & 0.99967 & $5-500$ \\
\hline
\end{tabular}

Table 2: Chromeleon calibration information for June 2013 calibration 


\begin{tabular}{|c|c|c|c|l|}
\hline Peak & Calibration Type & No. points & \multicolumn{1}{|c|}{$\mathbf{R}^{\mathbf{2}}$} & Range (ppb) \\
\hline $\mathbf{N a}^{+}$ & Linear with offset & 9 & 0.99994 & $2-400$ \\
\hline $\mathbf{K}^{+}$ & Linear with offset & 9 & 0.99859 & $5-1000$ \\
\hline $\mathbf{M g}^{2+}$ & Cubic with offset & 5 & 0.99947 & $12.5-250$ \\
\hline $\mathbf{C a}^{2+}$ & Linear with offset & 5 & 0.96779 & $5-100$ \\
\hline $\mathbf{M S}^{-}$ & Linear with offset & 7 & 0.99947 & $1.25-50$ \\
\hline $\mathbf{C l}^{-}$ & Linear with offset & 9 & 0.99968 & $2.5-500$ \\
\hline $\mathbf{N O}_{3}{ }^{-}$ & Linear with offset & 5 & 0.9959 & $2.5-50$ \\
\hline $\mathbf{S O}_{4}{ }^{2-}$ & Linear with offset & 9 & 0.99978 & $2.5-500$ \\
\hline
\end{tabular}

Tables 3: Chromeleon calibration information for October 2013 calibration.

\subsubsection{November 2015}

The November 2015 data used a 13-point anion and cation calibration (Table 4). All ions were fitted with a linear calibration, except potassium which was fitted with a quadratic (Table 4). The peaks were relatively well defined in this calibration, and therefore minimal manual manipulations were necessary. $\mathrm{Na}^{+}, \mathrm{Mg}^{2+}, \mathrm{Ca}^{2+}, \mathrm{MS}^{-}, \mathrm{Cl}^{-}$, and $\mathrm{SO}_{4}{ }^{2-}$ all report $\mathrm{R}^{2}$ values exceeding 0.9999 , with $\mathrm{NO}_{3}{ }^{-}$and $\mathrm{K}^{+}$recording values $>0.999$. To obtain a good linear/quadratic fit for $\mathrm{NO}_{3}{ }^{-}$and $\mathrm{K}^{+}$, respectively, required limiting the concentration range at which these ions could be calibrated. This could result in samples with values above/below this range being reported higher/lower than the accurate reading.

\begin{tabular}{|c|c|c|c|c|}
\hline Peak & Calibration Type & No. points & $\mathbf{R}^{\mathbf{2}}$ & Range (ppb) \\
\hline $\mathbf{N a}^{+}$ & Linear with offset & 11 & 0.99996 & $7.9-1479.0$ \\
\hline $\mathbf{K}^{+}$ & Quadratic with offset & 7 & 0.9995 & $7.4-37.4$ \\
\hline $\mathbf{M g}^{2+}$ & Linear with offset & 11 & 0.99995 & $2-371$ \\
\hline $\mathbf{C a}^{2+}$ & Linear with offset & 9 & 0.99991 & $3.8-300$ \\
\hline $\mathbf{M S}^{-}$ & Linear with offset & 11 & 0.99991 & $2.0-370.0$ \\
\hline $\mathbf{C l}^{-}$ & Linear with offset & 13 & 0.99997 & $4.9-1903.0$ \\
\hline $\mathbf{N O}_{3}{ }^{-}$ & Linear with offset & 9 & 0.9998 & $4.7-92.0$ \\
\hline $\mathbf{S O}_{4}{ }^{2-}$ & Linear with offset & 10 & 0.99993 & $4.9-745.0$ \\
\hline
\end{tabular}

Table 4: Chromeleon calibration information for November 2015 calibration

\subsubsection{July 2016}

The July 2016 IC samples were initially processed using a 13-point calibration for both the anions and cations; however this resulted in a weak fit/low $\mathrm{R}^{2}$, as they did not 
capture the full range of the data, particularly in the low ppb. Consequently, more calibration points were added and resulted in a 32-point calibration for the cations and a 22-point calibration for the anions (Table 5). Higher concentration calibration points were added for $\mathrm{Cl}^{-}$(up to $12,000 \mathrm{ppb}$ ), $\mathrm{SO}_{4}{ }^{2-}$ (up to $2800 \mathrm{ppb}$ ), $\mathrm{K}^{+}$(up to $90 \mathrm{ppb}$ ) and $\mathrm{Na}^{+}$(up to $7900 \mathrm{ppb}$ ). These were only "turned on" if a spike was present.

\begin{tabular}{|c|l|c|c|c|}
\hline Peak & \multicolumn{1}{|c|}{ Calibration Type } & No. points & \multicolumn{1}{|c|}{$\mathbf{R}^{\mathbf{2}}$} & \multicolumn{1}{|c|}{ Range (ppb) } \\
\hline $\mathbf{N a}^{+}$ & Linear with offset & 30 & 0.99987 & $11.6-2574.5$ \\
\hline $\mathbf{K}^{+}$ & Quadratic with offset & 16 & 0.99946 & $2.7-27.4$ \\
\hline $\mathbf{M g}^{2+}$ & Quadratic with offset & 17 & 0.9999 & $9.9-186.0$ \\
\hline $\mathbf{C a}^{2+}$ & Quadratic with offset & 16 & 0.99987 & $9.8-164.1$ \\
\hline $\mathbf{M S}^{-}$ & Quadratic with offset & 19 & 0.99961 & $1.3-91.1$ \\
\hline $\mathbf{C l}^{-}$ & Linear with offset & 30 & 0.99995 & $5.4-3842.9$ \\
\hline $\mathbf{N O}_{3}{ }^{-}$ & Linear with offset & 10 & 0.99893 & $12.1-66.5$ \\
\hline $\mathbf{S O}_{4}{ }^{2-}$ & Linear with offset & 21 & 0.9999 & $22.7-915.3$ \\
\hline
\end{tabular}

Table 5: Chromeleon calibration information for July 2016 calibration.

Anion calibration points were created by diluting the anion " $\mathrm{LO}$ " single standard mix solution (see Appendix A for concentration data) with water to 22 different solution/water ratios via pipette, making a total volume of $4 \mathrm{ml}$. The cation calibration points/levels were created by diluting the cation "LO" single standard mix solution (see Appendix A for concentration data) with water to 32 different solution/water ratios via pipette to a total volume of $4 \mathrm{ml}$. The true concentrations of these points/levels were determined by weighing the vial, the vial+standard, then the vial+standard+water on a Metler 5 -point scale. The weight of the water $\left(m_{\text {water }}\right)$ was calculated by subtracting the weight of the vial+standard from the vial +standard+water. The weight of the standard $\left(m_{\text {std }}\right)$ was calculated by subtracting the weight of the vial from the vial+standard. The concentration of each level was then calculated using the equation below:

Level concentration $=\quad$ LO conc (ion) $x$ $\left(m_{\text {water }}\right) /$ density of water $\left(m_{\text {std }}+m_{\text {water }}\right) /$ density of standard 
where the density of water and the standard both equal 0.9982 , as the standard was assumed to have approximately the same density as water for the lab temperature, which is maintained between $18-21^{\circ} \mathrm{C}$.

The additional higher calibration points for $\mathrm{Cl}^{-}, \mathrm{SO}_{4}{ }^{2-}, \mathrm{K}^{+}$and $\mathrm{Na}^{+}$were made by pipetting the approximate volume of " $\mathrm{LO}$ " solution in order to give the desired higher concentration and diluting this with water to $4 \mathrm{ml}$. The same weight and calculation method were applied as above to determine the true concentration.

The larger number of calibration points confirmed that for lower concentrations (see Appendix A), a curve/quadratic calibration is a more suitable fit, whereas the higher concentrations better fitted a linear calibration. A linear calibration was used for $\mathrm{Cl}^{-}$, $\mathrm{NO}_{3}{ }^{-}, \mathrm{SO}_{4}{ }^{2-}$ and $\mathrm{Na}^{+}$, whereas $\mathrm{K}^{+}, \mathrm{Mg}^{2+}, \mathrm{Ca}^{2+}, \mathrm{MS}^{-}$were fitted with a quadratic calibration (Table 5). For each ion, some levels were excluded from the calibration in order to improve the calibration fit in the regions where the data was most concentrated. For example, the median concentration for $\mathrm{Ca}^{2+}$ is $18 \mathrm{ppb}$, with $25-75 \%$ percentile of the data concentrated between 13-27 ppb. As Figure 3.3 shows, in this range the calibration data is curved, and therefore a quadratic calibration is used. In order to improve the fit and the accuracy of measuring this range in the $\mathrm{Ca}^{2+}$ data, points above 164 ppb and below 9.8 ppb were disabled. This was done for each ion (see Appendix A). 


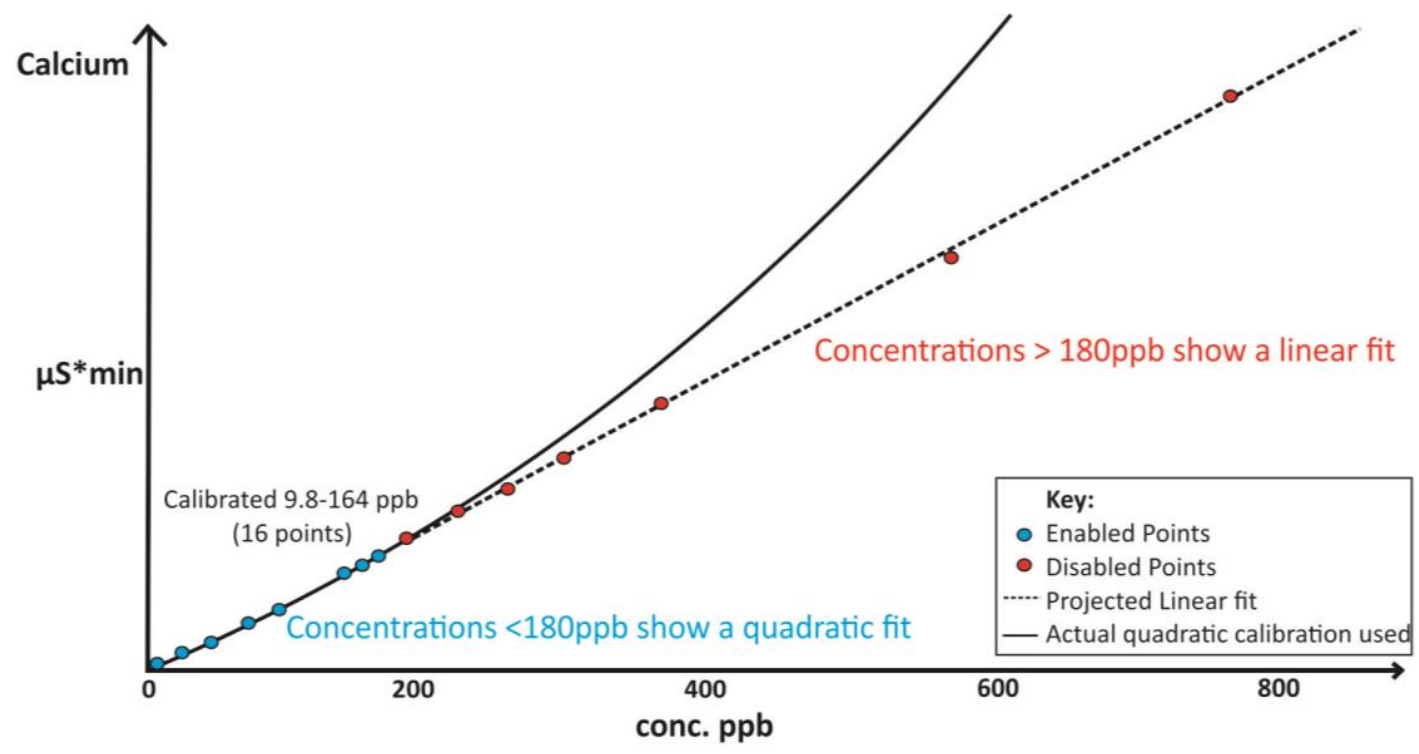

Figure 3.3: Schematic of calcium calibration on Chromeleon Software. $\mu S^{*}$ min is the measure of conductivity.

All ion calibrations report an $\mathrm{R}^{2}$ value of at least 0.999 , except $\mathrm{NO}_{3}{ }^{-}, \mathrm{K}^{+}$and $\mathrm{MS}^{-}$. These three ions also have very narrow resolvable ranges, which limited our ability to analyze the sample data.

\subsection{Quality control}

The table below summarises the decisions made on whether each calibrations data could be used based on its quality (Table 6). These decisions were largely based on the ability of the machine to accurately measure the Quality Control standards (QCs)

\begin{tabular}{|c|c|c|c|c|c|}
\hline Ion & Jun-13 & Oct-13 & Nov-15 & Jul-16 & ICP-MS \\
\hline $\mathbf{N a}^{+}$ & $\checkmark$ & $\checkmark$ & $\checkmark$ & $\checkmark$ & $\checkmark$ \\
\hline $\mathbf{C a}^{2+}$ & $\checkmark$ & $\checkmark$ & $\checkmark$ & $\checkmark$ & $\checkmark$ \\
\hline $\mathbf{M g}^{2+}$ & & & $\checkmark$ & $\checkmark$ & $\checkmark$ \\
\hline $\mathbf{K}^{+}$ & & & & & $\checkmark$ \\
\hline $\mathbf{C l}^{-}$ & $\checkmark$ & $\checkmark$ & $\checkmark$ & $\checkmark$ & \\
\hline $\mathbf{S O}_{4}^{2-}$ & $\checkmark$ & $\checkmark$ & $\checkmark$ & $\checkmark$ & $\checkmark$ \\
\hline $\mathbf{N O}_{3}^{-}$ & & & & & \\
\hline $\mathbf{M S}^{-}$ & & & & $\checkmark$ & \\
\hline $\mathbf{n s s S O}{ }^{2-}$ & $\checkmark$ & $\checkmark$ & $\checkmark$ & $\checkmark$ & $\checkmark$ \\
\hline $\mathbf{F e}$ & & & & & $\checkmark$ \\
\hline
\end{tabular}

Table 6: IC major ions that can be used based on confidence in calibration along with available ICP-MS major ion data (and Fe). Blue shows Capillary IC system, purple indicates the $2 \mathrm{~mm}$ Analytical System and orange indicates the ICP-MS data. 
A set of internal and external QC standards with known concentrations were analysed during sample processing. The external quality control mixed standards, AES and BigMoose, came with known manufacturer certified values, which were compared to the IC measured value. The internal quality controls were made by varying the dilution factors of the single standard mix solution "LO" for both anions and cations (see Appendix A for concentration data). The levels included L1.5 (ultra-low concentration$\sim 0.06 \%$ of LO), L3 (low concentration- $0.5 \%$ of L0), L7 (medium concentration $~ 5 \%$ of L0) and L11 (high concentration- 10\% of L0). The June and October 2013 calibrations both only used the external quality control, Big-Moose. The November 2015 calibration used both external quality controls, Big-Moose and AES, as well as three internal quality controls: L3, L7 and L11. The July 2016 calibration used AES and four internal quality controls: L1.5, L3, L7, L11. During the July calibration the L7 and L1.5 were alternated every 10 samples following the AES, switching between the anion and cation solutions so as to minimize the effects of consistent carry over. Every 50 samples, a whole set of L1.5, L3, L7 and L11 was run for both the cation and anion sides, ending with a blank water sample.

Table 7 summarizes the range of the RICE sample data in order to indicate the important range of concentrations for each ion and, based on this, which quality controls provide a good estimate of the uncertainty of the samples.

\begin{tabular}{|c|c|c|c|c|c|c|c|c|}
\hline & $\mathrm{MS}^{-}$ & $\mathrm{Cl}^{-}$ & $\mathrm{NO}_{3}^{-}$ & $\mathrm{SO}_{4}{ }^{2-}$ & $\mathrm{Na}^{+}$ & $\mathbf{K}^{+}$ & $\mathbf{M g}^{2+}$ & $\mathrm{Ca}^{2+}$ \\
\hline $\begin{array}{c}\text { Upper } \\
\text { Percentile } \\
(95 \%)\end{array}$ & 69.9 & 1717.2 & 43.6 & 361.5 & $\begin{array}{c}1004 . \\
4\end{array}$ & 29.0 & 174.3 & 49.5 \\
\hline Median & 21.4 & 635.9 & 19.3 & 116.1 & 321.7 & 8.1 & 62.0 & 18.8 \\
\hline $\begin{array}{c}\text { Lower } \\
\text { Percentile } \\
(\mathbf{5 \% )}\end{array}$ & 5.3 & 227.7 & 5.0 & 41.4 & 99.4 & 3.0 & 23.1 & 8.2 \\
\hline $\begin{array}{c}\text { Relevant } \\
\text { Internal QC }\end{array}$ & L3 ( 16) & L7 ( 462) & $\begin{array}{c}\text { L3 } \\
(\sim 4.3) / L 7(\sim 43) \\
\end{array}$ & $\begin{array}{c}\mathrm{L3} \\
(\sim 45) / \mathrm{L} 7(\sim 450) \\
\end{array}$ & & $\begin{array}{c}\mathrm{L3} \\
(\sim 1.8) / \mathrm{L} 7(\sim 19)\end{array}$ & & L3 ( 18) \\
\hline $\begin{array}{c}\text { Relevant } \\
\text { External QC }\end{array}$ & & $\begin{array}{c}\text { Big-Moose } \\
(\sim 463)\end{array}$ & & & $\begin{array}{c}\text { AES } \\
(\sim 224)\end{array}$ & & $\begin{array}{l}\text { AES } \\
(\sim 48)\end{array}$ & \\
\hline
\end{tabular}


Internal quality control concentrations quoted are averages of November/July calibrations. All values are in $p p b$.

\subsubsection{June/Oct 2013}

When we compare the Big-Moose certified values (from the manufacturer) (Table 8) with the median/range of the RICE sample data (Table 7), all of the values exceed those of the samples (apart from $\mathrm{Cl}^{-}$and $\mathrm{Na}^{+}$). Big-Moose therefore has relatively limited use as an uncertainity indicator for our samples, but this was the best available external quality control at the time. When we compare the certified values to the IC measured Big-Moose, $\mathrm{Ca}^{2+}$ and $\mathrm{Mg}^{2+}$ are $25 \%$ and $16 \%$ lower than expected, respectively, in the June 13 calibration and 55\% and $11 \%$ lower, respectively, in the October calibration (Table $8 \& 9$ ). This is because Big-Moose values are significantly higher than the range for which the calibration can resolve for $\mathrm{Mg}^{2+}$ (up to $250 \mathrm{ppb}$ in both June/Oct) and $\mathrm{Ca}^{2+}$ ( up to $375 \mathrm{ppb}$ and $100 \mathrm{ppb}$ in June/Oct, respectively). Despite Big-Moose's high values, $\mathrm{Na}^{+}, \mathrm{K}^{+}, \mathrm{Cl}^{-}, \mathrm{SO}_{4}{ }^{2-}$ are still within $7 \%$ of the certified values (Tables $8 \& 9$ ), even though for $\mathrm{Na}^{+}$and $\mathrm{SO}_{4}{ }^{2-}$ these exceed their calibration range. This highlights that for these ions, despite the smaller calibration range, the IC can still resolve higher concentrations accurately.

\begin{tabular}{|c|c|c|c|c|c|c|}
\hline Big MOOSE & $\mathbf{N a}^{+}$ & $\mathbf{K}^{+}$ & $\mathbf{M g}^{2+}$ & $\mathbf{C a}^{2+}$ & $\mathbf{C l}$ & $\mathbf{S O}_{4}{ }^{2-}$ \\
\hline Measured & $768 \pm 5$ & $303 \pm 49$ & $275 \pm 6$ & $1503 \pm 92$ & $468 \pm 9$ & $5287 \pm 14$ \\
\hline RSD & 0.7 & 16.2 & 2.3 & 6.1 & 1.9 & 0.3 \\
\hline Certified value & $731 \pm 58$ & $326 \pm 35$ & $327 \pm 27$ & $2000 \pm 200$ & $463 \pm 53$ & $5080 \pm 280$ \\
\hline Accuracy (\% dif) & 5 & -7 & -16 & -25 & 1.1 & 4.1 \\
\hline
\end{tabular}

\begin{tabular}{|c|c|c|c|c|c|c|}
\hline Big MOOSE & $\mathbf{N a}^{+}$ & $\mathbf{K}^{+}$ & $\mathbf{M g}^{2+}$ & $\mathbf{C a}^{2+}$ & $\mathbf{C l}$ & $\mathbf{S O}_{4}{ }^{-2}$ \\
\hline Measured & $743 \pm 3$ & $341 \pm 15$ & $291 \pm 4$ & $903 \pm 36$ & $488 \pm 5$ & $5408 \pm 76$ \\
\hline RSD & 0.4 & 4.3 & 1.4 & 4.0 & 1.0 & 1.4 \\
\hline Certified value & $731 \pm 58$ & $326 \pm 35$ & $327 \pm 27$ & $2000 \pm 200$ & $463 \pm 53$ & $5080 \pm 280$ \\
\hline Accuracy (\% dif) & 2 & 4 & -11 & -55 & 5 & 6 \\
\hline
\end{tabular}

Tables 8-9: Comparison of the external quality control Big Moose's certified values from the manufacturer with the concentrations measured on the IC during the June 2013 (upper table) and October 2013 (lower table) run. Concentrations are reported in parts per billion (ppb) and standard deviation is $1 \sigma$ measured from replicates (except Big Moose which reports in $2 \sigma$ ). RSD=relative standard deviation. Accuracy (\%dif) is the percentage difference between the average measured value and the certified value, therefore a lower value indicates a better accuracy. Red numbers indicate when values are outside the range of the calibration, therefore we expect these to show reduced accuracy/higher \% difference. Blue column denotes cations and orange, anions. 


\subsubsection{November 2015}

Tables 10 and 11 compare the measured IC values for the two external quality controls, Big-Moose and AES. AES is a more useful external QC compared to Big-Moose as the certified values are closer to our sample ranges (Table 10), particularly for $\mathrm{Na}^{+}$ and $\mathrm{Mg}^{2+}$. All measured ions are within the range of the certified values of the external quality controls AES and Big Moose, apart from $\mathrm{K}^{+}$, which is outside the range of Big Moose because it exceeds $\mathrm{K}^{+\prime}$ s calibration range (Table 11). However, this is not a concern as $326 \mathrm{ppb}$ far exceeds $95 \%$ of the RICE sample range for $\mathrm{K}^{+}$(Table 7 ).

\begin{tabular}{|c|c|c|c|c|c|c|}
\hline AES & $\mathbf{N a}^{+}$ & $\mathbf{K}^{+}$ & $\mathbf{M g}^{2+}$ & $\mathbf{C a}^{2+}$ & $\mathbf{C l}^{-}$ & $\mathbf{S O}_{4}{ }^{2-}$ \\
\hline Measured & $228 \pm 3$ & $47 \pm 2$ & $43 \pm 0.6$ & $228 \pm 6$ & $284 \pm 2$ & $1102 \pm 7$ \\
\hline RSD & 1.4 & 3.7 & 1.3 & 2.5 & 0.8 & 0.6 \\
\hline Certified value & $224 \pm 31$ & $41 \pm 11$ & $48 \pm 7$ & $222 \pm 40$ & $283 \pm 39$ & $1110 \pm 90$ \\
\hline Accuracy (\% dif) & 2 & 16 & -10 & 3 & 0.4 & -0.7 \\
\hline
\end{tabular}

\begin{tabular}{|c|c|c|c|c|c|c|}
\hline Big MOOSE & $\mathbf{N a}^{+}$ & $\mathbf{K}^{+}$ & $\mathbf{M g}^{2+}$ & $\mathbf{C a}^{2+}$ & $\mathbf{C l}^{-}$ & $\mathbf{S O}_{4}{ }^{2-}$ \\
\hline Average & $730 \pm 10$ & $221 \pm 2$ & $320 \pm 4$ & $2002 \pm 27$ & $465 \pm 3$ & $5022 \pm 17$ \\
\hline RSD & 1.4 & 0.9 & 1.3 & 1.3 & 0.6 & 0.3 \\
\hline Certified value & $731 \pm 58$ & $326 \pm 35$ & $327 \pm 27$ & $2000 \pm 200$ & $463 \pm 53$ & $5080 \pm 280$ \\
\hline Accuracy (\% dif) & -0.1 & -32 & -2 & 0.1 & 0.5 & -1 \\
\hline
\end{tabular}

Tables 10-11: Comparison of the external quality controls AES and Big Moose's certified values from the manufacturer with the concentrations measured on the IC during the November 2015 run. See description in Tables 8-9 above.

When the internal QC weight calculated estimates are compared to the measured values, $\mathrm{Na}^{+}, \mathrm{Mg}^{2+}, \mathrm{Ca}^{2+}, \mathrm{MS}^{-}, \mathrm{Cl}^{-}$and $\mathrm{SO}_{4}{ }^{2-}$ are accurate to within $9 \%$ (Tables $\left.12-14\right)$. The accuracy of $\mathrm{K}^{+}$and $\mathrm{NO}_{3}{ }^{-}$ranges from $4-91 \%$ and $8-60 \%$, respectively. Both of these large differences occur when compared to Level 3 , because they fall outside the range of $\mathrm{K}^{+}$and $\mathrm{NO}_{3}^{-}{ }^{-1} \mathrm{~s}$ calibrations. 


\begin{tabular}{|c|c|c|c|c|c|c|c|c|c|c|c|}
\hline L3 & $\mathrm{Na}^{+}$ & $\mathrm{K}^{+}$ & \multicolumn{2}{|c|}{$\mathrm{Mg}^{2+}$} & \multicolumn{2}{|c|}{$\mathrm{Ca}^{2+}$} & \multicolumn{2}{|c|}{ MS } & $\mathrm{Cl}^{-}$ & $\mathrm{NO}_{3}{ }^{-}$ & $\mathrm{SO}_{4}{ }^{2-}$ \\
\hline Measured & $71 \pm 0.6$ & $4 \pm 0.1$ & \multicolumn{2}{|c|}{$17 \pm 0.4$} & \multicolumn{2}{|c|}{$17 \pm 0.8$} & \multicolumn{2}{|c|}{$20 \pm 2$} & $43 \pm 0.3$ & $7 \pm 0.7$ & $45 \pm 0.5$ \\
\hline RSD & 0.9 & 3.0 & \multicolumn{2}{|c|}{2.4} & \multicolumn{2}{|c|}{4.5} & \multicolumn{2}{|c|}{8.2} & 0.6 & 11.5 & 1.0 \\
\hline Weight estimate & $72.9 \pm 0.4$ & $1.8 \pm 0.02$ & \multicolumn{2}{|c|}{$18.3 \pm 0.1$} & \multicolumn{2}{|c|}{$18.5 \pm 0.1$} & \multicolumn{2}{|c|}{$18.1 \pm 0.05$} & $45.1 \pm 0.3$ & $4.5 \pm 0.04$ & $45.6 \pm 0.3$ \\
\hline Accuracy (\% dif) & -2 & 91 & \multicolumn{2}{|c|}{-4} & \multicolumn{2}{|c|}{-6} & \multicolumn{2}{|r|}{8} & -5 & 60 & -1 \\
\hline L7 & $\mathrm{Na}^{+}$ & $\mathrm{K}^{+}$ & \multicolumn{2}{|c|}{$\mathrm{Mg}^{2+}$} & \multicolumn{2}{|c|}{$\mathrm{Ca}^{2+}$} & \multicolumn{2}{|r|}{ MS } & $\mathrm{Cl}^{-}$ & $\mathrm{NO}_{3}^{-}$ & $\mathrm{SO}_{4}^{2-}$ \\
\hline Measured & $729 \pm 6$ & $17 \pm 1$ & \multicolumn{2}{|c|}{$183 \pm 2$} & \multicolumn{2}{|c|}{$186 \pm 2$} & \multicolumn{2}{|c|}{$185 \pm 1$} & $457 \pm 2$ & $48 \pm 1$ & $458 \pm 2$ \\
\hline RSD & 0.8 & 6.0 & & & & 1.1 & & 0.6 & 0.4 & 2.0 & 0.4 \\
\hline $\begin{array}{c}\text { Weight } \\
\text { estimate }\end{array}$ & $713.62 \pm 4$ & $18.03 \pm 0.2$ & 178.9 & $3 \pm 1$ & 180 & $66 \pm 1$ & & $0.19 \pm 0.4$ & $439.31 \pm 3$ & $43.89 \pm 0.4$ & $443.44 \pm 3$ \\
\hline Accuracy (\% dif) & 2 & -5 & & & & 3 & & 5 & 4 & 9 & 3 \\
\hline L11 & $\mathrm{Na}^{+}$ & K & & $\mathrm{Mg}$ & & $\mathrm{Ca}^{2}$ & & MS $^{-}$ & $\mathrm{Cl}^{-}$ & $\mathrm{NO}_{3}^{-}$ & $\mathrm{SO}_{4}^{2-}$ \\
\hline Measured & $1489 \pm$ & $37 \pm$ & 0.7 & 375 & \pm 2 & $374=$ & \pm 2 & $368 \pm 3$ & $915 \pm 3$ & $91 \pm 1$ & $917 \pm 2$ \\
\hline RSD & 0.4 & 1. & & 0. & & 0.5 & & 0.9 & 0.3 & 1.3 & 0.2 \\
\hline Weight estimate & $1420.5 \pm$ & $35.9=$ & \pm 0.4 & 356.2 & \pm 2 & 359.6 & \pm 2 & $336.7 \pm 1$ & $839.4 \pm 6$ & $83.9 \pm 0.9$ & $847.3 \pm 6$ \\
\hline Accuracv (\% dif) & 5 & 4 & & 6 & 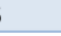 & 4 & & 9 & 9 & 8 & 8 \\
\hline
\end{tabular}

Tables 12-14: Comparison of the averaged weight estimated concentrations of the three internal quality controls (Level 3, 7, 11) with the corresponding average concentrations measured on the IC during the November 2015 run. As two bottles of each solution were made the data represents an average of these solutions. See description in Tables 8-9 above.

\subsubsection{July 2016}

The IC averaged measurements for the AES solution compared to the expected value for the ions is summarized in Table 15 below. As shown, all the measured ions are within the range of the certified values of the external quality control AES.

\begin{tabular}{|l|r|r|r|r|r|r|}
\hline \multicolumn{1}{|c|}{ AES } & \multicolumn{1}{c|}{$\mathbf{N a}^{+}$} & \multicolumn{1}{c|}{$\mathbf{K}^{+}$} & $\mathbf{M g}^{2+}$ & $\mathbf{C a}^{2+}$ & \multicolumn{1}{c|}{$\mathbf{C l}^{-}$} & \multicolumn{1}{c|}{$\mathbf{S O}_{4}{ }^{2-}$} \\
\hline Average & $231 \pm 1$ & $45 \pm 1$ & $48.39 \pm 0.6$ & $206.20 \pm 1$ & $285.16 \pm 2$ & $1131.17 \pm 15$ \\
\hline RSD & 0.5 & 2.9 & 1.3 & 1.5 & 0.80 & 1.3 \\
\hline Certified value & $224 \pm 31$ & $41 \pm 11$ & $48 \pm 7$ & $222 \pm 40$ & $283 \pm 39$ & $1110 \pm 90$ \\
\hline Accuracy (\% dif) & 3 & 11 & 0.8 & -7 & 0.8 & 1.9 \\
\hline
\end{tabular}

Table 15: Comparison of the external quality control AES certified values with the concentrations measured on the IC during the July 2016 run. As two bottles of $L 3 / L 11$ and three bottles of $L 1.5 / L 7$ were made the data represents an average of these solutions. See description in Tables 8-9 above.

When the internal quality controls are compared to their measured values, all the ions show low levels of accuracy at L1.5, because either the calibration range does not resolve concentrations this low or it is at the very low end of the range, as is the case for $\mathrm{MS}^{-}$and $\mathrm{Cl}^{-}$(Table 16). This is not of concern because none of the L1.5 concentrations are within the range of $90 \%$ of the sample data. While it is not a relevant uncertainty measure for the samples, L1.5 does demonstrate that the current IC set up cannot resolve these low concentrations accurately. 
When the expected and measured values are compared (excluding L1.5), $\mathrm{Na}, \mathrm{Cl}$ and $\mathrm{SO}_{4}$ are accurate to within $3 \%$ for all levels (Tables 17-19). $\mathrm{Ca}^{2+}, \mathrm{Mg}^{2+}, \mathrm{MS}^{-}$and $\mathrm{K}^{+}$are accurate to within $18 \%$ compared to the weighted estimates. Particularly low levels of accuracy are seen in L11 due to the concentrations exceeding the calibration range (Table 5). Nitrate is accurate to within 3\% for Level 7 and Level 11, but measures poorly when compared to Level 3 , because this is below the calibration range. As this is below the $5 \%$ percentile of the sample $\mathrm{NO}_{3}{ }^{-}$concentrations, this is not of concern.

\begin{tabular}{|c|c|c|c|c|c|c|c|c|}
\hline L1.5 & $\mathrm{Na}^{+}$ & $\mathrm{K}^{+}$ & $\mathrm{Mg}^{2+}$ & $\mathrm{Ca}^{2+}$ & MS & $\mathrm{Cl}^{-}$ & $\mathrm{NO}_{3}^{-}$ & $\mathrm{SO}_{4}{ }^{2-}$ \\
\hline Average & $11 \pm 0.06$ & $2 \pm 0.01$ & $7.42 \pm 0.2$ & $9 \pm 0.6$ & $6 \pm 1$ & $7 \pm 0.4$ & $5 \pm 0.5$ & $13 \pm 0.3$ \\
\hline RSD & 0.5 & 0.7 & 2.6 & 7.0 & 25.1 & 5.8 & 8.7 & 2.1 \\
\hline Weight estimate & $10.2 \pm 0.1$ & $0.3 \pm 0.004$ & $2.5 \pm 0.03$ & $2.5 \pm 0.03$ & $2.1 \pm 0.01$ & $6.2 \pm 0.06$ & $0.6 \pm 0.006$ & $6.2 \pm 0.06$ \\
\hline Accuracy (\% dif) & 11 & 654 & 192 & 238 & 163 & 14 & 726 & 115 \\
\hline L3 & $\mathrm{Na}^{+}$ & $\mathrm{K}^{+}$ & $\mathrm{Mg}^{2+}$ & $\mathrm{Ca}^{2+}$ & MS $^{-}$ & $\mathrm{Cl}^{-}$ & $\mathrm{NO}_{3}^{-}$ & $\mathrm{SO}_{4}{ }^{2-}$ \\
\hline Average & $72 \pm 2$ & $2 \pm 0.2$ & $19 \pm 0.6$ & $20 \pm 1$ & $18 \pm 2$ & $44 \pm 0.5$ & $6 \pm 0.5$ & $47 \pm 0.7$ \\
\hline RSD & 3.0 & 6.6 & 3.4 & 6.8 & 9.4 & 1.1 & 7.5 & 1.4 \\
\hline Weight estimate & $73.4 \pm 0.4$ & $1.9 \pm 0.02$ & $18.4 \pm 0.1$ & $18.3 \pm 0.1$ & $15.4 \pm 0.03$ & $45.4 \pm 0.3$ & $4.1 \pm 0.03$ & $45.4 \pm 0.3$ \\
\hline Accuracy (\% dif) & -1 & 18 & 2 & 9 & 14 & -3 & 53 & 3 \\
\hline L7 & $\mathrm{Na}^{+}$ & $\mathrm{K}^{+}$ & $\mathrm{Mg}^{2+}$ & $\mathrm{Ca}^{2+}$ & $\mathrm{MS}^{-}$ & $\mathrm{Cl}^{-}$ & $\mathrm{NO}_{3}{ }^{-}$ & $\mathrm{SO}_{4}{ }^{2-}$ \\
\hline Average & $747 \pm 3$ & $19 \pm 1$ & $185 \pm 1$ & $183 \pm 1$ & $149 \pm 2$ & $459 \pm 3$ & $43 \pm 2$ & $461 \pm 5$ \\
\hline RSD & 0.4 & 6.1 & 0.6 & 0.7 & 1.3 & 0.7 & 5.2 & 1.1 \\
\hline Weight estimate & $745.0 \pm 4$ & $19.6 \pm 0.2$ & $186.3 \pm 1$ & $186.1 \pm 1$ & $155.6 \pm 0.2$ & $458.1 \pm 3$ & $41.6 \pm 0.3$ & $458.0 \pm 3$ \\
\hline Accuracv (\% dif) & 0.3 & -2 & -0.4 & -2 & -4 & 0.1 & 3 & 0.6 \\
\hline L11 & $\mathrm{Na}^{+}$ & $\mathbf{K}^{+}$ & $\mathrm{Mg}^{2+}$ & $\mathrm{Ca}^{2+}$ & MS- & $\mathrm{Cl}^{-}$ & $\mathrm{NO}_{3}{ }^{-}$ & $\mathrm{SO}_{4}^{2-}$ \\
\hline Average & $1481 \pm 3$ & $36 \pm 0.5$ & $348 \pm 0.8$ & $325 \pm 0.8$ & $260 \pm 4$ & $913 \pm 11$ & $85 \pm 2$ & $919 \pm 16$ \\
\hline RSD & 0.9 & 1.5 & 0.2 & 0.2 & 1.5 & 1.2 & 2.0 & 1.8 \\
\hline Weight estimate & $1477.6 \pm 9$ & $38.9 \pm 0.3$ & $369.5 \pm 2$ & $369.0 \pm 2$ & $308.9 \pm 0.5$ & $909.2 \pm 5$ & $82.6 \pm 0.7$ & $909.0 \pm 5$ \\
\hline Accuracy (\% dif) & 0.3 & -7 & -6 & -12 & -16 & 0.5 & 2.7 & 1.1 \\
\hline
\end{tabular}

Tables 16-19: Comparison of the averaged weight estimated concentrations of the four internal quality controls (Level 1.5, 3, 7, 11) with the corresponding average concentrations measured on the IC during the July 2016 run. As two/three bottles of each solution were made the data represents an average of these solutions. See description in Tables 8-9 above.

\subsubsection{Data Quality Summary}

The previous sections ( $3.4 \& 3.5$ ) detail the confidence/issues surrounding the four calibrations based on the calibration method and comparison to quality controls.

Figures 3.3 and 3.4 below show all four calibrations plotted against time, representing the full set of IC data available for this study. 


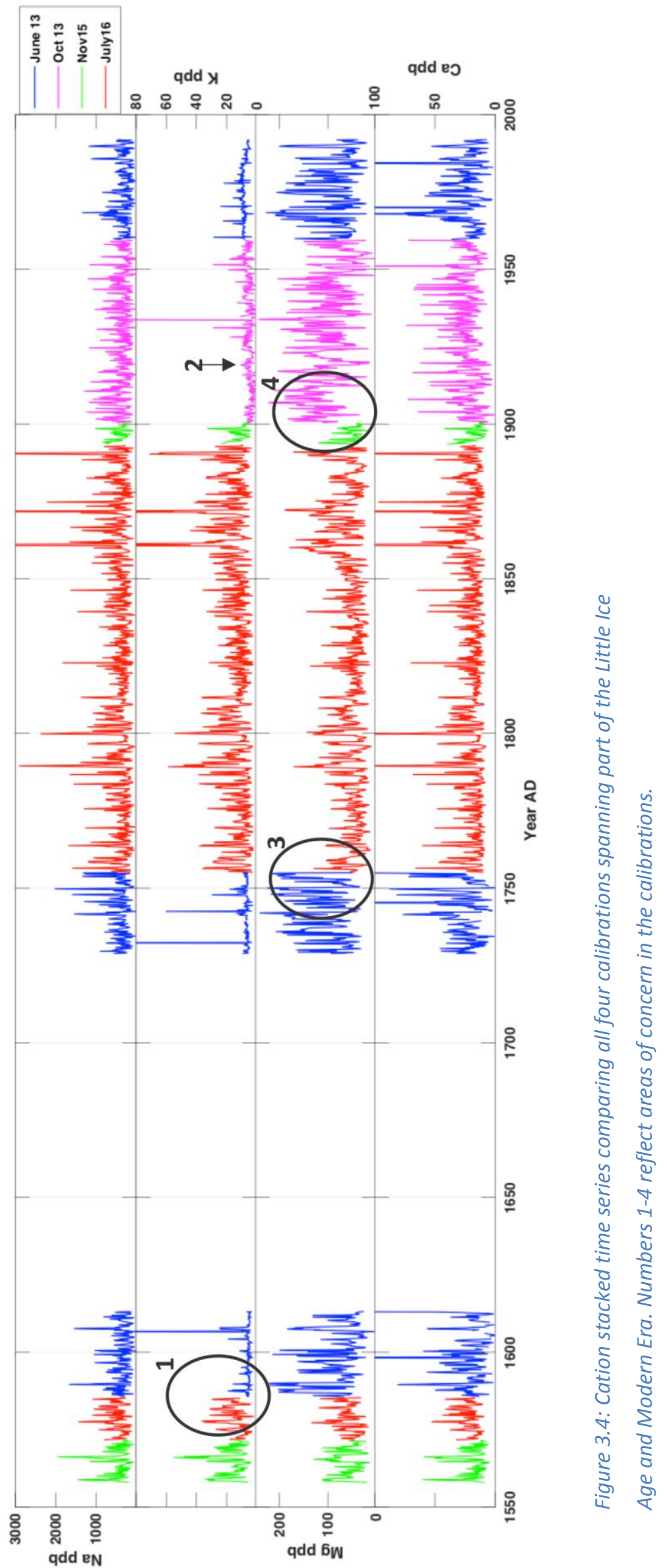




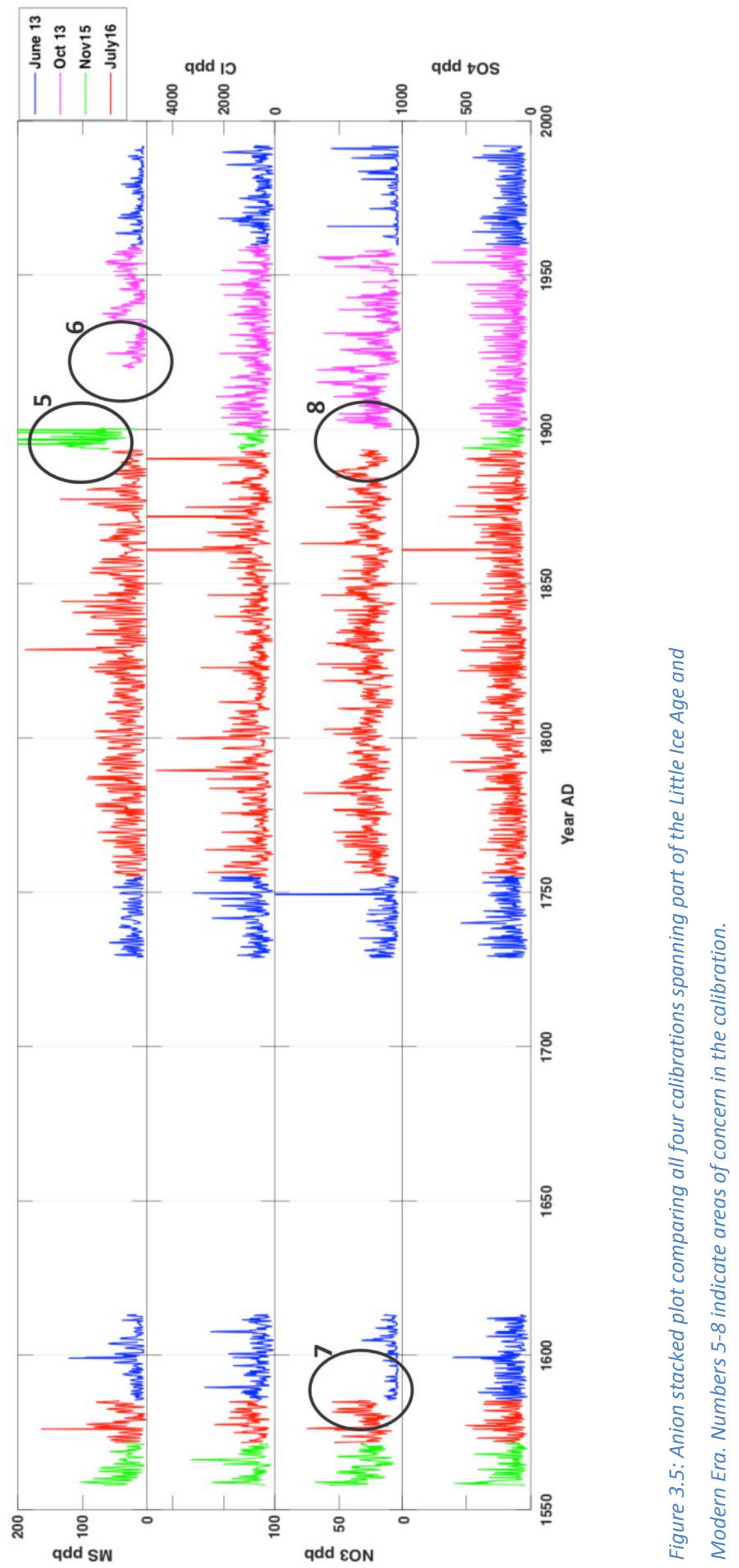


Figures 3.4 and 3.5 highlight regions of concern when the four calibrations are pieced together. Circle 1 indicates where the July 2016 and June $2013 \mathrm{~K}^{+}$calibration records do not align. Arrow 2 highlights where a dramatic change in amplitude and frequency of the $\mathrm{K}^{+}$records occurs between the Nov 2015/Oct 2013 data. This is supported by both the November 2015 and Oct/June 2013 calibrations having difficulties resolving the $\mathrm{K}^{+}$peaks. As we cannot be confident in this data, none of the $\mathrm{K}^{+}$calibrations results will be included in this study and only the ICP-MS concentrations will be used (Table 6). The $\mathrm{Mg}^{2+}$ time series also shows large issues in the June/Oct 2013 calibration sections, with a step change compared to the July and November calibrations (Circle 3 and 4). This is likely due to issues arising from distinguishing the $\mathrm{Ca}^{2+} / \mathrm{Mg}^{2+}$ peaks described in section 3.4.1. As a result, the Oct/June $2013 \mathrm{Mg}^{2+}$ data will not be used in this study (Table 6). The MS- record also shows problems, particularly with the November 2015 data showing a step change at Circle 5 and the Oct 2013 method not recording any data at Circle 6 . This is not surprising as both the June/Oct and November calibrations had issues with resolving the MS- peaks. Therefore only the July 2016 calibration will be used for $\mathrm{MS}^{-}$, this is disappointing, as it has been shown to be an accurate recorder of changes in sea ice and its inter-annual variability (Abram et al., 2013). The $\mathrm{NO}_{3}{ }^{-}$time series shows clear issues between calibrations, with a baseline shift between July/June calibrations at Circle 7 and Circle 8 indicates where the November 2015 method was unable to identify the peaks. Therefore none of the $\mathrm{NO}_{3}{ }^{-}$data will be analysed in this study (Table 6).

The $\mathrm{Na}^{+}, \mathrm{Ca}^{2+}, \mathrm{Cl}^{-}$and $\mathrm{SO}_{4}{ }^{2-}$ time series show no apparent issues when the calibrations are matched together in the time series above. Therefore the $\mathrm{Na}^{+}, \mathrm{Ca}^{2+}, \mathrm{Cl}^{-}$and $\mathrm{SO}_{4}{ }^{2-}$ data from all four calibrations will be used (Table 6).

\section{$\underline{3.6 \mathrm{nsSSO}_{4}{ }^{2-} \text { calculation: }}$}

Non-sea salt sulfate (nss $\mathrm{SO}_{4}{ }^{2-}$ ) concentration was calculated by subtracting the proportional sea salt sulfate ( $\mathrm{ss} \mathrm{SO}_{4}{ }^{2-}$ ), (which was calculated based on the estimate from the $\mathrm{SO}_{4}{ }^{2-} / \mathrm{Na}^{+}$marine ratio of 0.252 (in ng/g)) from total $\mathrm{SO}_{4}{ }^{2-}$ (Legrand and Delmas, 1984). As both the $\mathrm{SO}_{4}{ }^{2-}$ and $\mathrm{Na}^{+}$data was deemed usable in section 3.5, the nss $\mathrm{SO}_{4}{ }^{2-}$ data will be used from all four calibrations. 


\subsection{Additional Data}

\subsubsection{ICP-MS}

Induced Coupled Mass Spectrometry (ICP-MS) $\mathrm{Na}^{+}, \mathrm{Mg}^{2+}, \mathrm{Ca}^{2+}$ and Fe data spanning 1204-1992 AD was used to compare to the IC data and to extend the time series to before the start of the $\mathrm{LIA} . \mathrm{SO}_{4}{ }^{2-}$ was calculated by multiplying the Sulfur concentrations by 3 . These were processed by two previous PhD students at Victoria University; Peter Neff and Andrea Tuohy in 2014 (Tuohy et al., 2015). As part of ICP-MS analysis samples are acidified, which often leads to higher concentrations than the corresponding IC measurements. This is thought to be because of acidification occurring as a result of dust particles present in the solution (N.Bertler, pers. comms). Data from the period between 1894-2011 AD can be resolved sub-annually/seasonal (average spacing $=0.1259 \mathrm{yrs}$ ). Whereas samples between $1204-1893$ AD were combined to get a four year resolution.

\subsubsection{Stable Isotope Data}

The deuterium stable isotope record was measured using a continuous-flow laser spectroscopy system with an off-axis integrated cavity output spectroscopy (OA-ICOS) analyser, manufactured by Los Gatos Research (LGR). The water was derived from the inner section of the continuous flow analysis (CFA) section. Water from the outside of the CFA piece was collected for discrete samples. A detailed description of this set up and a quality assessment is provided by Emanuelsson et al. (2015). The combined uncertainty for Deuterium (?DD) at $2 \mathrm{~cm}$ resolution is $\pm 0.85 \%$. A detailed description of the isotope calibration, the calculation of cumulative uncertainties, and the assignment of depth is provided by Keller et al. (Submitted). 


\section{Chapter 4: Results}

\subsection{Time series data}

The IC data and modern ICP-MS (1894-2011 AD) samples were annually resolved by applying a MATLAB linear interpolation function to the age model resolved age, the respective ion concentration and the desired sampling interval; 1 year. The long term ICP-MS samples (1200-1992 AD) were interpolated to 4 years via the same method. These data are plotted as time series below.

\subsubsection{Long-term trend (1200-1992 AD) of 4 yearly resolved ICP-MS data}

The ICP-MS 4 year resolved data were initially analysed to determine the long-term trend in the major ion data over the LIA and ME (Figure 4.1).

$\mathrm{Na}^{+}$shows a step-function increase in concentrations mid $15^{\text {th }}$ century from an average of 197 ppb in 1204-1444 AD to 335 ppb between 1448-1848 AD (Figure 4.1). A twosample Student t-test was used on $\mathrm{Na}^{+}$and the subsequent ions to test the significance of this shift (Table 20). This confirmed the $70 \%$ increase in sodium to be statistically significant. Following $1880 \mathrm{AD}$ a decline in $\mathrm{Na}^{+}$concentrations towards $1992 \mathrm{AD}$ is observed. This will be discussed further in section 4.1 .2

\begin{tabular}{|c|c|c|c|c|c|c|}
\hline & $\mathrm{Na}^{+}$ & $\mathrm{Ca}^{2+}$ & $\mathrm{K}^{+}$ & $\mathrm{Mg}^{2+}$ & $\mathrm{SO}_{4}$ & $\mathrm{nsSSO}_{4}{ }^{2-}$ \\
\hline$p$-value & $p<0.01$ & $p<0.01$ & $p<0.01$ & $p<0.01$ & $p<0.01 *$ & $P<0.01$ \\
\hline $\begin{array}{l}\% \\
\text { Difference } \\
\text { in means }\end{array}$ & $70 \%$ & $43 \%$ & $45 \%$ & $52 \%$ & $19 \%$ & $-18 \%$ \\
\hline
\end{tabular}

Table 20: Two sample t-test between ICP-MS 4 yr resolved 1204-1444 AD data and 1448-1848 AD data to test for step function. *Could be due to increasing trend not step function

$\mathrm{Ca}^{2+}$, like sodium also shows a statistically significant mid $15^{\text {th }}$ century $43 \%$ increase from a mean of $13 \mathrm{ppb}$ between 1204-1444 AD to $18 \mathrm{ppb}$ between 1448-1848 AD (Figure 4.1) (Table 20). $\mathrm{Ca}^{2+}$ also shows a decline from 1880s-1992 AD. 


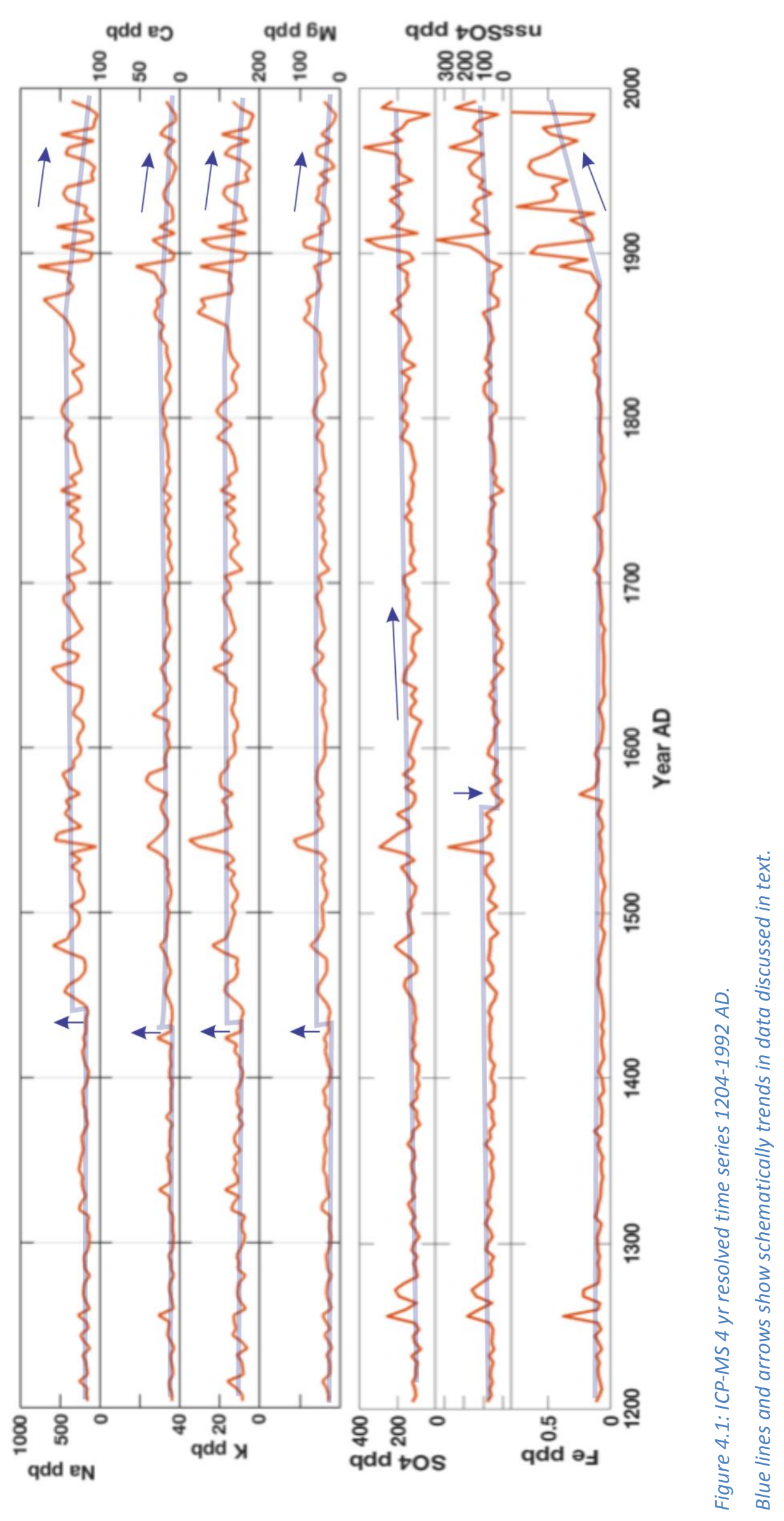


$\mathrm{K}^{+}$, shows a statistically significant $45 \%$ increase in concentration from a mean of 10 ppb in 1204-1444 AD to 15 ppb between 1448-1848 AD (Figure 4.1). From 1880 AD a decline is also observed until 1992 AD.

$\mathrm{Mg}^{2+}$, showed a significant $52 \%$ shift mid $15^{\text {th }}$ century from a mean of $31 \mathrm{ppb}$ in $1204-$ 1444 AD to 48 ppb between 1448-1848 AD (Figure 4.1). Consistent with the aforementioned ions, $\mathrm{Mg}^{2+}$ also records a decrease from 1880-1992 AD. As shown, $\mathrm{Na}^{+}, \mathrm{Mg}^{2+}, \mathrm{Ca}^{2+}$ and $\mathrm{K}^{+}$all exhibit very similar trends in the $4 \mathrm{yr}$ resolved ICP-MS data.

The $\mathrm{SO}_{4}{ }^{2-}$ two sample t-test shows a smaller increase compared to previous species of only $14 \%$ from a mean of 118 ppb in $1204-1444$ AD to 140 ppb between 1448-1848 AD (Table 20). This increase was deemed statistically significant at the $99 \%$ level (Figure 4.1). $\mathrm{SO}_{4}{ }^{2-}$ subsequently shows a steady incline until $1992 \mathrm{AD}$.

$\mathrm{nsSO}_{4}{ }^{2-}$ is the only ion which showed a statistically significant decrease between 1204$1444 A D$ and $1448-1848$ AD of 18\% (Figure 4.1). This shift appears to occur later than the aforementioned ions, decreasing in the late $16^{\text {th }}$ century. From the late $19^{\text {th }}$ century an increasing trend is observed until 1992 AD.

In addition, the ICP-MS measured trace element Fe (a dust indicator) was analysed (Figure 4.1). Fe appears to remain consistent from 1200-1850 AD, however there appears to be a long term cyclicity peaking mid $13^{\text {th }}$ century and in late $16^{\text {th }}$ century. Following $1850 \mathrm{AD}$, Fe shows a dramatic increase in concentration to 1992 . Fe shows a statistically significant increase of 0.0088 ppb per year between 1850-1992 AD (Table 21).

\subsubsection{Modern Era Trends of IC and ICP-MS annually resolved data (1850-2011 AD)}

In order to analyse the trends during the Modern Era (ME) transition, the annually resolved ICP-MS and IC measurements were compared between 1850-2011 AD (Figure 4.2). Statistical analysis was carried out on both the annual IC data and the 4 year resolved ICP-MS data in order to determine the significance of the trends (Tables 19 
and 20). This was not carried out on the annual ICP-MS data as this only extends back to $1894 \mathrm{AD}$, this record was therefore deemed too short to capture any ME trend.

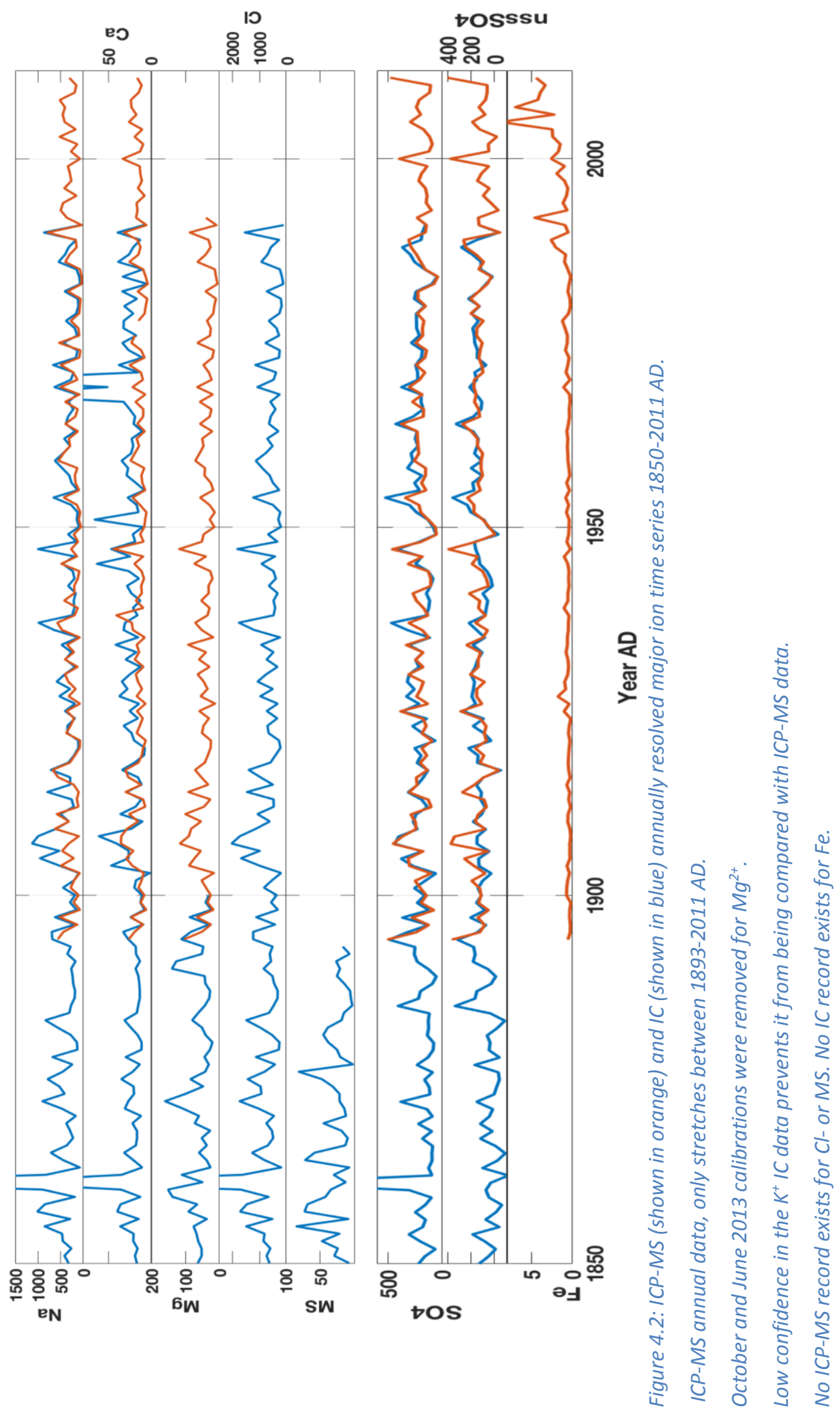


$\mathrm{Na}^{+}, \mathrm{Mg}^{2+}, \mathrm{Ca}^{2+}$ and $\mathrm{K}^{+}$show similar trends since $1850 \mathrm{AD}$ (Figure 4.2). $\mathrm{Na}^{+}$shows a statistically significant decline ( $p$-value $<0.01$ ) of $2-3$ ppb per year from the mid $19^{\text {th }}$ century to $1992 . \mathrm{Ca}^{2+}$ also shows a significant decline ( $p$-value $<0.01$ ), but with a decrease of $0.13 \mathrm{ppb}$ per year (Table 21 ). $\mathrm{K}^{+}$and $\mathrm{Mg}^{2+}$ also show a statistically significant decline ( $p$-value $<0.01$ ) of $0.1 \mathrm{ppb}$ and $0.3 \mathrm{ppb}$, respectively between 1850 1992 AD (Table 21). 1

\begin{tabular}{|l|c|cccc|} 
& \multicolumn{2}{|c}{$\mathrm{Na}^{+}$} & \multicolumn{1}{c}{$\mathrm{Ca}^{2+}$} & $\mathrm{K}^{+}$ & $\mathrm{Mg}^{2+}$ \\
\hline $\mathbf{p}$-value & $<0.01$ & $<0.01$ & $<0.01$ & $<0.01$ & $<0.01$ \\
\hline $\mathbf{R}^{2}$ & 0.21761 & 0.049 & 0.26307 & 0.299909 & 0.38275 \\
\hline $\mathbf{p p b} / \mathbf{y r}$ & -2.2399 & -3.002 & -0.1301 & -0.1064 & -0.3322 \\
\hline
\end{tabular}

\begin{tabular}{|c|c|c|c|c|c|c|}
\hline & \multicolumn{2}{|c|}{$\mathrm{SO}_{4}{ }^{2-}$} & \multicolumn{2}{|c|}{$\mathrm{nsSSO}_{4}{ }^{2-}$} & \multirow{2}{*}{$\begin{array}{c}\mathrm{Cl}^{-} \\
<0.01\end{array}$} & \multirow{2}{*}{$\begin{array}{c}\mathrm{Fe} \\
<0.01\end{array}$} \\
\hline p-value & $>0.1$ & $>0.1$ & $<0.01$ & $<0.01$ & & \\
\hline $\mathbf{R}^{2}$ & 0.01626 & 0.00158 & 0.2077 & 0.18 & 0.068 & 0.22301 \\
\hline ppb/yr & 0.2003 & 0.15 & 0.7647 & 0.91 & -5.3 & 0.0088 \\
\hline
\end{tabular}

Tables 21 (upper) and 22 (lower): Modern era trend analysis. Where available IC annual (1850-1991 AD) and ICP-MS 4 yr (1852-1992 AD) data is tested for significance of a trend. Orange columns are ICP-MS data and Blue are IC data. Some ions don't have both due to no ICP-MS being available or the quality of the IC data prevents it from being analysed. Bold indicates where the trend is significant.

$\mathrm{SO}_{4}{ }^{2-}$ does not show a statistically significant trend. In contrast, non-sea salt sulphate exhibits a statistically significant ( $p$-value< 0.01 ) increase of $\sim 0.8 \mathrm{ppb}$ per year from 1850-1992 AD (Table 22).

As $\mathrm{Cl}^{-}$cannot be analysed via ICP-MS we only have the IC data spanning 1557-1613 AD and 1728-1991 AD. The 5.3 ppb per year decline in concentration between 1850-1991 $A D$, is statistically significant ( $p$-value $<0.01$ ) (Table 22 ).

As MS- cannot be analysed by the ICP-MS, we only have the IC data and only the July 2016 calibration spanning 1585-1613 AD and 1755-1893 AD, due to issues arising from the other calibrations. This time series does appear to decrease from mid $19^{\text {th }}$ century to the late $19^{\text {th }}$ century, however as there is not sufficient data to test its modern era (1850-1992 AD) decline this is not included in Table 22. 


\subsection{Major ion source regions}

\subsubsection{Molar ratios}

The background chapter highlighted the common sources of the major ions used in this study. However, in order to test whether the RICE concentrations reflect these sources at Roosevelt Island, we can compare the RICE molar ratios with the molar ratios expected in seawater (Table 23).

\begin{tabular}{|c|c|c|c|c|}
\hline & $\mathrm{Cl} / \mathrm{Na}^{+}$ & $\mathrm{Mg}^{2+} / \mathrm{Na}^{+}$ & $\mathrm{SO}_{4}{ }^{2-} / \mathrm{Na}^{+}$ & $\mathrm{Ca}^{2+} / \mathrm{Na}^{+}$ \\
\hline Expected & 1.8 & 0.12 & 0.25 & 0.038 \\
\hline Observed & 1.86 & 0.126 & 0.383 & 0.048 \\
\hline
\end{tabular}

Table 23: Comparison of expected molar ratios in seawater (Pilson, 1998) with observed IC annual average molar ratios. Using the July 2016 data (1755-1893 AD) data.

We find our observed $\mathrm{Cl}^{-} / \mathrm{Na}^{+}$molar ratios to fall within the expected molar ratios of seawater (Table 23), confirming these ions as a sea salt indicator for RICE.

As previously noted, the Danish RICE team determined the Roosevelt Island $\mathrm{Ca}^{2+}$ record as an indicator of sea salt (P.Vallelonga, pers. comms). Our analysis confirms this suggestion. However, the $\mathrm{Ca}^{2+} / \mathrm{Na}^{+}$ratio is a little high, suggesting an additional source (Table 23). We propose that this could indicate a terrestrial source.

As previously noted, $\mathrm{Mg}^{2+}$ has been used as both a sea salt and terrestrial indicator in the past. However, the similarity of our $\mathrm{Mg}^{2+}$ time-series record to that of the other sea salt species e.g. $\mathrm{Na}^{+}$, suggests this could represent a sea salt signature. This is confirmed by the similarity of the IC data's $\mathrm{Mg}^{2+} / \mathrm{Na}^{+}$ratio to that expected from seawater (Table 23).

Total $\mathrm{SO}_{4}{ }^{2-}$ shows a steady increase in concentration from the mid $15^{\text {th }}$ century, which carries through until 1992. However, the $\mathrm{SO}_{4}{ }^{2-} / \mathrm{Na}^{+}$ratio is much higher than can be expected from wholly a sea salt source, highlighting the influence of nss $\mathrm{SO}_{4}{ }^{2-}$ (Table 23). 


\subsubsection{Spatial Correlations}

To further understanding of dominant major ion and Fe sources and transport mechanisms, we compare their modern concentrations to the European Reanalysis Interim (ERA-interim) (1979-2015 AD) surface meridional and zonal wind strength and sea ice concentration. The annual major ion concentrations (ICP-MS 1979-2011 AD) were compared to the summer time ERA-interim meridional and zonal wind strength as we see the strongest correlations during this period due to the connection with the ENSO and SAM.

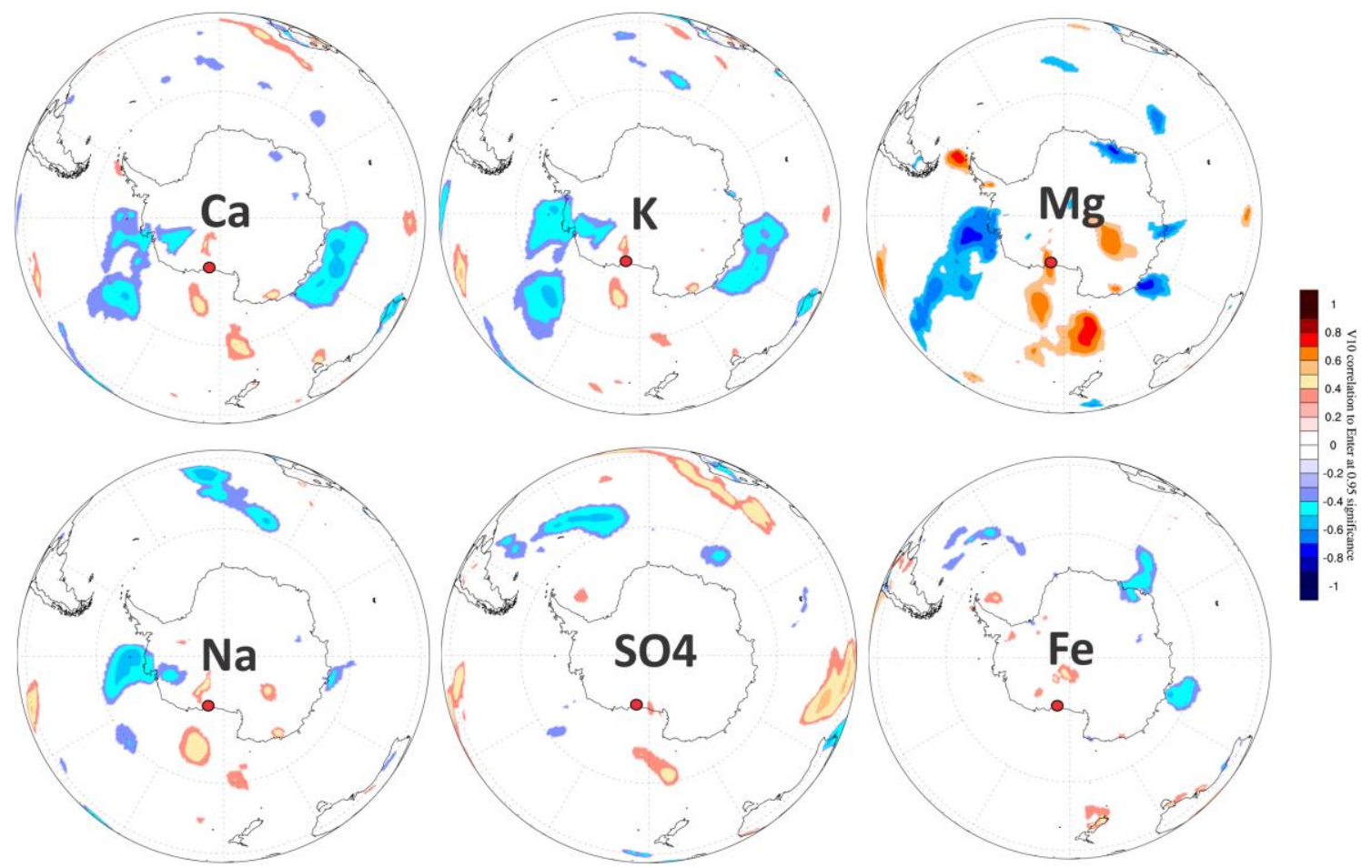

Figure 4.3: The ERA-interim 1979-2015 AD summer (DJF) meridional surface $(10 \mathrm{~m})$ winds ( $\mathrm{V}$ winds) data set correlated with the ICP-MS 1979-2011 AD ions at the 95\% confidence level. Positive (negative) correlation indicates a poleward (equatorward) flow with increased major ion concentration. Pearson product-moment correlation coefficient calculated using the 'escorc' function is used. Obtained using Climate Reanalyzer (UMaine, 2016). Red circle denotes RICE location.

Figure 4.3 shows that our sea salt species $\mathrm{Ca}^{2+}, \mathrm{K}^{+}, \mathrm{Mg}^{2+}, \mathrm{Na}^{+}$exhibit a negative correlation with the meridional wind off West Antarctica/Marie Byrd Land. As this region is intrinsically linked to the Amundsen Sea Low, we suggest that the sea salt species are transported to Roosevelt Island by the northerly winds linked to the eastern branch of the ASL (Figure 2.6). This is supported by the positive correlation off 
the western Ross Ice Shelf, linked to the southerly flow that could be associated with the western branch of the ASL.

$\mathrm{SO}_{4}{ }^{2-}$ and $\mathrm{Fe}$ do not appear to show any significant links to the meridional winds which could affect transport to Roosevelt Island (Figure 4.3).

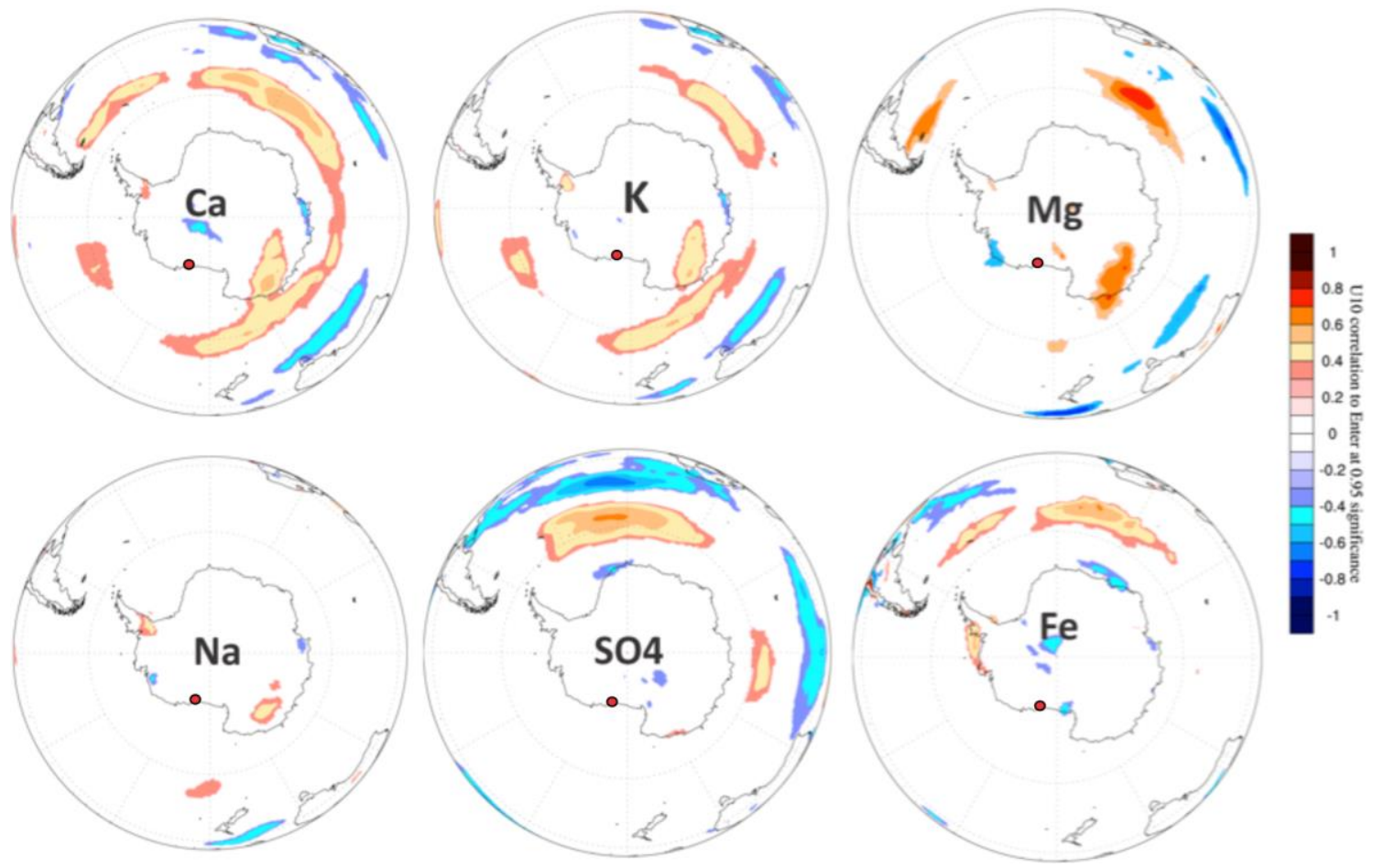

Figure 4.4: ERA-interim summer (DJF) zonal (u) surface $(10 \mathrm{~m})$ wind correlation with ICP-MS annual 19792011 AD ions. Positive (negative) correlation indicates a westerly (easterly) flow with increased major ion concentration. Pearson product-moment correlation coefficient calculated using the 'escorc' function is used. Obtained using Climate Reanalyzer (UMaine, 2016). Red circle denotes RICE location.

Figure 4.4 shows the correlation of the ICP-MS ions with the ERA-interim summer zonal winds. $\mathrm{Ca}^{2+}$ particularly shows a strong positive correlation with the westerlies, which is not surprising as a sea salt species. $\mathrm{K}^{+}$and $\mathrm{Mg}^{2+}$ also show similar links to the westerly wind belt but not as well defined as $\mathrm{Ca}^{2+}$. Somewhat surprising is the lack of a significant pattern with the zonal winds and sodium. It was initially thought a more significant trend in $\mathrm{Ca}^{2+}, \mathrm{K}^{+}$data might have correlated with the increasing SAM trend, however this data was run again detrended and the same pattern arose. $\mathrm{SO}_{4}{ }^{2-}$ and $\mathrm{Fe}$ show a strong correlation with the westerly winds to the east of the Drakes Passage, which likely reflects the relationship of the well-known Antarctic Dipole between the Ross/Amundsen and Weddell Seas (Yuan \& Martinson, 2001). 


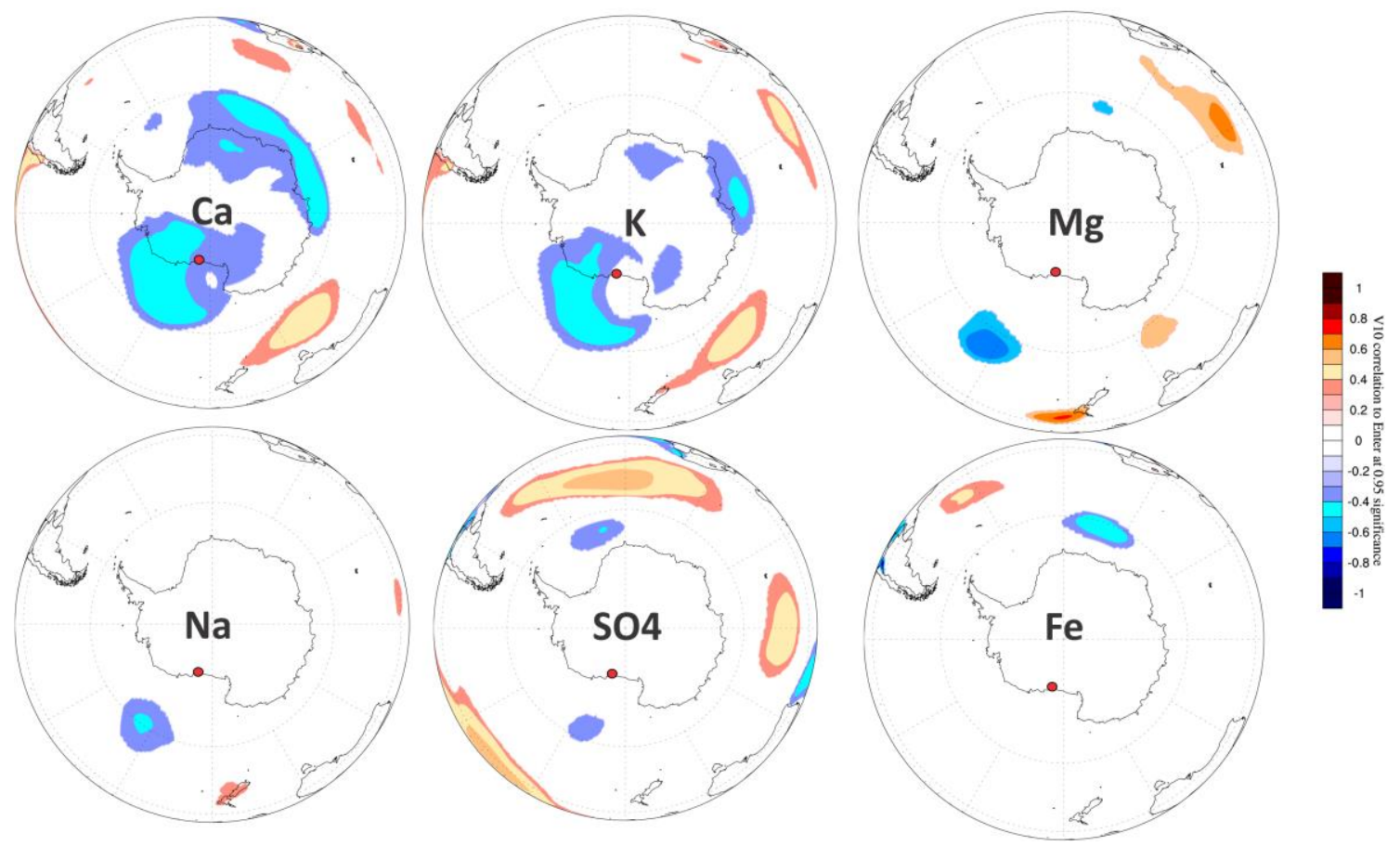

Figure 4.5: ERA-interim summer (DJF) mean sea level pressure correlation with ICP-MS annual 1979-2011 $A D$ ions. Positive (negative) correlation indicates a high (low) MSLP with increased major ion concentration. Pearson product-moment correlation coefficient calculated using the 'escorc' function is used. Obtained using Climate Reanalyzer (UMaine, 2016). Red circle denotes RICE location.

When the ions are compared with the mean sea level pressure (Figure 4.5), $\mathrm{Ca}^{2+}$ and $\mathrm{K}^{+}$ show a strong correlation with the Amundsen Sea Low (ASL). $\mathrm{Na}^{+}$and $\mathrm{Mg}^{2+}$ also show a strong correlation to an area of low pressure off the Marie Byrd Land, however it is not to the same extent as the $\mathrm{Ca}^{2+}$ and $\mathrm{K}^{+}$pattern (Figure 4.5). Again, $\mathrm{SO}_{4}{ }^{2-}$ and Fe do not appear to show a statistically significant correlation with any region that would likely affect the Roosevelt Island region.

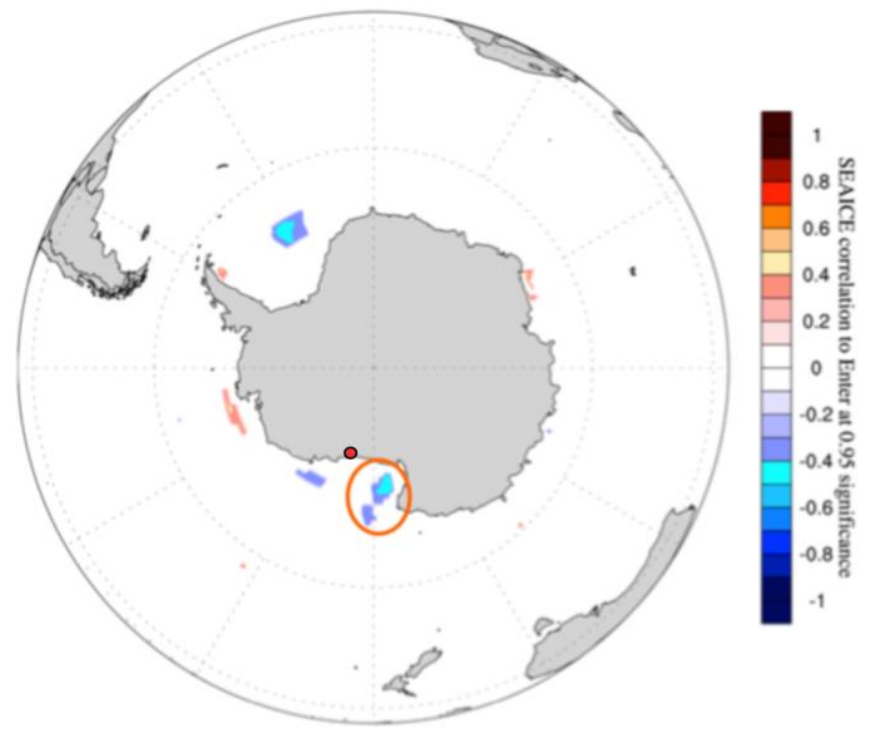

Figure 4.6: ICP-MS annual nssSO4 1979-2011 AD record correlation with ERA-interim annual sea ice concentration. Pearson product-moment correlation coefficient calculated using the 'escorc' function is used. Obtained using Climate Reanalyzer (UMaine, 2016). Orange circle indicates likely Ross Sea Polynya correlation. Red circle denotes RICE location. 
The correlation between $\mathrm{nsSO}_{4}{ }^{2-}$ and ERA-interim sea ice concentration shows small regions of statistically significant correlations in the Ross Sea (Figure 4.6). The largest negative correlation in the Ross Sea (circled) falls in the region of the Ross Sea/Terra Nova polynya and could therefore link to the winter open ocean extent of the polynya. The negative correlation is expected between $\mathrm{nsSSO}_{4}{ }^{2-}$ and sea ice as in the Ross Sea as more open ocean is more conducive to biological productivity.

\subsubsection{Sea salt source and timing}

$\mathrm{Na}$ has been demonstrated to be derived from a marine source. The $\mathrm{SO}_{4}{ }^{2-} / \mathrm{Na}^{+}$ratio is used to differentiate between an open water source via bubble bursting or frost flowers during sea ice extent (Rankin et al., 2000; Wolff et al., 2003). As evinced by Table 24, the $\mathrm{SO}_{4}{ }^{2-} / \mathrm{Na}^{+}$ratio exceed that expected from frost flowers. Therefore, we assume the majority of sea salt is brought to the site directly from the sea water via bubble bursting.

\begin{tabular}{|l|r|r|r|}
\hline & \multicolumn{1}{|c|}{ Seawater ratio expected } & Frost flower expected & Observed \\
\hline $\mathrm{SO}_{4}{ }^{2-} / \mathrm{Na}^{+}$ & 0.25 & 0.11 & 0.38 \\
\hline
\end{tabular}

Table 24: Comparing $\mathrm{SO}_{4}{ }^{2-} / \mathrm{Na}^{+}$molar ratios in order to determine likely sea salt source. Seawater ratio expected is reported in Pilson (1998). Frost flower ratio expected is reported by Wolff et al., 2003.

By comparing the $\mathrm{MS}^{-}$and $\mathrm{Na}^{+}$record we can determine when this snow precipitation occurs (Figure 4.7). As $\mathrm{MS}^{-}$is an indicator of biological activity (as described in section 2.3.2) and has shown a negative relationship with sea ice in the Ross Sea, peaks in MSindicate more open ocean, which occurs during summer, hence it is a summer indicator. Previous analysis of the RICE core has exhibited $\mathrm{MS}^{-}$aligning with $\mathrm{Na}^{+}$in deep sections of the core due to post depositional processes (N. Bertler, pers. comms.). However, when $\mathrm{Na}^{+} / \mathrm{MS}^{-}$data from close to the surface is compared, the ions are also in phase. Therefore it is assumed post-depositional processes are not causing this relationship between 1840-1860 AD. Figure 4.7 shows the comparison of $\mathrm{Na}^{+}$and MS- over a 20 year section of the July 2016 data (section where there is confidence in $\mathrm{MS}^{-}$data). The graph shows that the peaks in $\mathrm{Na}^{+}$generally coincide with the peaks in 
$\mathrm{MS}^{-}$(occur in summer), therefore indicating that snow precipitation occurs in summer. If the peaks were opposing, this would suggest a winter signature and the significant sea salt signature would be due to increased transport of air masses. Instead, summer precipitation confirms that the sea salt signature is due to proximity to the open ocean, continually supplying the site, through periods of reduced storm activity (summer).

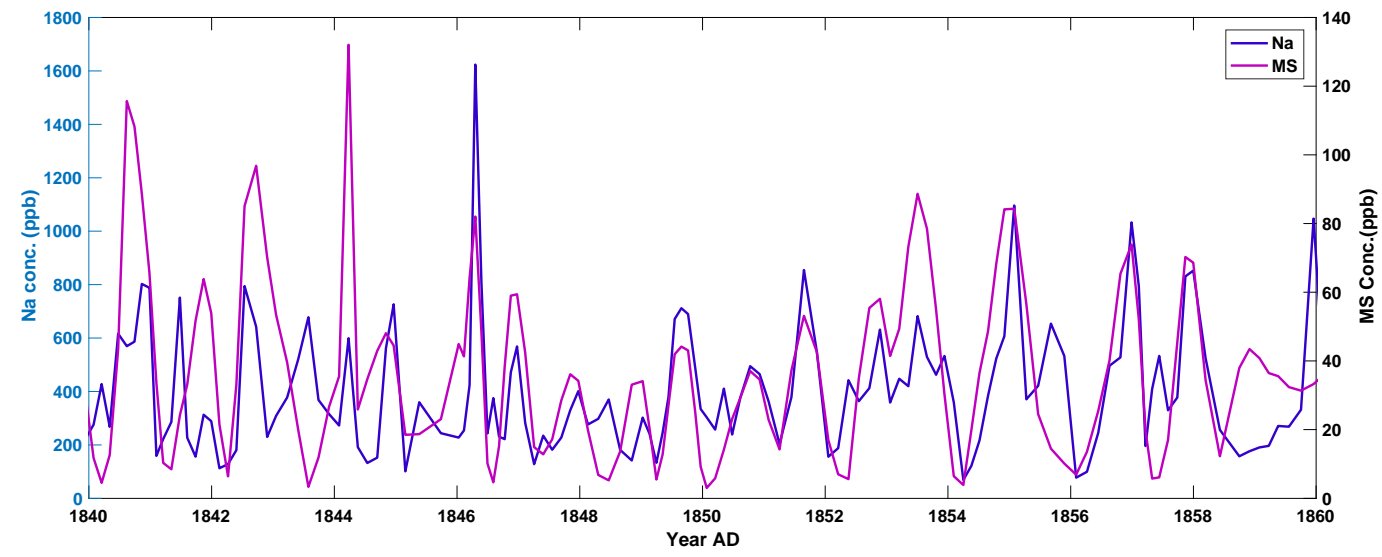

Figure 4.7: Segment of July 2016 data comparing $\mathrm{MS}^{-}$and $\mathrm{Na}^{+}$concentration peaks. Indicates that MS and $\mathrm{Na}^{+}$coincide, indicating summer snow deposition.

\subsubsection{Non-sea salt source}

Generally, $\mathrm{nsSSO}_{4}{ }^{2-}$ data are used as evidence for biological activity or volcanic eruptions. Biological activity is closely related to sea ice production, with an increase coinciding with a decrease in sea ice in the Ross Sea (Rhodes et al., 2009). Figure 4.8 shows the correlation between the $\mathrm{nsSSO}_{4}{ }^{2-}$ annual record over 1979-1991 AD to the sea ice extent in the Ross Sea from (Raymond, 2009, 2014). Between 1979 and 1987 $A D$ this relationship is opposing, which is to be expected based on the negative correlation between sea ice and biological productivity in the Ross Sea with regards to MS- (Figure 4.8) (Rhodes et al., 2009; Sinclair et al., 2014). Following 1987 AD there is a shift to a statistically significant positive correlation ( $p$-value $<0.1$ ) between the two records. This could represent a shift in source region for $\mathrm{nsSSO}_{4}{ }^{2-}$ from a Ross Sea to another source, which could link to the position of the Amundsen Sea Low. 


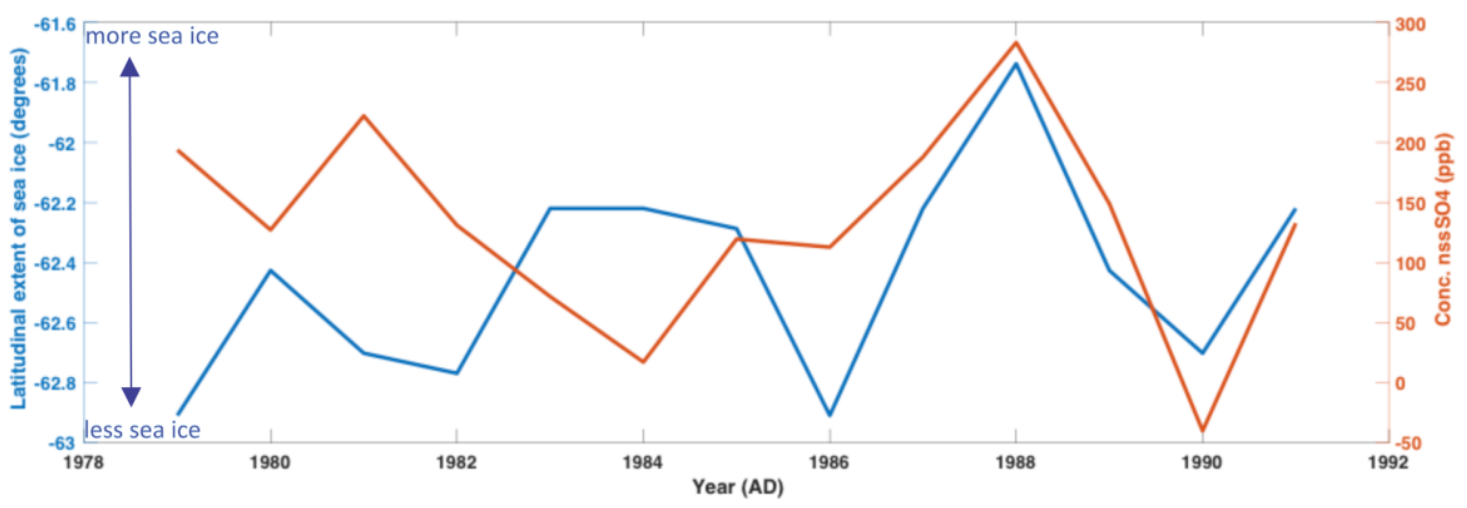

Figure 4.8: IC nss $\mathrm{SO}_{4}{ }^{2-}$ record compared to (Raymond, 2009, 2014) sea ice extent data from $160^{\circ}$ longitude (roughly Ross Sea region).

To investigate the influence of volcanic eruptions on the sulphate record, we compare the RICE nssSO ${ }_{4}^{2-}$ record with the Victoria Lower Glacier (Bertler et al., 2011) and EPICA Dronning Maud Land nssSO ${ }_{4}^{2-}$ record. In Bertler et al. (2011) 5 volcanic peaks are resolved by both the EPICA and VLG cores (Figure 4.9) (Traufetter et al., 2004). According to Bertler et al. (2011) the EDML record is an exceptional record to decipher volcanic eruptions due to its high resolution, suitable age control and was drilled at an elevation of $3233 \mathrm{~m}$ and $\sim 500 \mathrm{~m}$ inland from the coast, which reduces the influence of $\mathrm{Ss} \mathrm{SO}_{4}{ }^{2-}$ compared to coastal sites like RICE and VLG. Only two coinciding major peaks are observed in RICE; the Samalas (Indonesia) eruption (Lavigne et al., 2013) at 1257 $A D$ and the Agung eruption at 1963 AD. There may be a modest signals of the Tambora, Krakatau and Huayanaputina eruptions, but the background biological record at RICE appears to mask those signals. The RICE age model does use the Agung 1965 AD eruption and the Kuwae eruption in 1453 AD, which have been noted in conductivity and $\mathrm{Ca}^{2+}$ data, the latter cannot be identified in our $\mathrm{nsSOO}_{4}{ }^{2-}$ record. Therefore it is argued that the $\mathrm{nssSO}_{4}{ }^{2-}$ record represents mainly a biological indicator. 


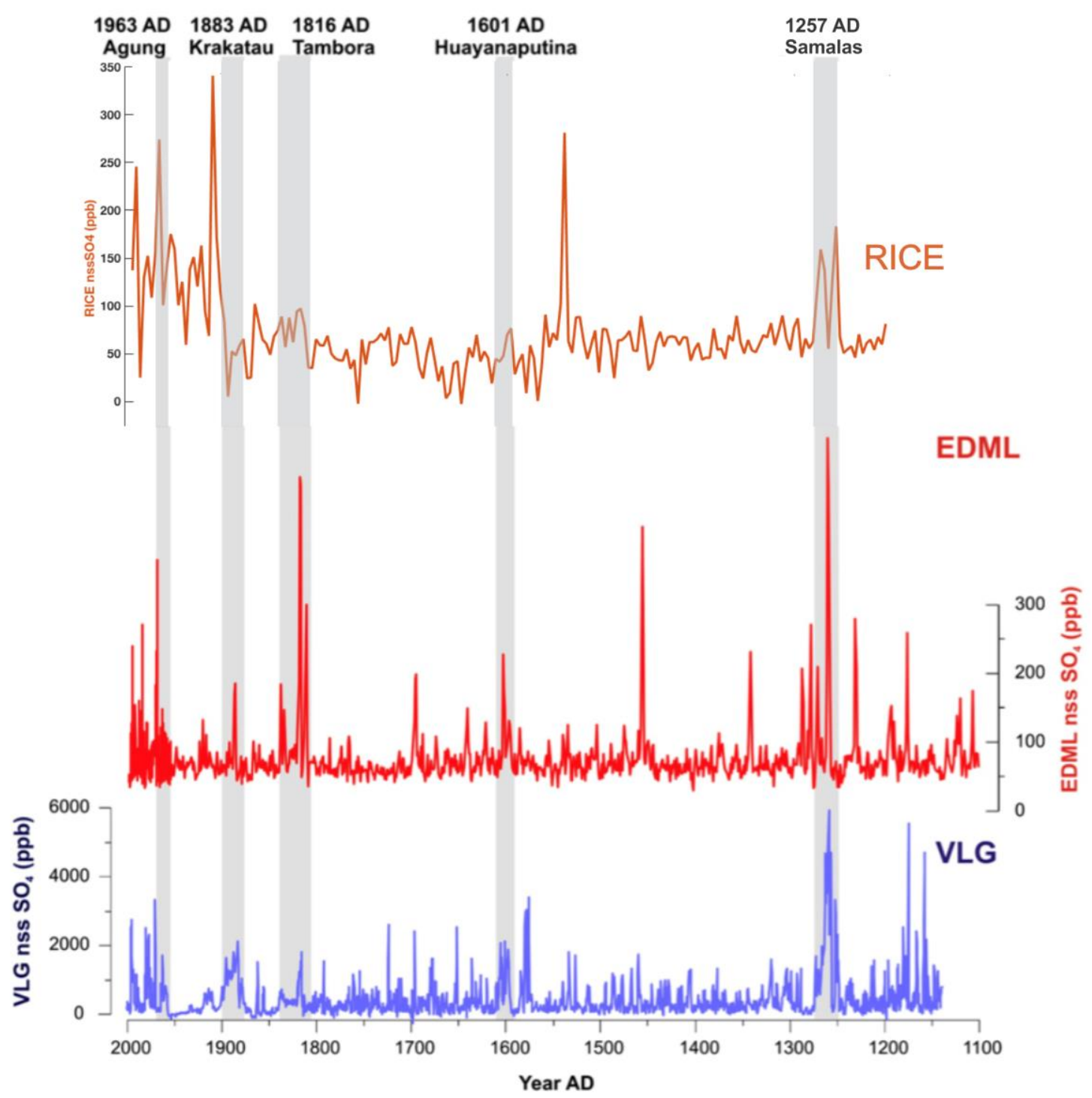

Figure 4.9: Comparison of the Victoria Lower Glacier (Bertler et al., 2011), EPICA Dronning Maud Land

(EDML) and RICE ICP-MS nsSSO ${ }_{4}^{2-}$ record for the past 900 years. Shaded areas indicate eruptions that are shown in both the EDML and VLG nsSSO ${ }_{4}^{2-}$ as dated in the EDML record. Figure modified from Bertler et al. (2011), EDML data from Traufetter et al. (2004). RICE data is set to 4 year resolution.

\subsection{Principal Component Analysis}

A principal component analysis was conducted on two data sets; the long term (12041992 AD) 4 year resolved ICP-MS data set (Appendix C) and the annually resolved middle continuous IC section (1729-1991 AD) (Appendix B). The IC annual principal component analysis was conducted using $\mathrm{Na}^{+}, \mathrm{Cl}^{-}, \mathrm{Ca}^{+}, \mathrm{SO}_{4}{ }^{2-}$ and $\mathrm{nssSO}_{4}{ }^{2-}$ (Table 25). Magnesium was not used due to the lack of confidence in the 1900-1991 AD (Oct/June 13) data (section 3.6), if we did use it then the time period in the PCA would be substantially reduced. The PCA was conducted using PAST software (Hammer, 2016). 


\begin{tabular}{|l|c|}
\hline & PC1 \\
\hline Eigenvalue & 3.4653 \\
\hline \% Variance & 63 \\
\hline
\end{tabular}
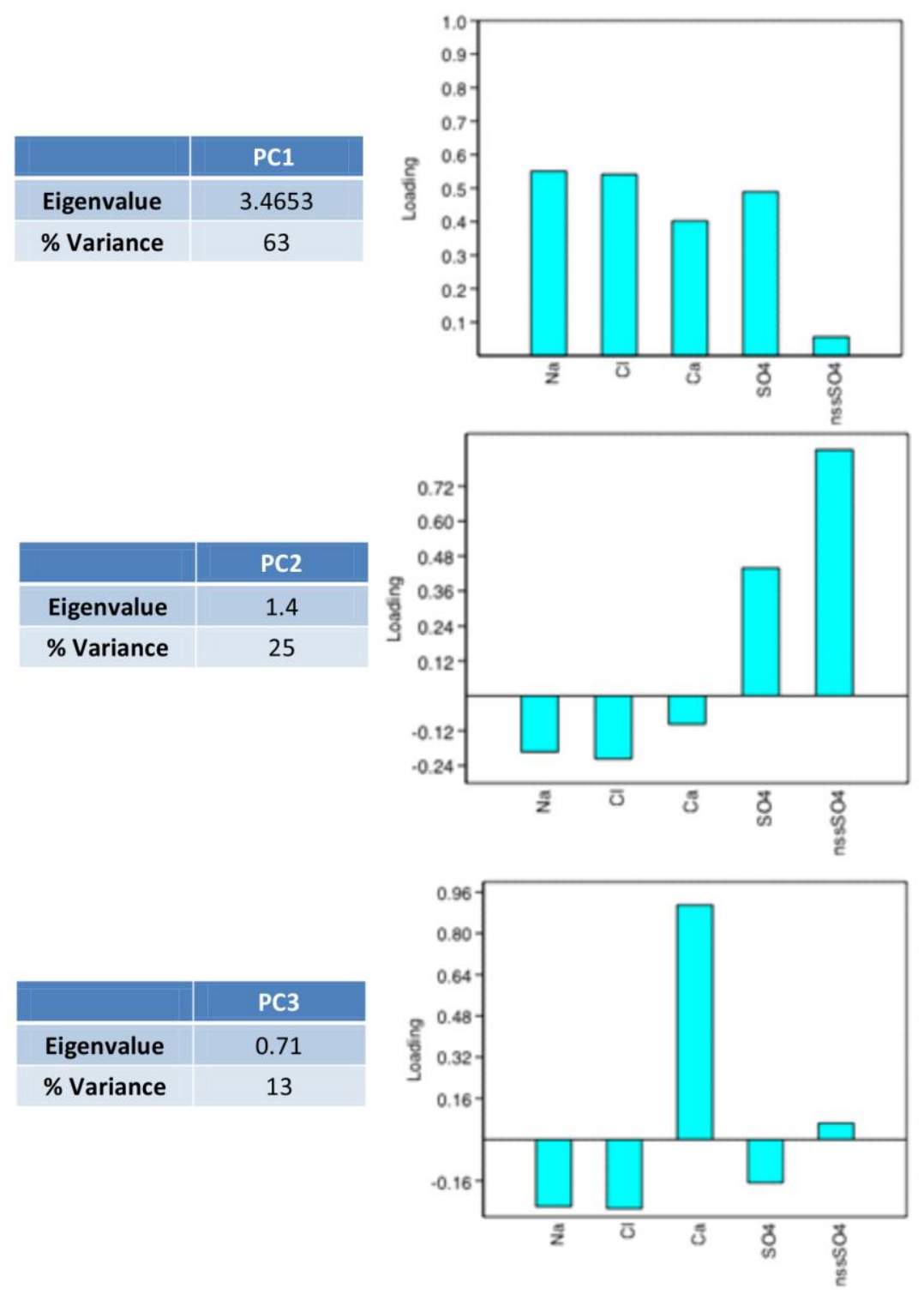

Table 25: Principal component analysis on IC 1729-1991 AD annual data.

Table 25 shows the results of the PCA on the IC 1729-1991 AD annual data (Appendix B). The first principal component (PC1), explains $63 \%$ of the variability. This shows a high level of contribution from $\mathrm{Na}^{+}, \mathrm{Cl}^{-}, \mathrm{Ca}^{2+}$ and $\mathrm{SO}_{4}{ }^{2-}$, with a negative relationship with $\mathrm{nsSOO}_{4}{ }^{2-}$. PC2, which explains $25 \%$ of the variance, shows high levels of contribution from nssSO ${ }_{4}{ }^{2-}$ and $\mathrm{SO}_{4}{ }^{2-}$, with negative relationships with $\mathrm{Na}^{+}, \mathrm{Cl}^{-}$and $\mathrm{Ca}^{2+}$. Finally, PC3 explains $13 \%$ of the variance with high levels of $\mathrm{Ca}^{2+}$. However, when plotting the scores against time there appears to be a correlation between the areas of higher concentration in PC3 and the outliers in the Oct/June 13 calibration for $\mathrm{Ca}^{2+}$ (Figure 3.3), therefore this principal component will not be used. PC4 and 5 explain too little (defined as $<5 \%$ ) of the overall variability to be considered. 


\begin{tabular}{|l|l|}
\hline & $\mathrm{PC} 1$ \\
\hline Eigenvalue & 3.8 \\
\hline \% Variance & 62 \\
\hline
\end{tabular}

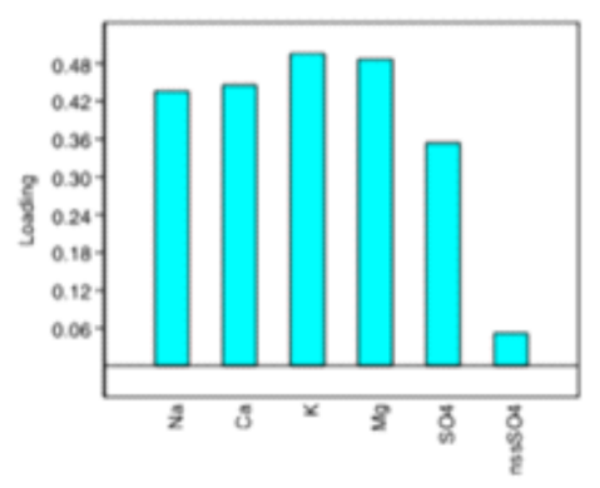

\begin{tabular}{|l|c|}
\hline & $\mathrm{PC} 2$ \\
\hline Eigenvalue & 1.7 \\
\hline \% Variance & 28 \\
\hline
\end{tabular}

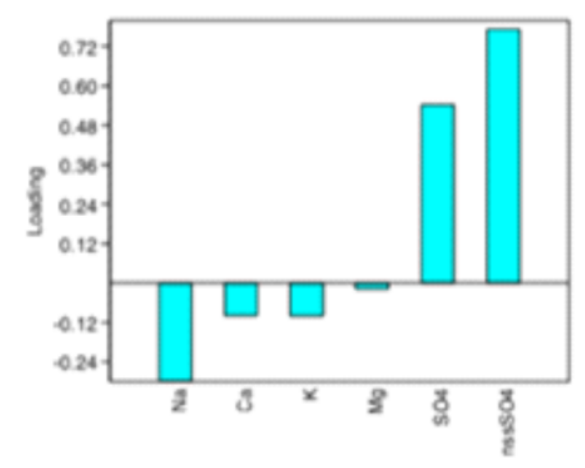

\begin{tabular}{|c|c|}
\hline & $\mathrm{PC} 3$ \\
\hline Eigenvalue & 0.3 \\
\hline \% Variance & 6 \\
\hline
\end{tabular}

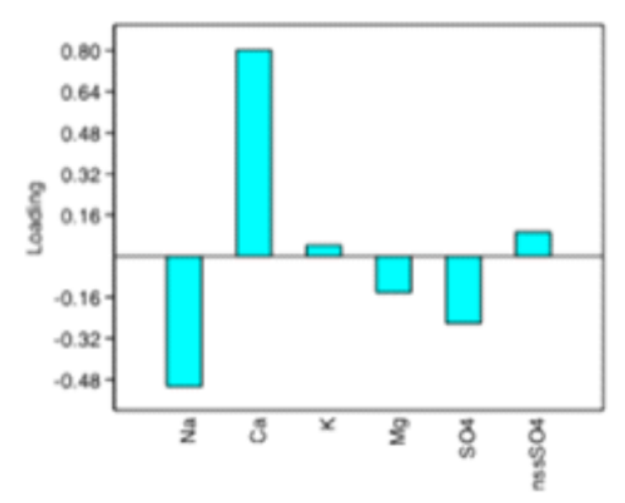

Table 26: Principal component analysis on ICP-MS 4yr 1204-1992 AD resolved data.

Table 26 show the principal component analysis on the 4 year resolved ICP-MS data spanning 1204-1992 AD (Appendix C). Iron was not included in the PCA due to very high values in the last 4 years that would have dominated the analysis. PC1, explains $62 \%$ of the variance, with a large contribution from $\mathrm{Na}^{+}, \mathrm{K}^{+}, \mathrm{Ca}^{2+}, \mathrm{Mg}^{2+}$ and $\mathrm{SO}_{4}{ }^{2-}$ as well as the negative contribution from nssSO ${ }_{4}^{2-}$ (Table 26$)$. PC2, explains $28 \%$ of the variance with a large contribution from non-sea salt sulphate and sulphate (Table 26). PC3 only explains $6 \%$ of the variance, but appears to capture a complex contribution, dominated by $\mathrm{Ca}^{2+}$ and $\mathrm{nsSSO}_{4}{ }^{2-}$ components. PC4, 5 and 6 explain too little (defined as $<5 \%$ ) of the overall variability to be considered. 


\subsection{Investigation of Important Climate Indices}

Decadal scale climate drivers including the ENSO, SAM and the PDO influence the Ross Sea (Emanuelson, 2016). Therefore it is essential to assess how much of the variability seen in the major ion record can be explained by individual drivers.

\subsection{1 $1^{\mathrm{ST}}$ Principal Component}

When the annual PC1 data is correlated with the ENSO, SAM and PDO indexes no statistically significant relationships are identified (Table 27 ).

\begin{tabular}{|c|c|c|c|}
\hline & SAM & SOI & PDO \\
\hline P-value & 0.058 & 0.891 & 0.359 \\
\hline $\mathbf{R}^{\mathbf{2}}$ & 0.01378 & 0.00015 & 0.00618 \\
\hline
\end{tabular}

Table 27: Statistical relationship between the IC annually resolved PC1 and the annual averaged SAM index (Abram et al., 2011), SOI index (NCAR), PDO index (NOAA).

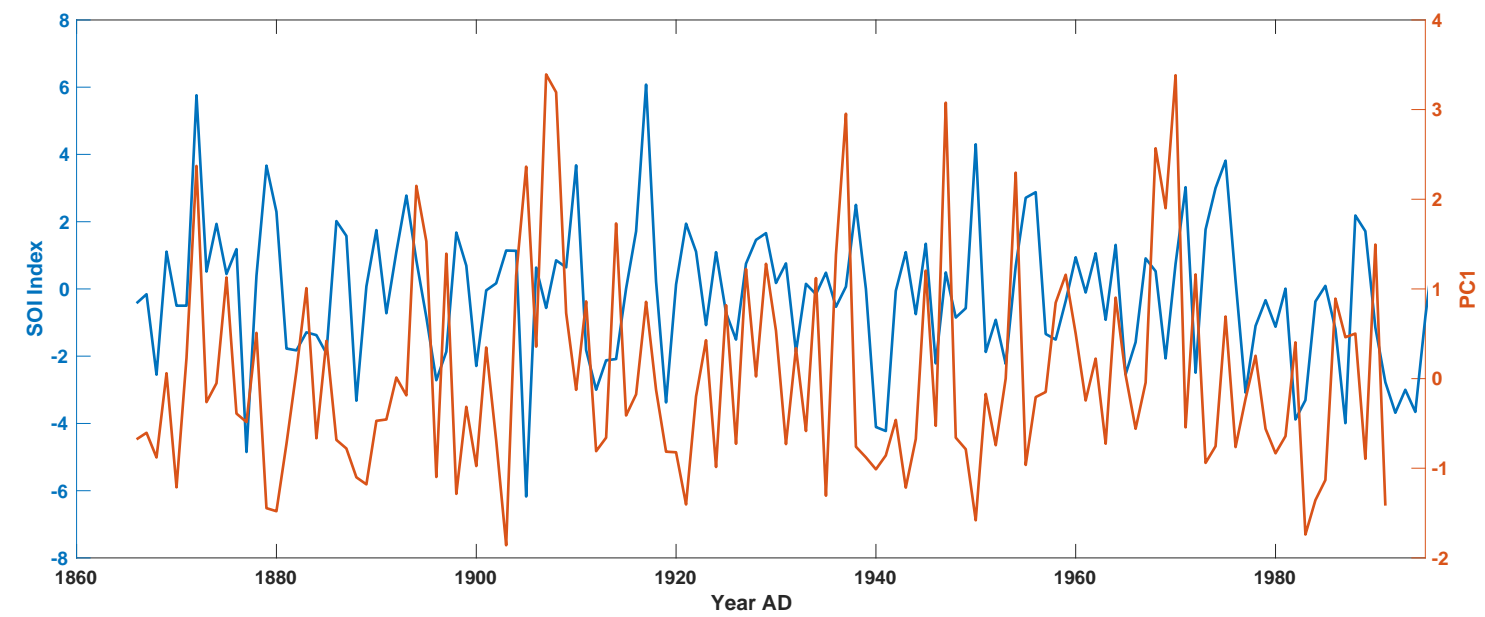

Figure 4.10: Time series comparing the average annual Southern Oscillation Index (SOI) (NCAR) and the IC PC1 between 1866-1991 AD.

The comparison with the SOI shows similar frequencies between the SOI index and PC1, but peaks are as much antiphase as in phase (Figure 4.10). However the decline in the SOI index since $\sim 1950$ s does coincide with a decline in PC1 . 


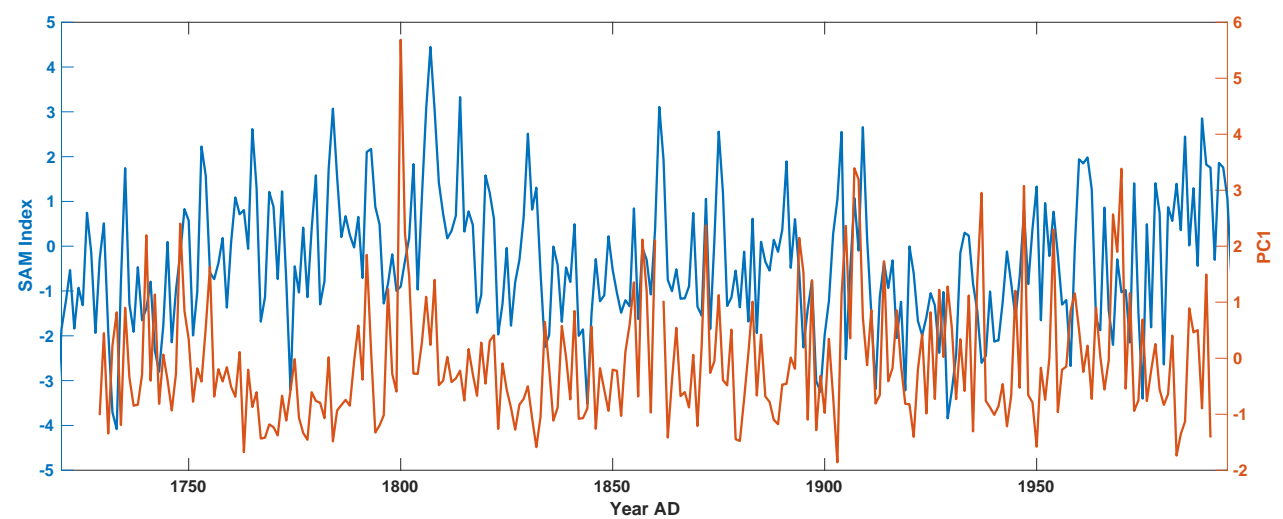

Figure 4.11: Time series comparing the SAM reconstructed index (Abram et al., 2014) with the IC annual PC1 between 1729-1991 AD. 1861AD peak removed from PC1.

The SAM comparison, shows peaks in PC1 coinciding roughly with the positive SAM

(Figure 4.11). However, peak amplitude and 50 year trends are random.

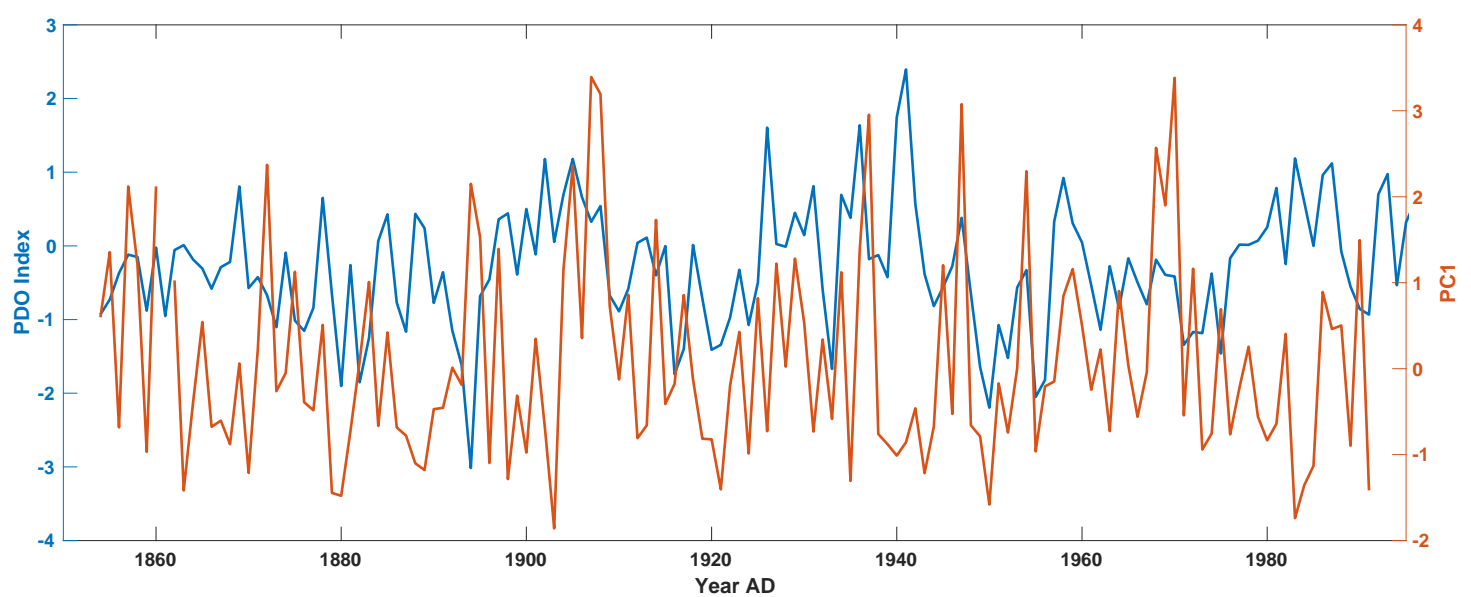

Figure 4.12: time series comparing the average annual PDO index (NOAA) and the IC PC1 between 18541992AD. Removed peak at 1861.

The PDO comparison with PC1 shows few similarities in the frequencies or trends

(Figure 4.12). 


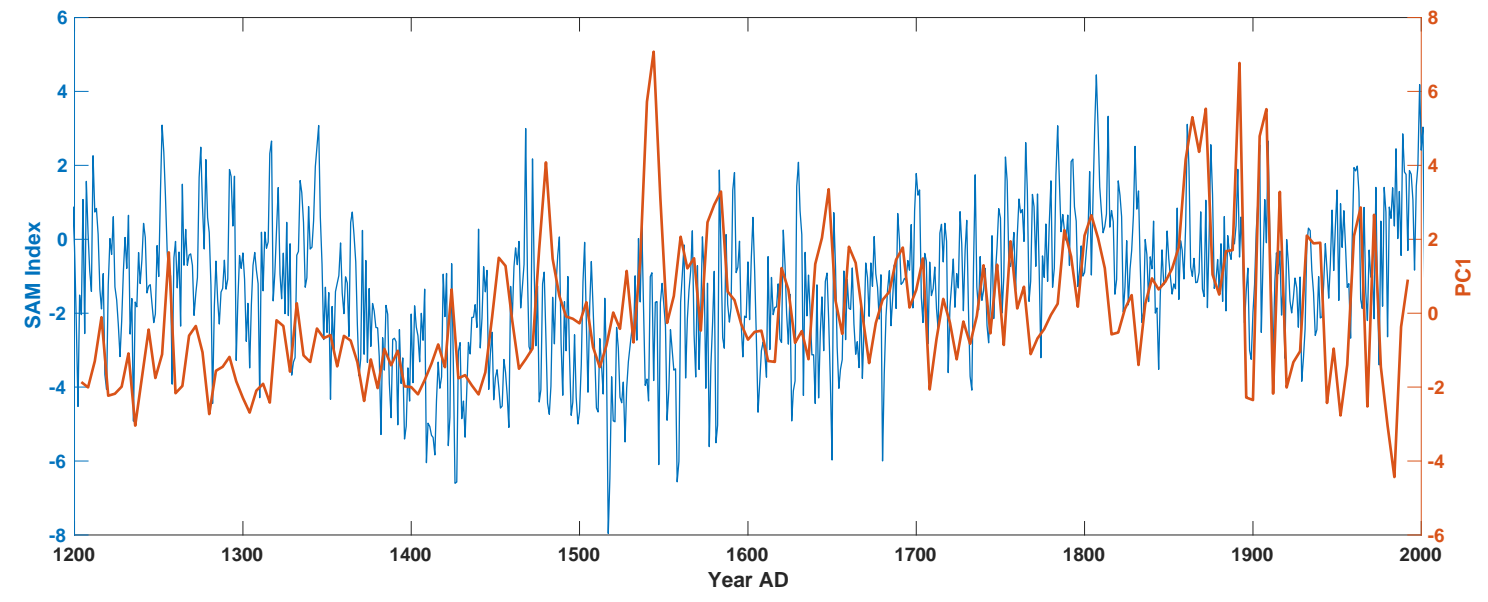

Figure 4.13: Time series comparing the Southern Annular Mode (SAM) reconstruction (Abram et al., 2014) and the ICP-MS PC1 between 1200-1992 AD.

The ICP-MS PC1 was also compared to the Abram et al. (2014) SAM reconstruction back to $1200 A D$, to determine any correlations over the longer timescale (Figure 4.13). The mid $15^{\text {th }}$ century rise in PC1 appears to coincide with the shift towards the positive phase SAM, which continues until 1800 AD. PC1's decline in the late $19^{\text {th }}$ century shortly follows a shift in the SAM to a negative phase in $1800 \mathrm{AD}$. In the $20^{\text {th }}$ century the two patterns diverge with the sea salt continuing on a downward trajectory and the SAM shifting back to a positive phase. However, no statistically significant correlation was found (Table 28).

\begin{tabular}{|c|c|}
\hline & SAM \\
\hline P-value & 0.64 \\
\hline $\mathbf{R}^{2}$ & 0.00112 \\
\hline
\end{tabular}

Table 28: Statistical relationship between the ICP-MS 4 year resolved PC1 and the SAM index interpolated to 4 year resolution(Abram et al., 2011).

\subsection{2 $2^{\text {nd }}$ Principal Component}

The annual second principal component was then correlated with the SAM, SOI and PDO indexes. Once again, no statistically significant relationship was determined (Table 29). 


\begin{tabular}{|l|r|r|r|}
\hline & \multicolumn{2}{|l|}{ SAM } & \multicolumn{1}{l|}{ SOI } \\
\hline P-value & 0.137 & 0.835 & 0.608 \\
\hline $\mathbf{R}^{\mathbf{2}}$ & 0.0085 & 0.00035 & 0.00194 \\
\hline
\end{tabular}

Table 29: Statistical relationship between the IC annually resolved PC2 and the annual averaged SAM index (Abram et al., 2014), SOI index (NCAR), PDO index (NOAA)

The SOI comparison shows that until 1920 AD the time series experienced sections of in phase and out of phase behaviour (Figure 4.14). However, since 1920 AD they appear to be in phase and both decline from the mid $20^{\text {th }}$ century.

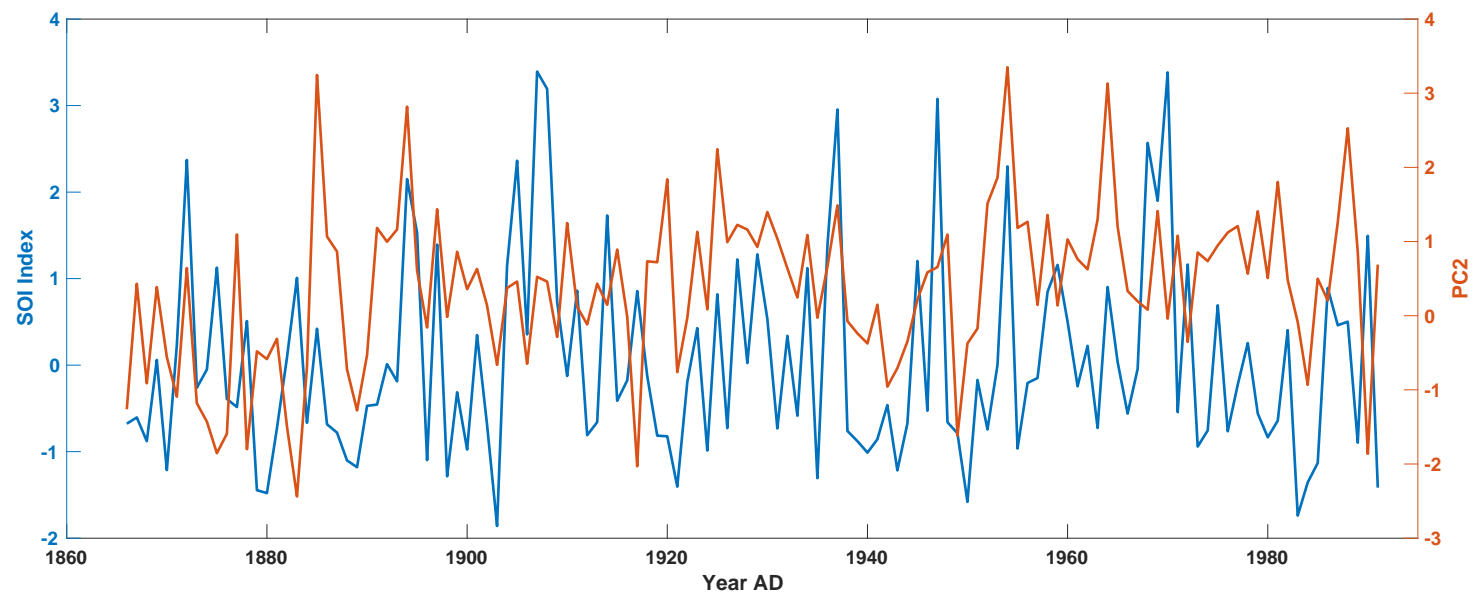

Figure 4.14: Time series comparing the average annual SOI index (NCAR) and the IC annual PC2 between 1866-1991AD.

The correlation between the PDO and the annual PC2 show that since 1920 AD the records are in phase, however prior to this, the relationship switches (Figure 4.15).

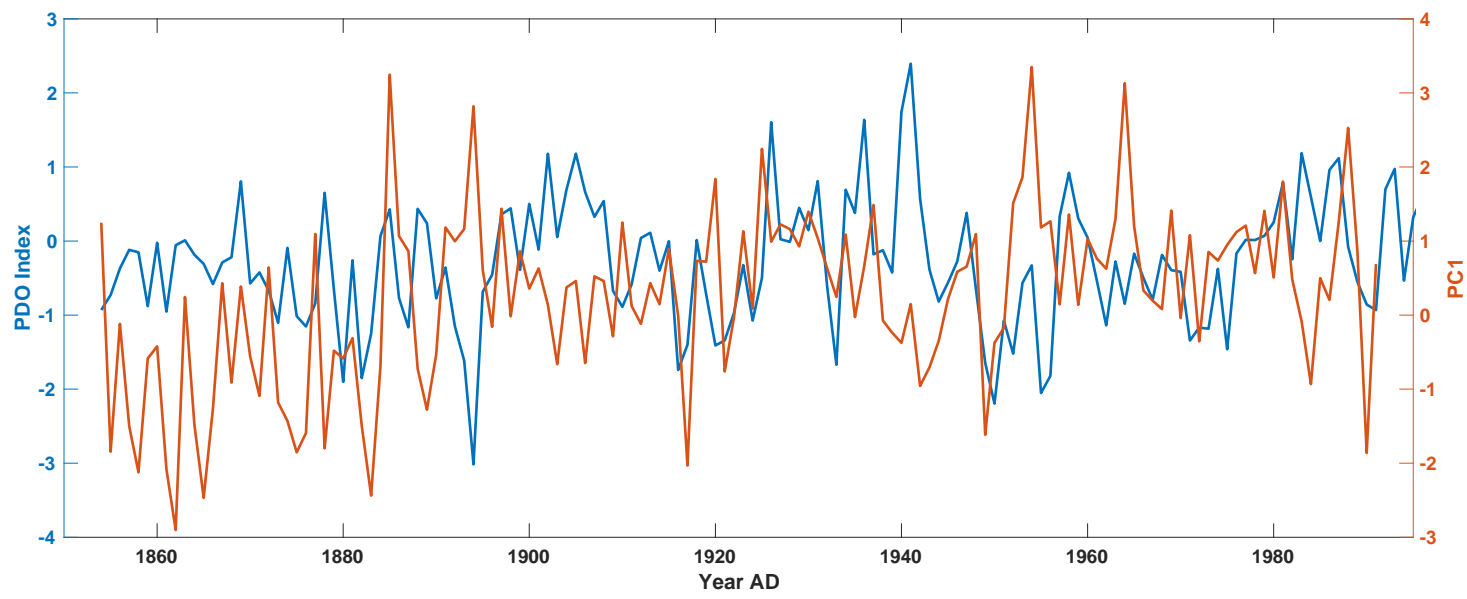

Figure 4.15: Time series comparing the average annual PDO index (NOAA) and the IC PC2 between 1854$1992 A D$. 


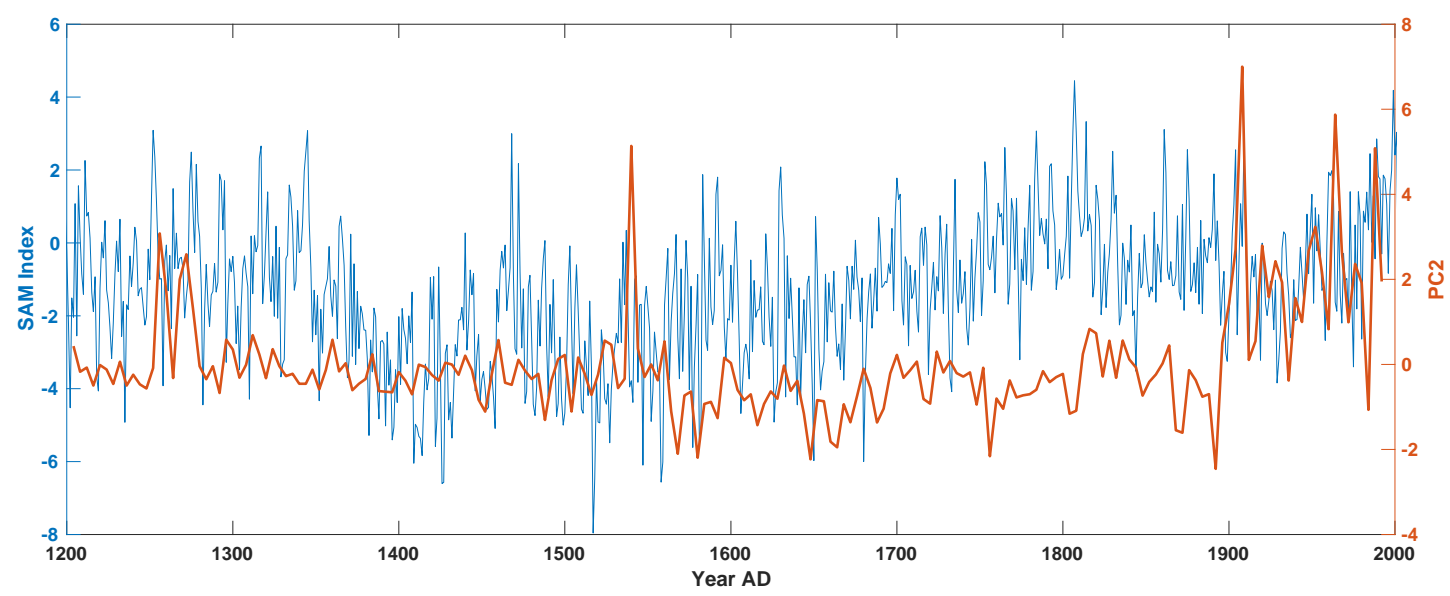

Figure 4.16: Time series comparing the annual SAM reconstruction (Abram et al., 2014) and the ICP-MS PC2 (red) between 1200-1992 AD.

The comparison between the long term PC2 time series and the SAM index between 1200-2000 AD confirms the lack of significant relationship (Figure 4.16) (Table 30).

\begin{tabular}{|c|c|}
\hline & SAM \\
\hline P-value & 0.279 \\
\hline $\mathbf{R}^{\mathbf{2}}$ & 0.00597 \\
\hline
\end{tabular}

Table 30: Statistical relationship between the ICP-MS 4yr resolved PC2 and the SAM index (Abram et al., 2011).

\subsubsection{Summary of $\mathrm{PC} /$ Climate Indice Comparison}

As described, no statistically significant correlations are observed between the RICE principal components and the climate indices. However similarities do occur between the frequencies and trends, which will be addressed further in the following sections.

\subsubsection{Climate vs. PC Spatial Trends}

In order to further assess any relationship between the discussed climate indices and our two principal components, we compared the spatial correlation patterns when plotted against ERA-interim (1979-2015 AD) meridional winds, zonal winds and mean sea level pressure. 


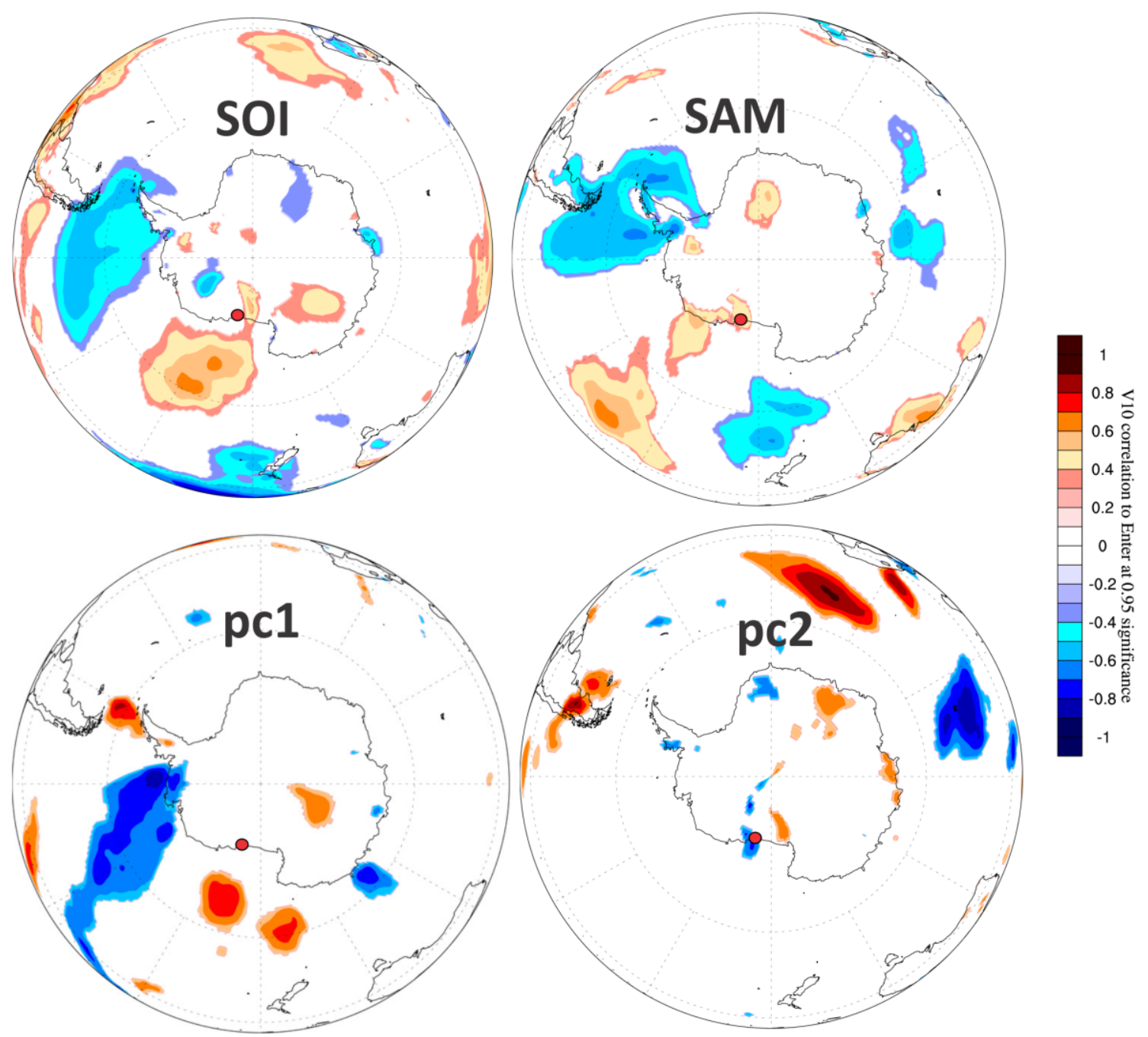

Figure 4.17: The ERA-interim 1979-2015 annual meridional winds ( $V$ winds) data set correlated with the annual SOI record (1979-2015)(NCAR) and the SAM record (1979-2007 AD) (Abram et al., 2014) compared with the ERA-interim 1979-2015 AD summer (DJF) meridional winds (V winds) dataset correlation with the annual IC principal components for 1979-1991 AD at the 95\% confidence level. Positive (negative) correlation indicates a southerly (northerly). Pearson product-moment correlation coefficient calculated using the 'escorc' function is used. Obtained using Climate Reanalyzer (UMaine, 2016). Red circle denotes RICE location.

The first principal component appears to show a similar pattern to ENSO/SOI, with meridional northerly winds associated with West Antarctica and then Southerly/offshore winds coming from the western Ross Sea (Figure 4.17). PC2 shows a small negative correlation over Roosevelt Island, which suggests southerly flow coincides with increased biological activity perhaps influencing the local Roosevelt Island polynya. 

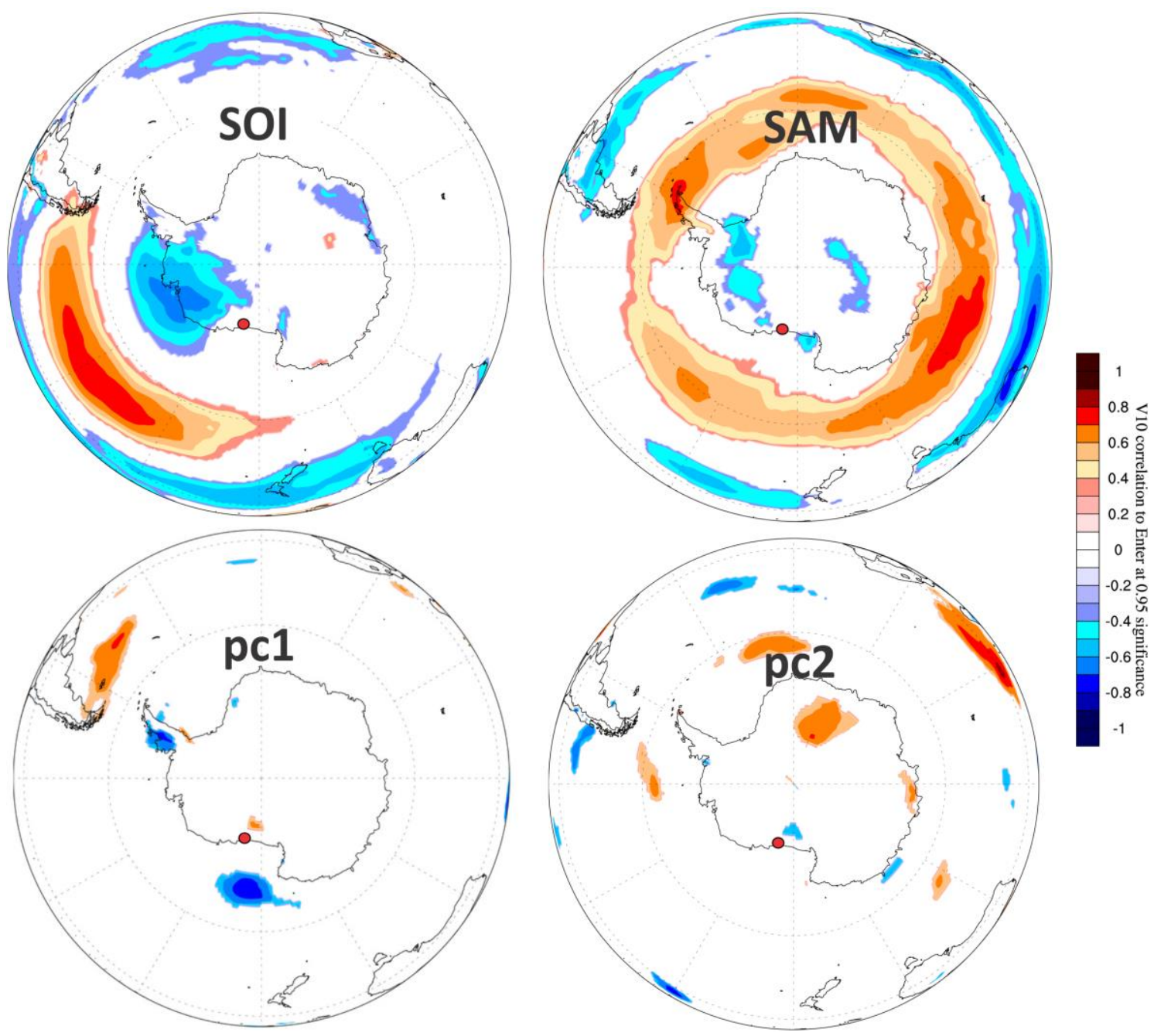

Figure 4.18: The ERA-interim 1979-2015 AD annual zonal winds ( $u$ winds) data set correlated with the annual SOI record (1979-2015)(NCAR) and the SAM record (1979-2007 AD) (Abram et al., 2014) compared with the ERA-interim 1979-2015 summer (DJF) zonal winds (u winds) data set correlation with the annual IC principal components for 1979-1991 AD at the 95\% confidence level. Positive (negative) correlation indicates a westerly (easterly) flow. Pearson product-moment correlation coefficient calculated using the 'escorc' function is used. Obtained using Climate Reanalyzer (UMaine, 2016). Red circle denotes RICE location.

The correlation of zonal wind, PC1 and 2 shows little resemblance to the ENSO/SAM pattern (Figure 4.18). However, when we compare to the patterns of individual ions (Figure 4.4), PC1 does not appear to capture the zonal wind signal shown in $\mathrm{Ca}^{2+}$ and $\mathrm{K}^{+}$, which is very similar to the SAM zonal wind pattern. 

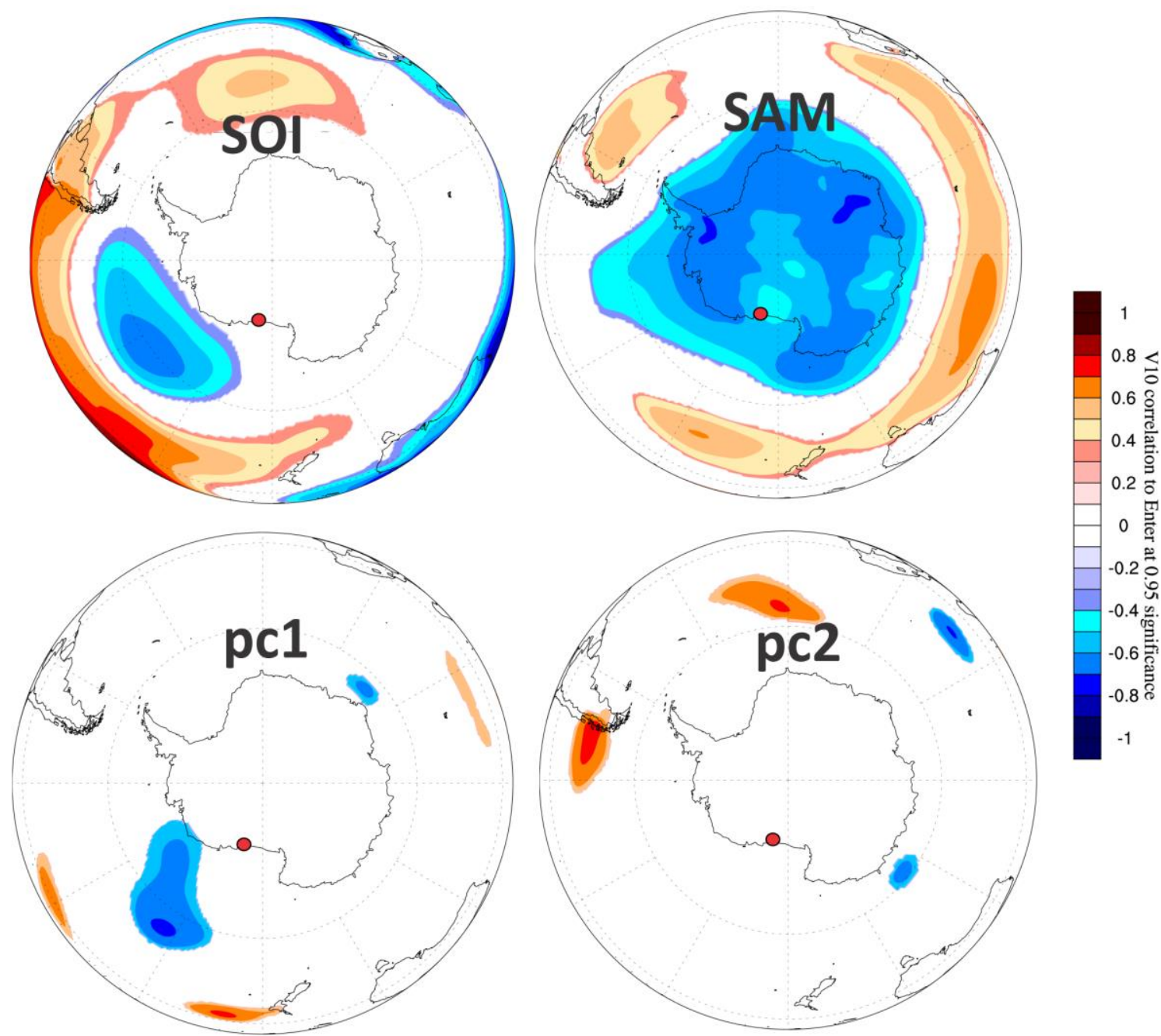

Figure 4.19: The ERA-interim 1979-2015 AD annual MSLP data set correlated with the annual SOI record (1979-2015)(NCAR) and the SAM record (1979-2007 AD)(Abram et al., 2014) compared with the ERAinterim 1979-2015 AD summer (DJF) MSLP data set correlation with the annual IC principal components for 1979-1991 AD at the 95\% confidence level. Pearson product-moment correlation coefficient calculated using the 'escorc' function is used. Obtained using Climate Reanalyzer (UMaine, 2016). Red circle denotes RICE location.

The correlation of PC1 with MSLP shows an area of strong negative correlation which likely represents the ASL, which coincides with an area of low pressure in the ENSO pattern (Figure 4.19). The PC2 shows no similarity to the ENSO or SAM pattern.

\subsection{Time Series Cyclicity/Spectral Analysis:}

Spectral analysis of the PCA data was made to test if the records share frequencies with ENSO, SAM and the PDO. A white noise and redfit filter were applied to determine which peaks are significant with respect to white (random) and red 
(frequency dependent) noise, using a rectangular window, oversampling two times and in two segments. A wavelet analysis was also undertaken to test the temporal extent of observed frequencies. A Morelet function was applied with a lag of 0 and sample interval of 1 . The cone of influence was plotted to indicate that the regions outside of this zone could be impacted by the padding effects of the analysis. The analysis was conducted on PAST software (Hammer, 2016).

\subsection{1 $1^{\text {ST }}$ Principal Component}

Figure 4.20 shows the spectral analysis of annually resolved IC PC1 between 1729-1991 AD. The large peak at 1861 AD (Figure 4.2) was removed from the wavelet analysis as it obstructed the other signals (Figure 4.21). The spectral analysis shows a significant peak $(99 \% \mathrm{Cl})$ at 58 years, which is present in the wavelet analysis as a band from around $42-78$ years, across the entire time series. Before the mid $19^{\text {th }}$ century the band ranges from 42-78 years, following this it becomes more constrained to 42-60 years. However, the more recent section of this wavelet cycle goes beyond the cone of influence, therefore this loss in significance could be caused by the extremes of the wavelet. Signals of 2.8-4 years are also picked up by the spectral analysis, which can be seen in frequent but somewhat irregular spacing throughout the whole record. These frequencies coincide with the ENSO 2-7 year periodicity, suggesting the influence of ENSO at Roosevelt Island during this time period.

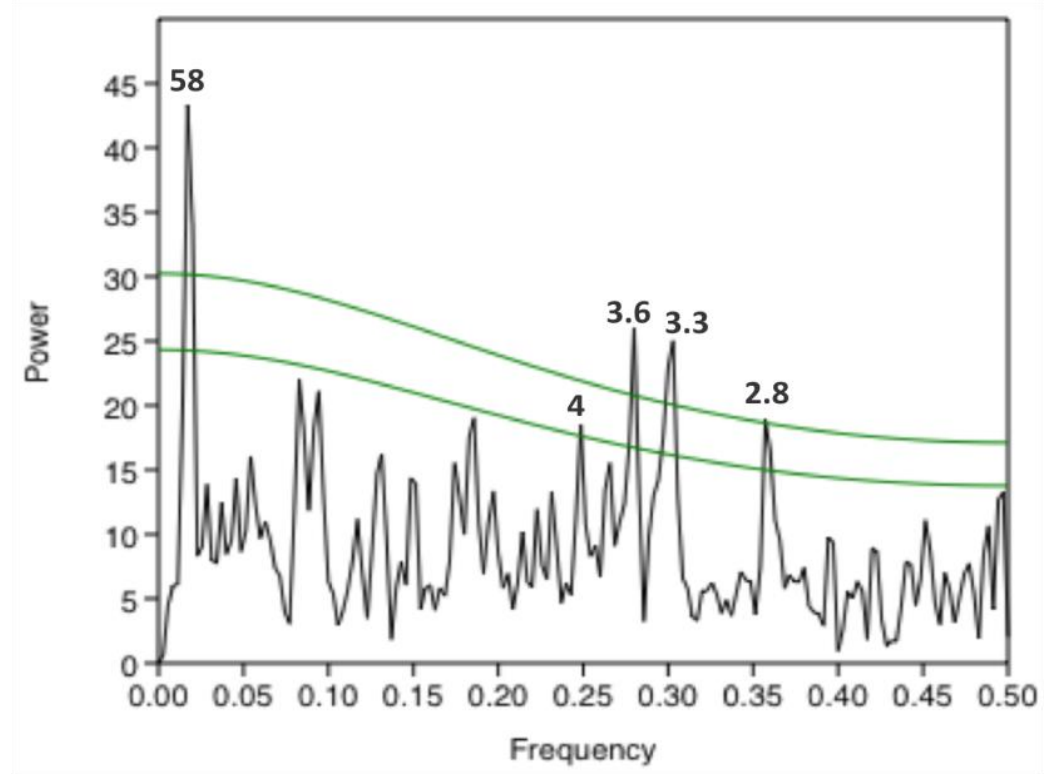

Figure 4.20: Spectral Analysis with REDFIT of the annual PC1 1729-1991 AD data. The lower and upper green lines represent the $90 \%$ and 95\% levels confidence intervals of the REDFIT analysis, respectively. 


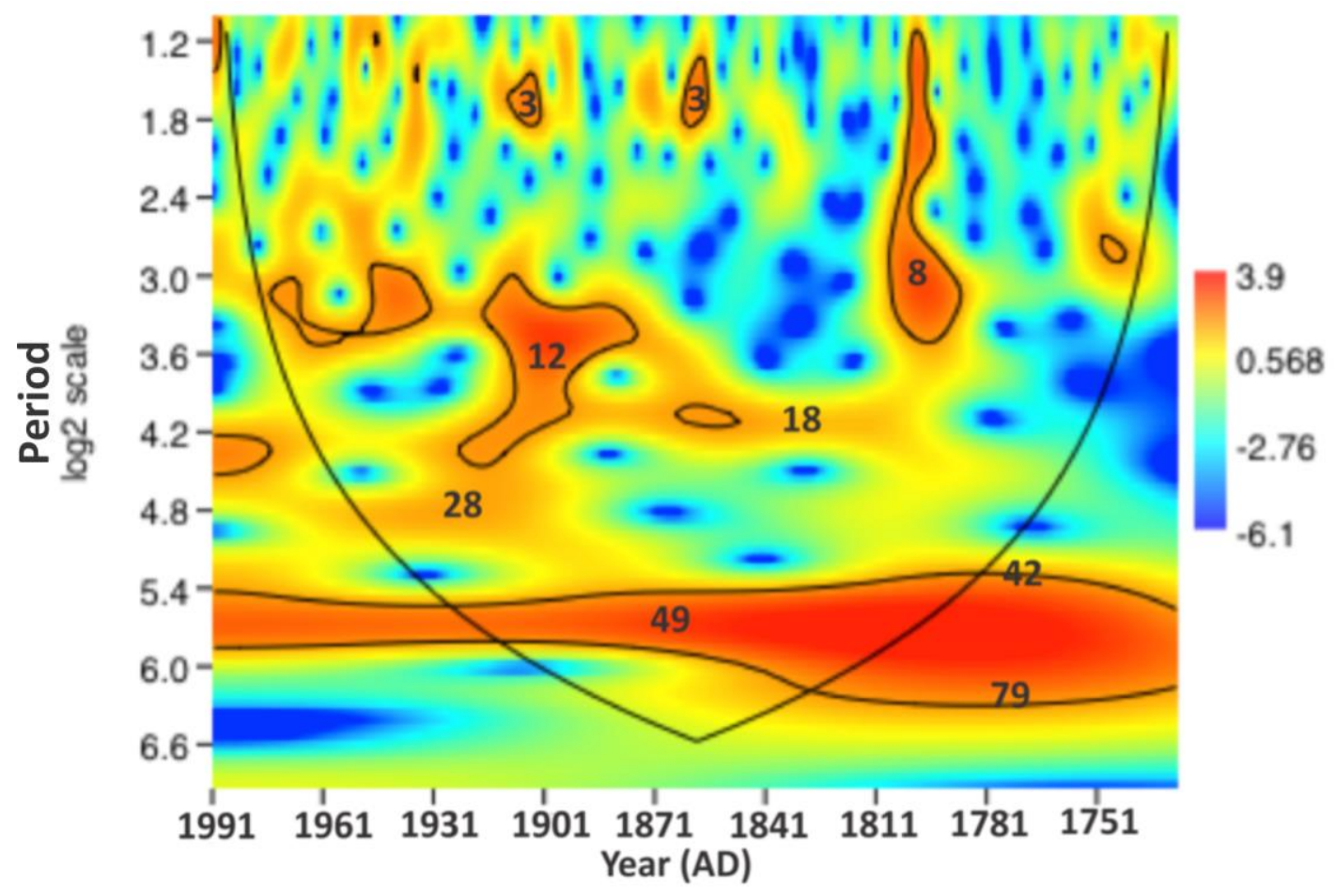

Figure 4.21: Wavelet analysis on IC annual 1729-1991 AD PC1 data. Without peak at 1861. Line is cone of significance and circles around red is the $p=0.05$ significance level. Black numbers indicate period of cycles.

\subsection{2 $2^{\text {nd }}$ Principal Component}

The spectral analysis on the IC annual PC2 data shows 7 significant peaks, at the $95 \%$ confidence level $(87,8.5,4.7,3.4,2.4,2.2,2$ years) (Figure 4.22). The 87 year cycle can be seen in the wavelet analysis as a 64-97 year cycle. However, it is only inside the cone of influence in the middle period as the moving window at this frequency quickly reaches outside the time series (Figure 4.23). The 2-4 year cycles appear to occur throughout the time period, with not all recording at the $95 \%$ significance level. These periodicities, like in PC1, are likely associated with the ENSO influence on the record. 


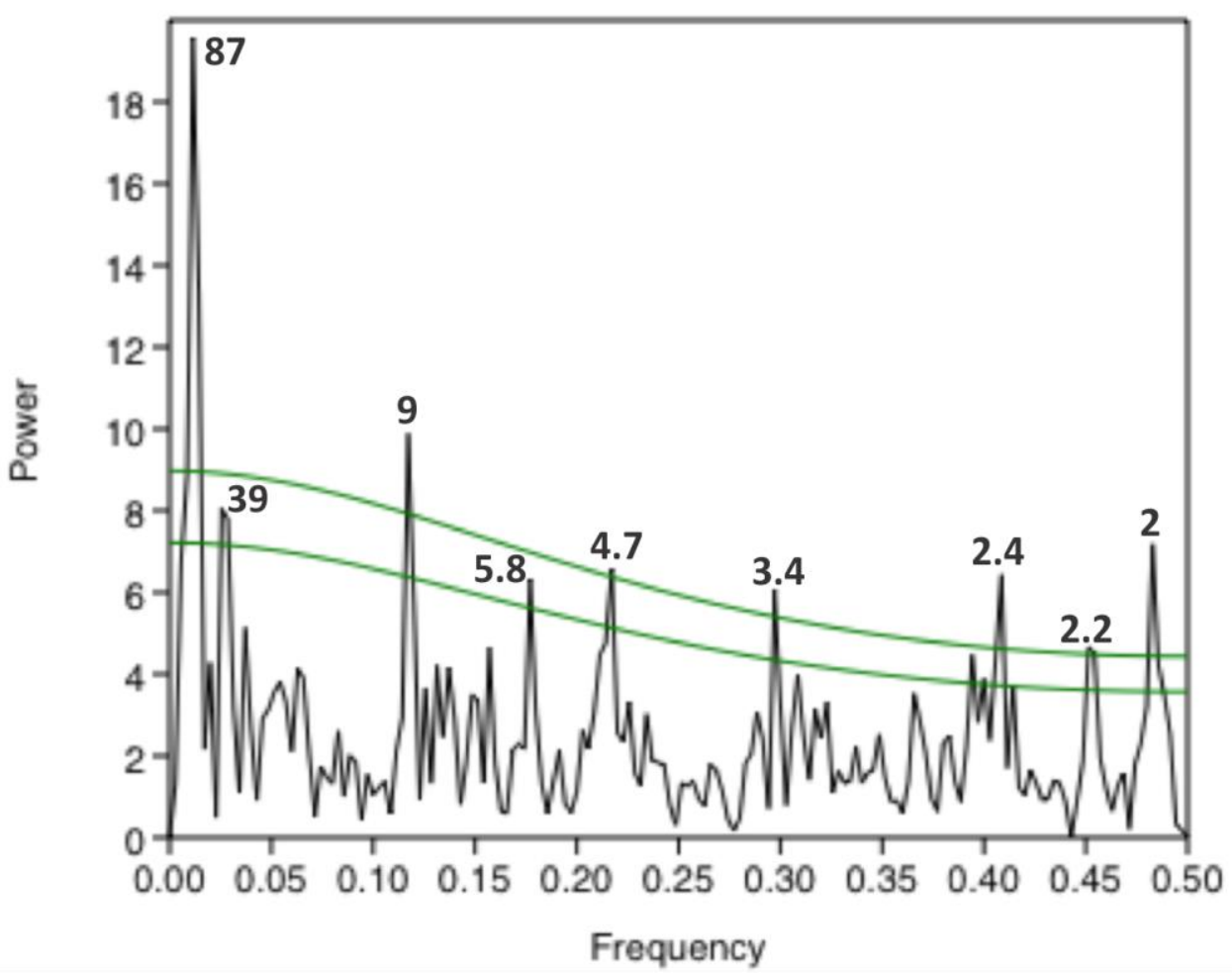

Figure 4.22: REDFIT analysis of IC PC2 annual 1729-1991 AD data. The lower and upper green lines represent the $90 \%$ and $95 \%$ levels confidence intervals, respectively.

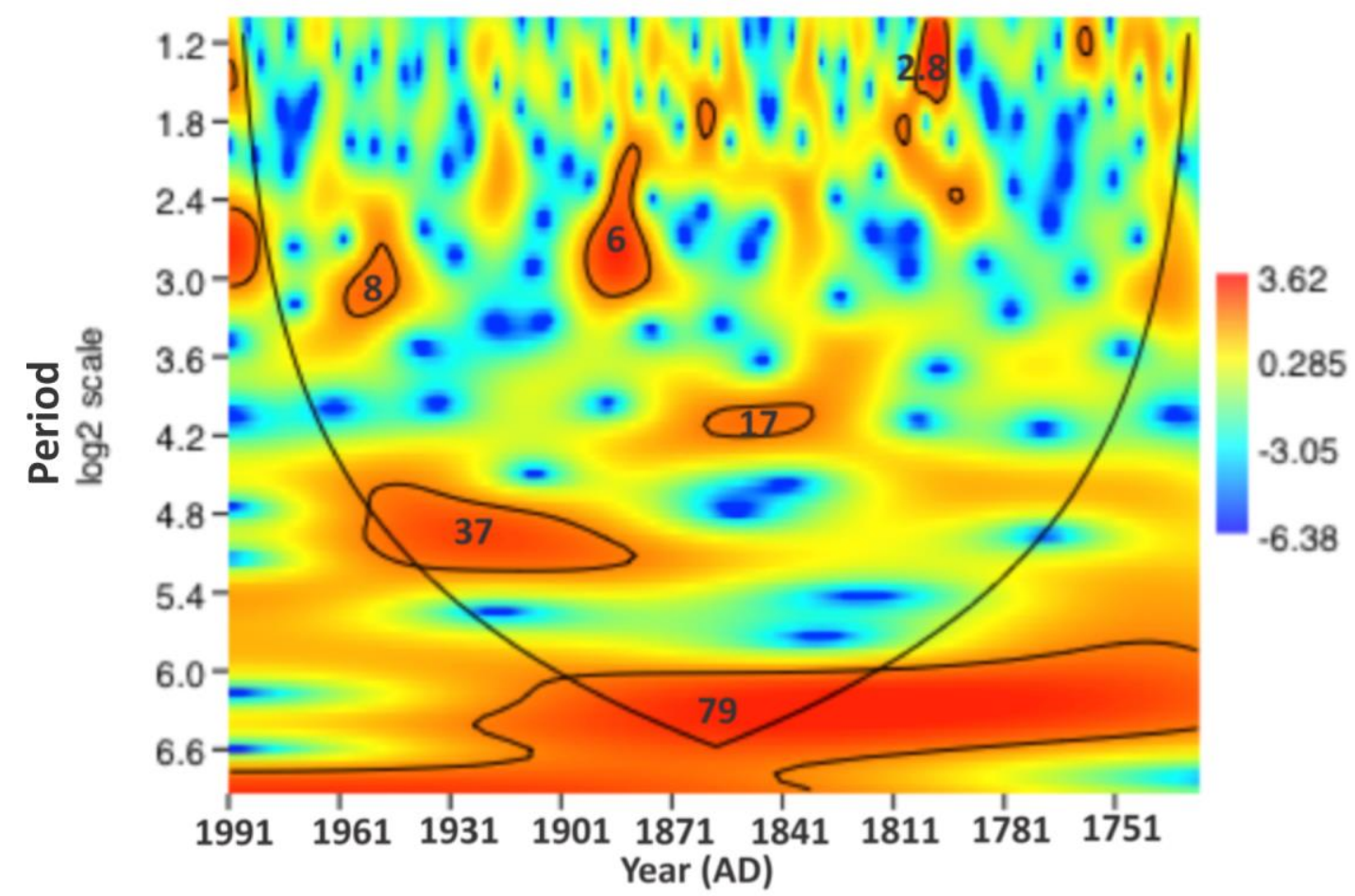

Figure 4.23: Wavelet analysis on IC annual 1729-1991 AD PC2 data. Line is cone of significance and circles around red is the $p=0.05$ significance level. Black numbers indicate period of cycles. 


\subsubsection{Fe Record}

Spectral analysis was also conducted on the Fe ICP-MS record. The data show 4 significant peaks, at the $95 \%$ confidence level $(519,207,12,9$ years) (Figure 4.24). As the data is resolved at a 4 year resolution, cycles with a periodicity of less than 8 years cannot be resolved, therefore any ENSO signature cannot be observed.

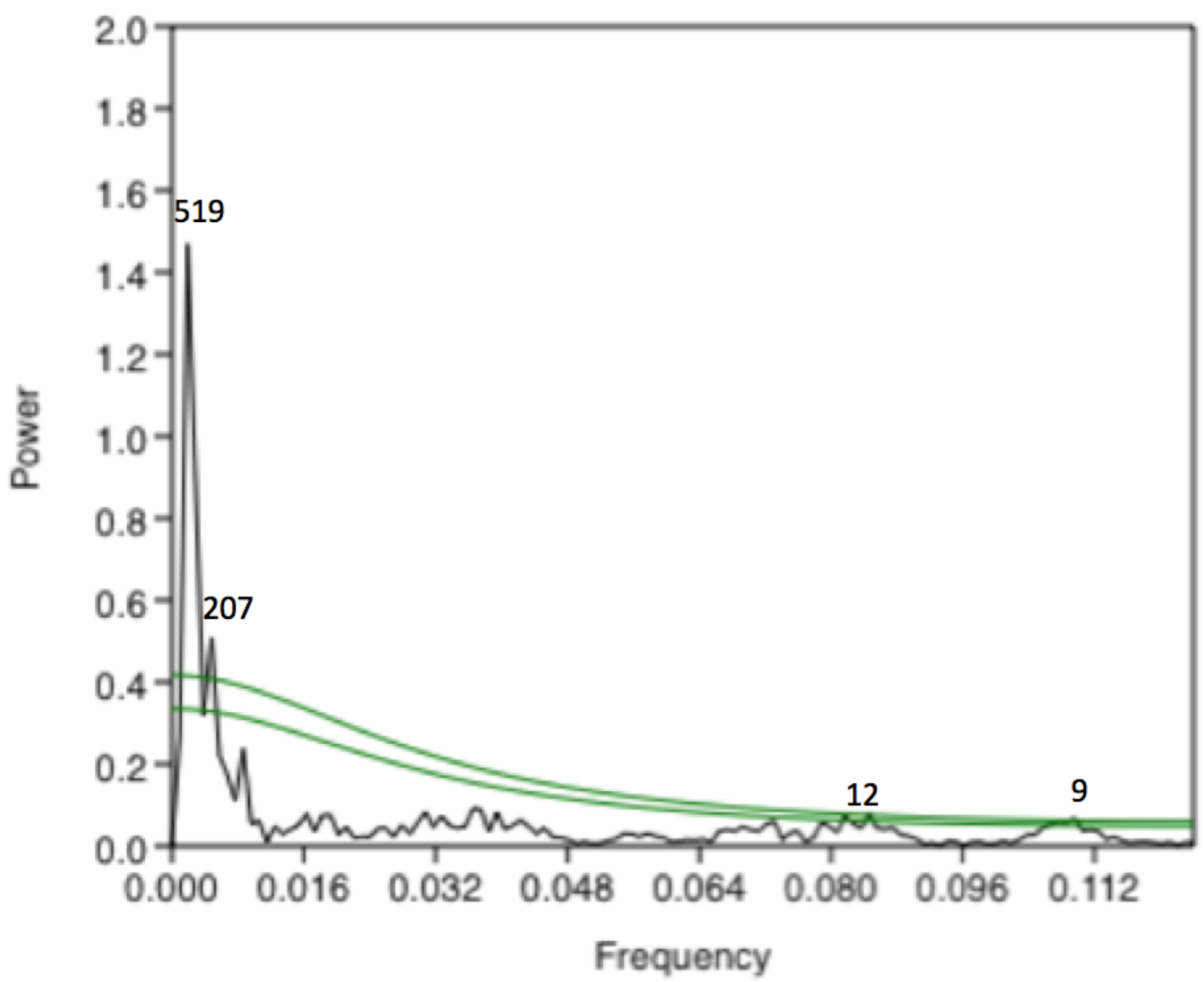

Figure 4.24: REDFIT analysis of ICP-MS 4yr 1204-1984 AD Fe record data. 1992 AD and 1988 AD peak removed as they were obstructing spectral frequencies. The lower and upper green lines represent the 90\% and 95\% levels confidence intervals, respectively. 


\section{Chapter 5: Discussion}

Three research questions were set out at the beginning of this thesis to determine the conditions experienced at Roosevelt Island during the LIA/ME and how this is placed in the context of the wider Ross Sea region. Answering these questions will therefore contribute to our understanding of the atmospheric and oceanic circulation in the Ross Sea.

\subsection{Research Question 1: What were the atmospheric and climatic conditions} experienced at Roosevelt Island during the Little Ice Age/ Modern Era transition?

During the Little Ice Age (LIA) ( 1400-1850 AD), the RICE records received more enriched isotopes, suggesting warmer conditions at Roosevelt Island (Figure 5.1) (Bertler et al., in prep). This period coincided with a decrease in snow accumulation rate (Figure 5.1) (Winstrup et al., In prep). Entering into the modern era ( 1850 AD), a dominance of more enriched isotopes occurs, suggesting warmer conditions, coinciding with the $0.2^{\circ} \mathrm{C}$ increase in temperature recorded on average throughout Antarctica (Schneider et al., 2006). This shift in temperature was also met with an additional decrease in accumulation rate (compared to the LIA time period) (Figure $5.1)$.

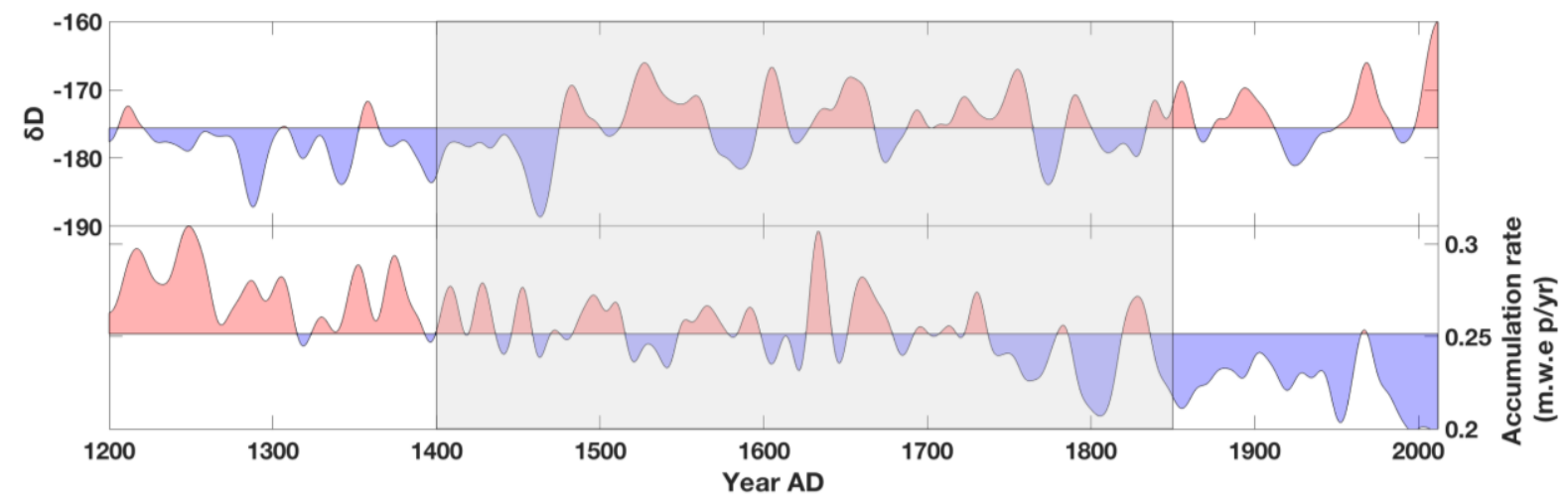

Figure 5.1: RICE deuterium isotope record and accumulation rate ( $m$ water equivalent per year) over the Little Ice Age/Modern Era period (1200-2000 AD) (Bertler et al., in prep). Grey box indicates the generally accepted Little Ice Age period. Method of isotope preparation is detailed in Emanuelsson et al. (2016). Method of accumulation rate detailed in Winstrup et al. (in prep). Smoothed by a factor of 50. 
The causes for these changes are potentially linked to the changes in atmospheric/oceanic circulation, which can be assessed by analysis of the RICE major ion record.

The principal component analysis indicated two main sources of major ions (Chapter 4.3) (Appendices B \& C). The large contribution of identified sea salt species; $\mathrm{Na}^{+}, \mathrm{Cl}^{-}$, $\mathrm{Ca}^{+}$and $\mathrm{SO}_{4}{ }^{2-}$ in the IC PCA and $\mathrm{Na}^{+}, \mathrm{Ca}^{2+}, \mathrm{K}^{+}, \mathrm{Mg}^{2+}, \mathrm{SO}_{4}{ }^{2-}$ in the ICP-MS PCA, confirms in both cases that the first principal component represents marine sourced winds. When ICP-MS PC1 is plotted as a proxy for marine air mass intrusions against time, we find that marine winds increased in the mid $15^{\text {th }}$ century continuing in a roughly steady state through the LIA until the mid-late $19^{\text {th }}$ century when greater variability occurs superimposed on a declining trend until 1992 AD (Figure 5.2).

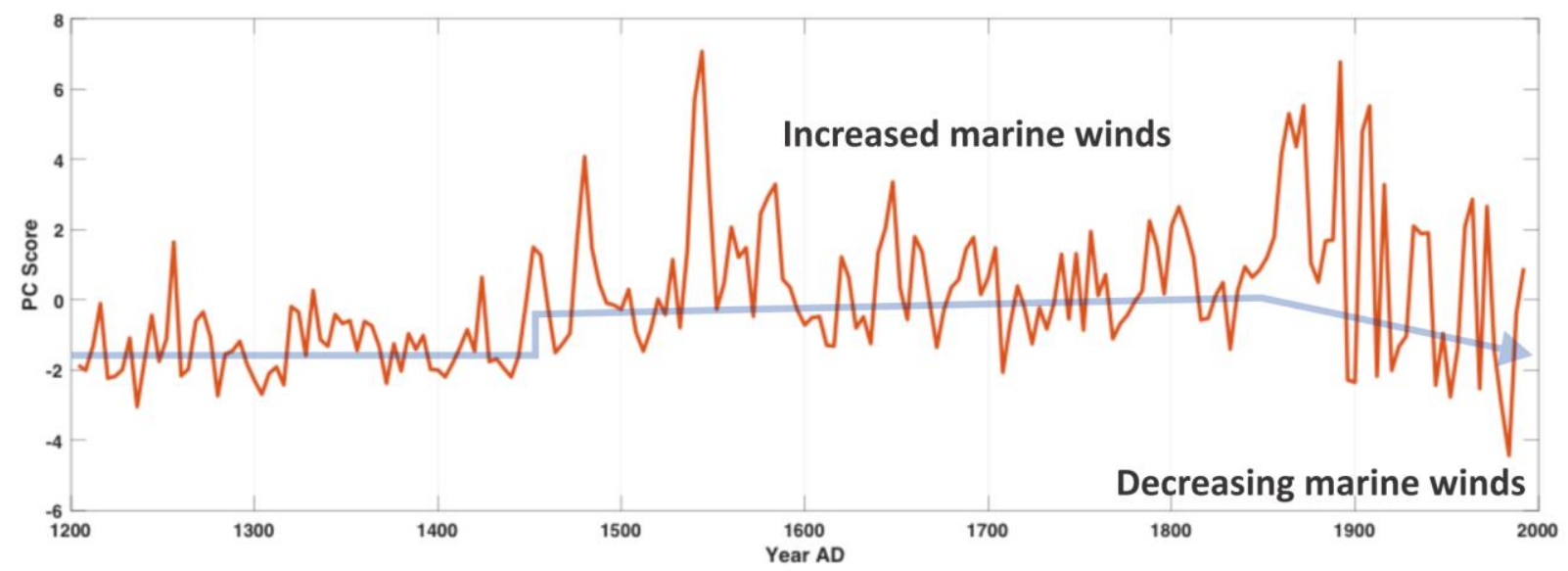

Figure 5.2: ICP-MS 4 yr resolved PC1: sea salt/marine influence proxy. Blue lines indicate schematically changes in trend.

PC2 shows a significant contribution from $\mathrm{nsSSO}_{4}{ }^{2-}$ and sulphate in the IC and ICP-MS PC2. As evinced, nssSO ${ }_{4}^{2-}$ is largely linked to biological productivity near Roosevelt Island, therefore PC2 is assumed to indicate a biological influence. When the ICP-MS PC2/our biological proxy is plotted against time, biological productivity is shown to decline mid $16^{\text {th }}$ century until a sharp increase in the late $19^{\text {th }}$ century that on to 1992 $\mathrm{AD}$ (Figure 5.3). This record also shows the $\mathrm{nssSO}_{4}-$ related spikes of the two volcanic events; the Samalas eruption at 1257 AD and Agung at 1963 AD. 


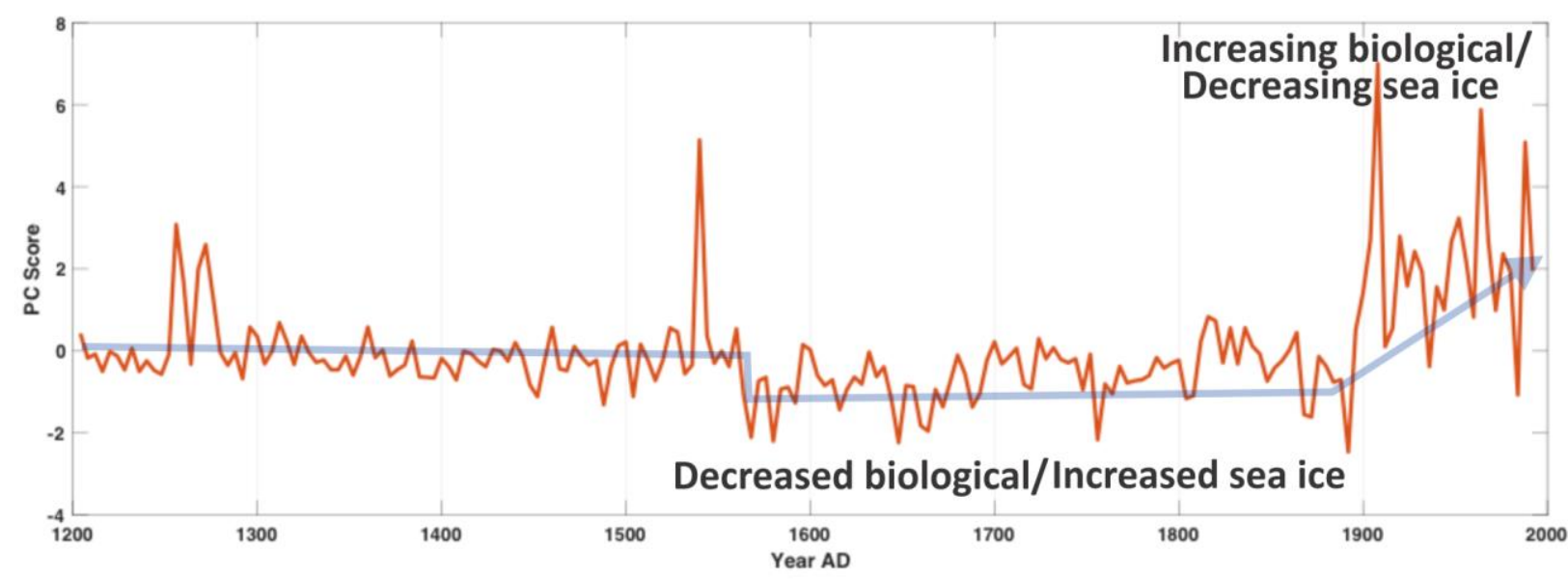

Figure 5.3: ICP-MS 4 yr resolved PC2: biological proxy. Blue lines indicate schematically changes in trend.

Fe is a terrestrial/dust indicator (Bertler, 2004). However, determining the source of dust to West Antarctic ice cores is difficult as there are three main sources as highlighted by Neff and Bertler (2015). Firstly, a small component comes from exposures on the mountain ranges from West Antarctica. Secondly, dust is derived from rock outcrops in the Transantarctic Mountains e.g. Executive Committee Range and Ford Ranges. However, the atmospheric patterns that bring this dust to Roosevelt Island are considered unusual (Neff and Bertler, 2015; Bertler, perss comm.). Finally, a large component of dust may be derived from New Zealand, South America (in particular Patagonia), Australia and South Africa (Neff \& Bertler, 2015). As the principal source of dust to Roosevelt Island is not yet identified, the Fe record could indicate a change in source in addition to changes in transport strength. The decrease marine air mass intrusions during elevated Fe concentrations, does not support a strong marine source. Therefore it is proposed that the Fe record can be used as a proxy for katabatic winds derived from West Antarctic sources. This would suggest that katabatic winds were weaker through the LIA, but during the late $19^{\text {th }}$ century, and increased again into the $20^{\text {th }}$ century (Figure 5.4). 


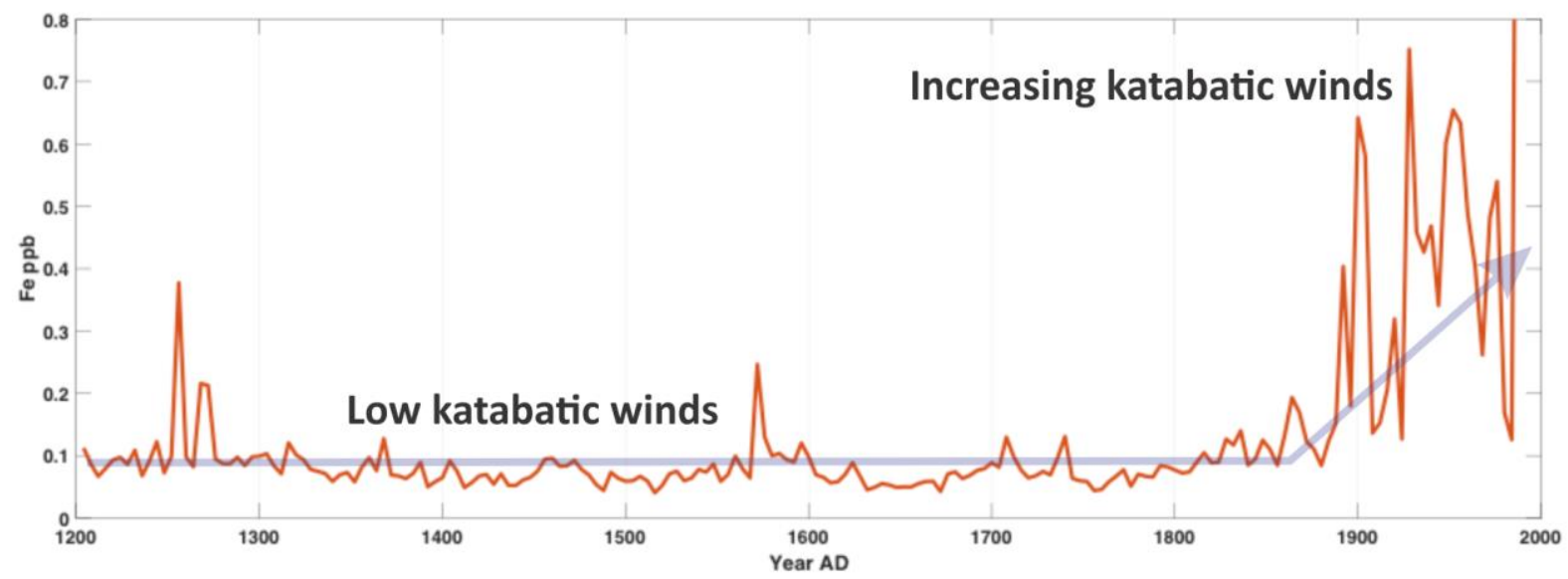

Figure 5.4: ICP-MS 4 yr resolved Fe time series for 1204-1992 AD. Large peak in 1992 AD was cut off to see more variability at lower concentrations. Blue lines indicate schematically changes in trend.

5.2 Research Question 2: What climate drivers can be linked to the processes observed at Roosevelt Island during the Little Ice Age/Modern Era transition?

Emanuelsson (2016) identified the influence of climate modes including El Niño Southern Oscillation (ENSO) and the Southern Annular Mode (SAM) at Roosevelt Island. These climate modes, as well as the Pacific Decadal Oscillation (PDO) time series are compared with the marine/biological record, but there is no statistically significant relationship. This result is not surprising, as the influence of these drivers are: (i) cumulative, (ii) seasonally variable, and (iii) not independent (Bertler, 2004; Fogt \& Bromwich, 2011; Stammerjohn et al., 2012; Turner et al., 2013). However, spectral analyses suggest a measurable influence of ENSO at Roosevelt Island, with 2-5 year frequencies observed in both the marine influence record (PC1) and the biological record (PC2). The PDO might also affect the biological record with a 39 year cyclicity. The 9 year cycle could also indicate either a sunspot cycle (nominally 11 year cyclicity), which has been shown to influence local atmospheric circulation patterns (Bertler et al., 2005). The $40-90$ year long trend seen in both the marine and biological records cannot be explained by a single climate driver alone, but could be the manifestation of the interaction between multiple drivers or the long term solar cycle.

The iron spectral analysis has a 519 long cycle. When the SAM reconstruction is run through a spectral analysis a 528 year cycle arises at the $95 \%$ significance level, which could explain the frequency in the Fe record. 
The lack of statistically significant relationships between the PC1/marine influence and biological (PC2) records with either ENSO, SAM or the PDO, does not suggest that these climate drivers do not affect the records, but rather that the relationships are complex. This can be seen when the ENSO/ERA-interim meridional winds were compared with PC1 (Figure 4.17), which showed a similar region of correlation off the West Antarctic coast. In addition, several sea salt species also showed statistically significant correlations in the zonal wind pattern coinciding with the SAM. This highlights the complexity of the relationship with both climate patterns clearly having an impact on the marine winds.

5.3 Research Question 3: How do the climatic conditions at Roosevelt Island fit in the context of the wider Ross Sea setting during the LIA/ME transition?

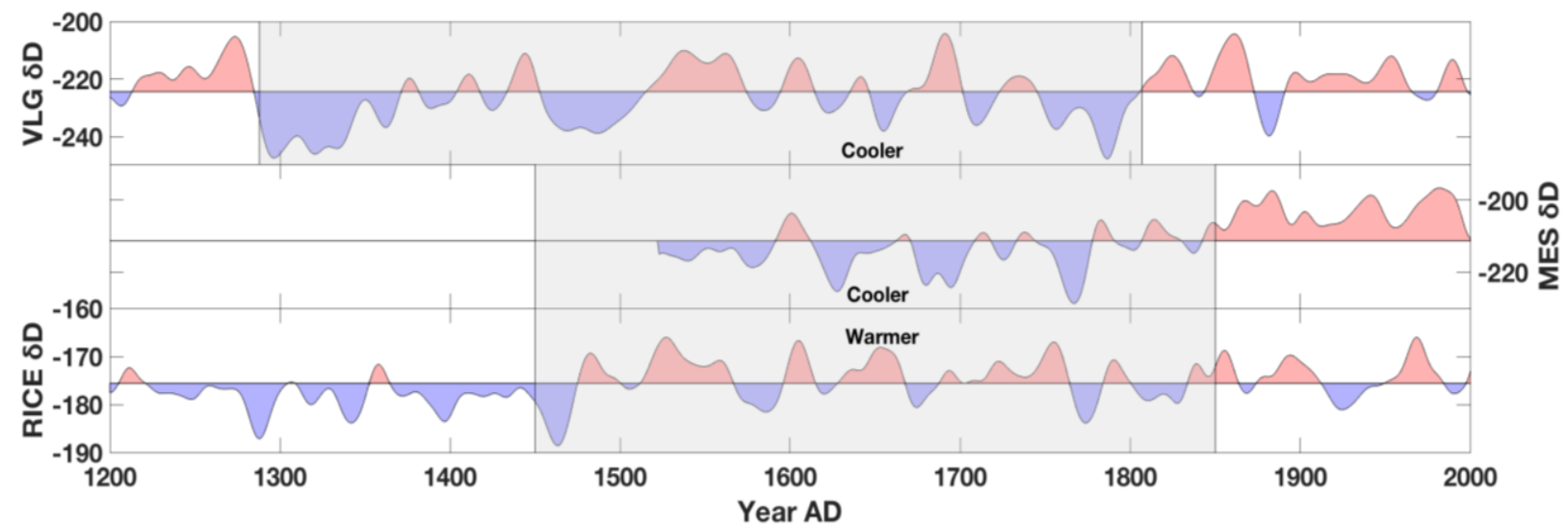

Figure 5.5: Comparison of deuterium isotopes from the Victoria Lower Glacier (VLG) core (Bertler et al., 2011), Mt. Erebus Saddle (MES) (Rhodes et al., 2012) and RICE (this study). Grey box marks Little Ice Age cooling, RICE and MES show the generally accepted LIA period and VLG shows site-specific period described by Bertler et al. (2011). Smoothed by a factor of 50.

\subsubsection{Little Ice Age}

Based on the RICE deuterium isotope data, the LIA extends from 1450 to 1850 AD (Figure 5.5). Roosevelt Island experienced increased marine air mass intrusions during the LIA and probably decreased biological activity, with weaker katabatic winds. This is also supported by the near-by Siple Dome site, which recorded higher sea salt 
concentrations from 1400 AD until the $20^{\text {th }}$ century (Kreutz et al., 2000). However, this pattern, was not synchronous across the entire Ross Sea region. The Victoria Lower Glacier record, located in the western Ross Sea, recorded higher Fe concentrations and reduced sodium (Bertler et al., 2011). This was interpreted to reflect stronger katabatic winds and increased sea ice extent and/or a shorter sea ice break-out season between 1300-1850 AD. Bertler et al. (2011) also recorded 67\% decrease in snow accumulation in the LIA compared to the Medieval Warm Period (1140-1287 AD), whereas RICE experienced only an $8 \%$ decrease compared to the previous 200 years (1200-1400 AD) (Figure 5.1).

Another southwestern Ross Sea record, the Mount Erebus Saddle (MES) ice core, indicates strong prevailing katabatic winds between 1500-1800 AD and that the biological productivity in the Ross Sea polynya was 80\% higher prior to 1875 AD than at any subsequent time (Rhodes et al., 2012).

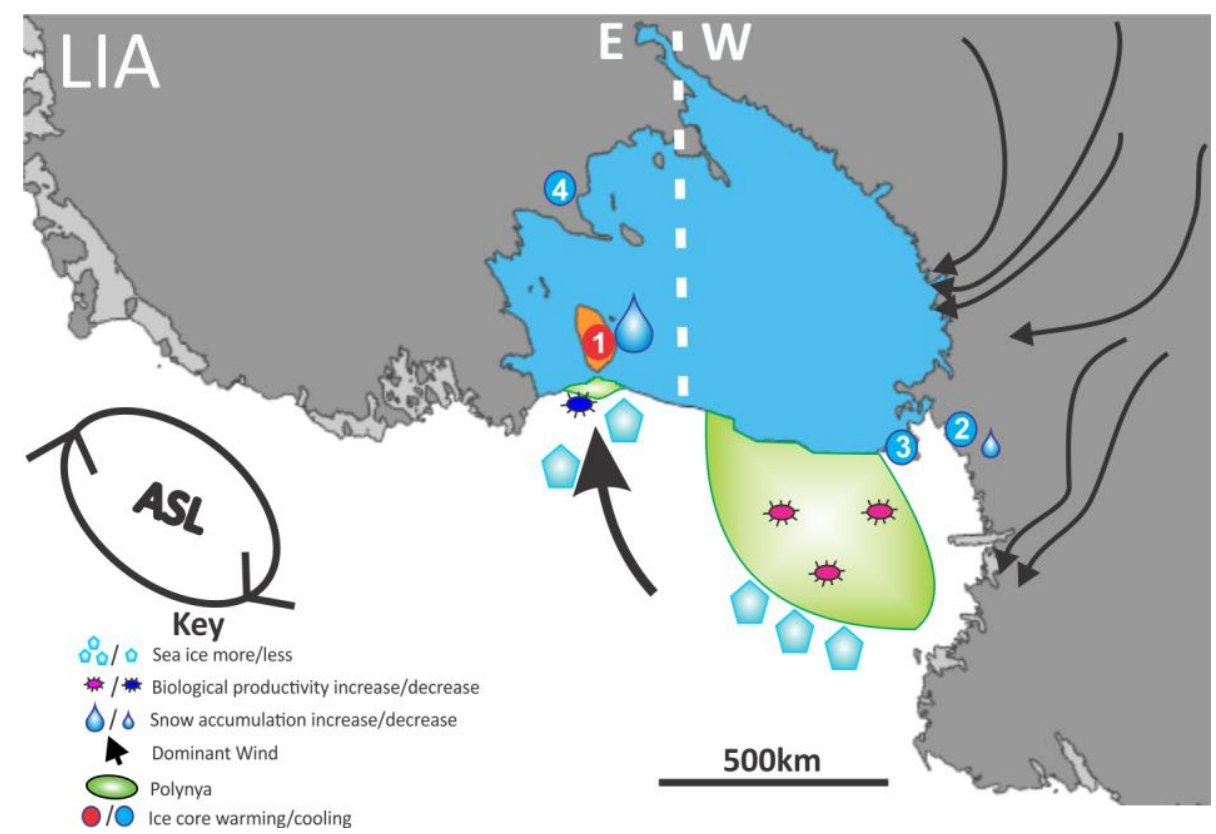

Figure 5.6: Little Ice Age (1450-1850 AD) conditions in the Ross Sea. 1) RICE 2) Victoria Lower Glacier (Bertler et al., 2011) 3) Mt. Erebus Saddle (Rhodes et al., 2012) 4) Siple Dome (Kreutz et al., 2000).

These records suggest an east-west divide in the Ross Sea in the LIA (Figure 5.6). Whereby the western Ross Sea records (Victoria Lower Glacier (2 in Fig. 5.6) and Mount Erebus Saddle (3 in diagram) show a cooling during the LIA, which can likely be explained by the dominance of cold katabatic winds flowing off the continent. Whereas, the RICE record shows a dominance of the marine sourced winds, warmer, 
more moist air masses to Roosevelt Island. Sinclair et al. (2010) revealed that in the McMurdo Sound $90 \%$ of snow precipitation was derived from cyclones from the Ross Sea and further afield, whereas only $10 \%$ occurred during katabatic events, this could account for the greater in snow accumulation at RICE (compared to Modern Era) and the decrease at VLG.

We also see this divide in biological productivity, with the west experiencing an increase in the marine productivity and size of the Ross Sea polynya and RICE recording a decrease in biological productivity. This could potentially be due to RICE picking up a signal from the smaller polynya off its coast, which could have seen a decrease in biological productivity. However, both regions record an increase in sea ice during the LIA.

\subsubsection{Modern Era (1850-1992AD)}

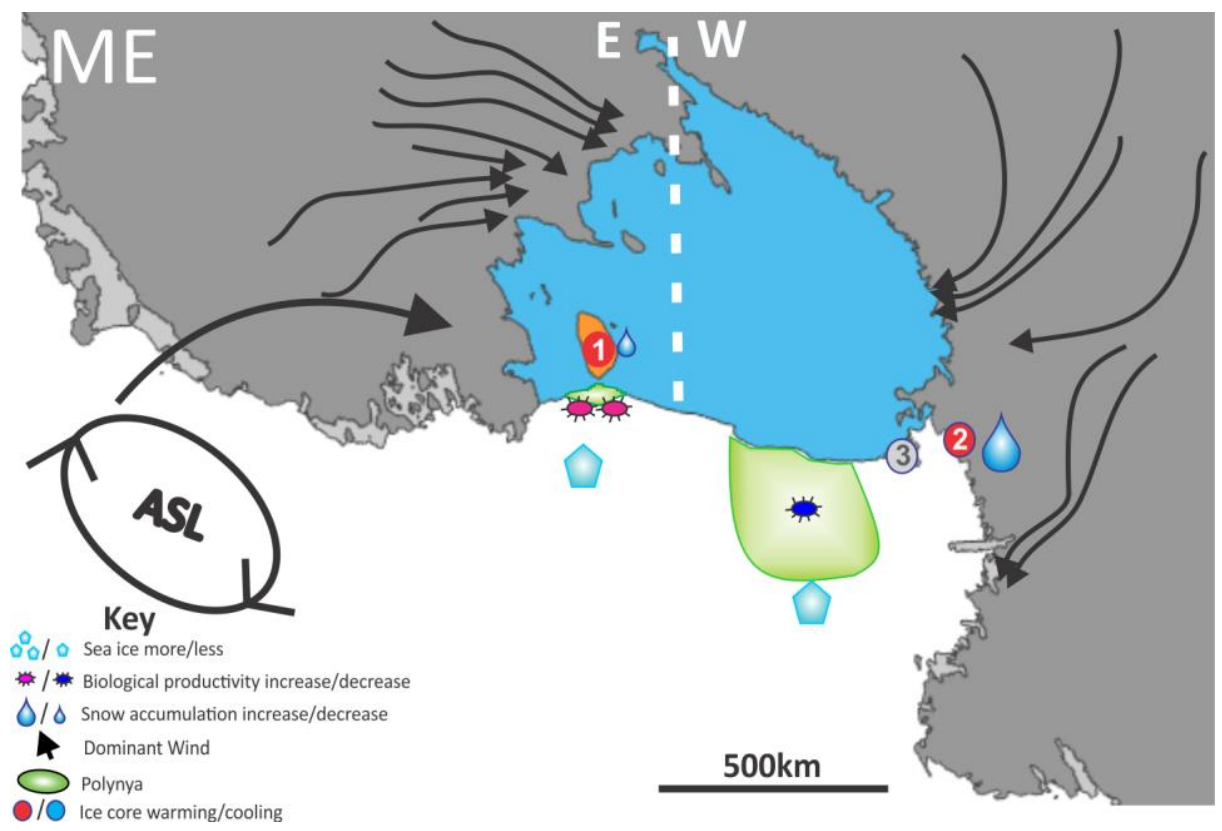

Figure 5.7: Modern era (1850-1992 AD) conditions in the Ross Sea. 1) RICE 2) Victoria Lower Glacier (Bertler et al., 2011) 3) Mt. Erebus Saddle (Rhodes et al., 2012).

In the modern era (1850-1992 AD), the records appear to align more, with both VLG and RICE recording more enriched isotopes/warming following 1850 AD (Figure 5.5). Both records show a dominance of katabatic winds and a reduction in sea ice (Figure 
5.7). MES also indicates the Ross Sea polynya size decreased (Rhodes et al., 2012). However, the RICE record shows an increase in biological productivity during this period, whereas VLG data show a reduction. Our data suggest that RICE might be sensitive to air masses that travelled over the local polynya off its coast, and not the much larger Ross Sea Polynya.

\subsubsection{Explanation for trends in LIA}

These opposing differences in the Ross Sea can be explained by two hypotheses:

\section{1) Roosevelt Island location}

The VLG and MES sites are located in regions dominated by katabatic flow from the Transantarctic Mountains and katabatic surges derived from the West Antarctic ice streams. In contrast, Roosevelt Island is influenced by katabatics off Marie Byrd Land (Figure 5.8). The differences in the marine record are partly accounted for by Roosevelt Island's position in the path of the mesoscale and synoptic scale cyclones that enter the Ross Sea, bringing warm, moist air, laden with sea salts (Sinclair et al., 2010).

Redacted figure due to copyright. Please refer to hard copy.

Figure 5.8: Reconstruction of simulated streamlines of time average katabatic winds over Antarctica, as taken from Parish and Bromwich (1987). Image taken from Carrasco and Bromwich (1994). 1) Roosevelt Island. 2) Victoria Lower Glacier (Bertler et al., 2011), 3) Mount Erebus Saddle (Rhodes et al., 2012). 


\section{2) Ross Sea Low Pressure system/potential shift in ASL}

The proposed east-west divide could be explained by a deep low pressure system shifting into the Ross Sea, with the eastern branch bringing warm marine winds to RICE and the western branch prompting more katabatic winds off the continent at VLG/MES. Kreutz et al. (2000) and Bertler et al. (2011) suggest that during the LIA the ASL probably deepened and previous research has also suggested that zonal shifts in the ASL outside its usual seasonal progression could occur (Cullather et al., 1996; Kreuzt et al., 2000).

According to Cullather et al. (1996) and Kreutz et al. (2000) these zonal shifts can affect the amount of precipitation the Ross Ice Shelf receives. During normal net precipitation conditions, the ASL on average sits near the eastern Ross Ice Shelf. In this instance, moisture is brought to the eastern Ross Sea directly from the north. In this position, the eastern branch brings warmer surface air temperatures and higher precipitation to West Antarctica (Hosking et al., 2013; Schneider et al., 2006; Vaughan et al., 1999). The increased western flank of the ASL will also intensify, causing cold, southerly air to flow off the continent, which has been associated with an increase sea ice extent (SIE) in the western Amundsen and Ross Sea (Massom et al., 2008). We observe very similar conditions during the LIA at RICE. However, in low precipitation events, the ASL moves to the east and closer to the Antarctic Peninsula. The majority of the marine air that reaches the eastern Ross Sea during these conditions travels over West Antarctica, delivering colder, drier air (Cullather et al., 1996).

As previously discussed, the ENSO and SAM phases have a large impact on the ASL. Despite neither climate modes showing a statistically significant effect on the zonal position, evidence has shown an impact on ASL intensity (Turner et al., 2013). The positive SAM phase intensifies the circulation of the ASL and the ENSO has been shown to have a significant influence on the frequency of the marine air mass trajectories from the Ross Sea and Amundsen Seas (Turner et al., 2013; Markle et al., 2012). Emanuelsson et al. (2016) highlights that during El Niño events and negative SAM there is an increased frequency of anticyclone formation in the AmundsenBellinghausen Sea, which results in air masses travelling over western Marie Byrd Land 
and the eastern Ross Sea. During these periods, high precipitation rates and more enriched isotopes are said to occur at Roosevelt Island, as observed at RICE during the LIA. Whereas during La Niña and positive SAM, increased cyclonic activity occurs in the Amundsen-Bellingshausen Sea and anti-cyclonic activity occurs farther northeast over South America, thus air mass intrusion decreases over western Marie Byrd Land/eastern Ross Sea. This leads to a reduced snow accumulation and depletion in the isotope signal at Roosevelt Island (Emanuelsson et al., 2016). According to Emanuelsson et al. (2016) these large differences in precipitation at RICE are due to Roosevelt Island being sheltered from direct moisture from La Niña cyclones due to the West Antarctic orography.

Our records support an association between a westward shift of the ASL and its deepening and/or more EI Niño/negative SAM conditions during the LIA. However, we cannot fully determine the behaviour of the ENSO/SAM during the Little Ice Age. Although zonal shifts/deepening in the ASL can occur, the RICE data do not provide evidence of the behaviour of SAM and ENSO during the LIA. 


\section{Chapter 6: Conclusions and Future Work}

\section{$\underline{6.1 \text { Conclusions }}$}

The Little Ice Age (LIA) is an important climatic interval to study as it is an historically recent event, which is captured in a growing number of records and sites, enabling analysis at relatively high spatial and temporal resolution. The LIA ended with the rise of industrialisation. It has been suggested that the termination might have been premature due to anthropogenic forcing (Painter et al., 2013). Previous work on Antarctic records has indicated an overall cooling during the LIA, however with significant spatial and temporal variability, e.g. sites such as Siple Station recording a distinct warming period (Bertler et al. 2011). The RICE record provides a new opportunity to improve our understanding of the regional expression of the LIA, providing a record for a relatively undersampled region. Moreover, the eastern Ross Sea is a region that is particularly sensitive to changes in the mid-latitudes and tropics and thus can evaluate not only local conditions but the influence of teleconnections through time (Emanuelson, 2016).

For this work, 1020 ice core samples were analysed for eight major ions; $\mathrm{Na}^{+}, \mathrm{Mg}^{2+}$, $\mathrm{Ca}^{2+}, \mathrm{K}^{+}, \mathrm{MS}^{-}, \mathrm{Cl}^{-}, \mathrm{NO}_{3}{ }^{-}$and $\mathrm{SO}_{4}{ }^{2-}$ on an ion chromatograph spanning the LIA to $\mathrm{ME}$ transition. $\mathrm{Na}^{+}, \mathrm{Cl}^{-}, \mathrm{Mg}^{2+}, \mathrm{Ca}^{2+}$ and $\mathrm{K}^{+}$, were identified as sea salt species, mainly sourced from the open ocean. nssSO ${ }_{4}^{2-}$ was determined to capture primary productivity with contributions from volcanic eruptions. Sea salt species show a close relationship to sea ice concentration and evidence of two main volcanic eruptions. A Principal Component Analysis (PCA) identified two main major ion sources; one associated with marine sourced winds (oceanic) and one linked to primary productivity (biological). Fe was used as a proxy for the katabatic winds (inland). Trends in the marine sourced winds/biological record show a complex relationship with climate modes including the El Niño Southern Oscillation, the Southern Annular Mode and the Pacific Decadal Oscillation. 
The RICE record indicates Roosevelt Island experienced warmer conditions with increased snow accumulation (compared to the $\mathrm{ME}$ ), increased marine air mass intrusions, reduced katabatics, increased sea ice and decreased biological productivity. Whereas during the modern era, katabatic winds dominated, along with decreased snow accumulation, decreased sea ice and increased biological activity.

We find that the Ross Sea is characterised by an east-west divide during the LIA, with the western Ross Sea being dominated by katabatic winds and the eastern region by marine sourced winds. This is hypothesised to be due to a low-pressure system sitting in the Ross Sea region, which could be associated with the Amundsen Sea Low.

\section{$\underline{6.2 \text { Limitations and Implications for Future Work }}$}

\subsubsection{Ion Chromatograph Calibration improvements}

This study demonstrated that in order to determine the concentrations of $\mathrm{MS}^{-}, \mathrm{K}^{+}$, $\mathrm{Mg}^{2+}$ and $\mathrm{Ca}^{2+}$ in the low ppb range, a quadratic/curve function must be applied to the calibration, whereas a linear function could be used at higher concentrations. Due to time constraints, this study fitted either a linear or quadratic calibration to each major ion depending on the relevant concentration range. Further work could test the capability of the ion chromatograph to resolve these low concentrations and then subsequently fit these with a quadratic calibration, while still using a linear calibration for the higher values of that ion.

\subsubsection{Iron source}

Assigning a source to dust (i.e. by the use of iron concentration) remains challenging. There are three possible source regions; the West Antarctic ice sheet (WAIS), the Transantarctic Mountains and arid regions of the Southern Hemisphere continents, e.g. Patagonia, South Africa and New Zealand (Neff, 2016). The RICE rare earth element record for this time period could be analysed to identify the dust provenance. Alternatively, assessing another West Antarctic ice core e.g. Siple Dome's iron source 
could also confirm whether our Fe record is sourced from WAIS and hence determine whether it does represent a katabatic wind proxy.

\subsubsection{Climatology}

The patterns we observe during the LIA are consistent with a low-pressure system located in the Ross Sea region and a likely a shift in ASL. Further work could model the climatology in the region to determine its sensitivity to changes in the position and intensity of the ASL, thus confirming whether the trends observed in the LIA could be attributed to this. Analysis of deuterium excess could also help determine the source of the winds.

Further analysis could be undertaken into the complex relationship between the RICE major ion signal and the El Niño Southern Oscillation, Southern Annular Mode and Pacific Decadal Oscillation. Correlating these climate indices (along with their interactions) with the RICE record at seasonal resolution could further our understanding of their impact on Roosevelt Island. A preliminary assessment has been carried out here with the recent finalisations of the annually resolved age model for the RICE record for the past 2,000 years. 


\section{Appendices}

The following appendices are attached on Disc 1:

Appendix A: Ion chromatograph calibration and Quality Control standard data

Appendix B: IC July 2016 Raw Data and Annual Principal Component Analysis

Appendix C: 4 year ICP-MS Principal Component Analysis 


\section{References:}

Abram, N. J., Mulvaney, R., Vimeux, F., Phipps, S. J., Turner, J., \& England, M. H. (2014). Evolution of the Southern Annular Mode during the past millennium. Nature Climate Change, 4(7), 564-569. doi: 10.1038/nclimate2235

Abram, N. J., Mulvaney, R., Wolff, E. W., \& Mudelsee, M. (2007). Ice core records as sea ice proxies: An evaluation from the Weddell Sea region of Antarctica. Journal of Geophysical Research, 112(D15). doi: 10.1029/2006jd008139

Abram, N. J., Wolff, E. W., \& Curran, M. A. J. (2013). A review of sea ice proxy information from polar ice cores. Quaternary Science Reviews, 79, 168-183. doi: 10.1016/j.quascirev.2013.01.011

Arrigo, K. R., \& van Dijken, G. (2003). Phytoplankton dynamics within 37 Antarctic coastal polynya systems. Journal of Geophysical Research, 108(C8). doi: 10.1029/2002jc001739

Arrigo, K. R., van Dijken, G. L., \& Bushinsky, S. (2008). Primary production in the Southern Ocean, 1997-2006. Journal of Geophysical Research, 113(C8). doi: 10.1029/2007jc004551

Bard, E., Raisbeck, G., Yiou, F., \& Jouzel, J. (2000). Solar irradiance during the last 1200 years based on cosmogenic nuclides. Tellus, 52B, 985-992.

Barlow, L. K., White, J. W. C., Barry, R. G., Rogers, J. C., \& Grootes, P. M. (1993). The North Atlantic Oscillation Signature in Deuterium and Deuterium Excess Signals in the Greenland Ice Sheet Project 2 Ice Core, 1840-1970. Geophysical Research Letters, 20(24), 2901-2904.

Bertler, N. A. N. (2004). El Niño suppresses Antarctic warming. Geophysical Research Letters, 31(15). doi: 10.1029/2004gl020749

Bertler, N. A. N., \& Barrett, P. J. (2010). Vanishing Polar Ice Sheets. 49-83. doi: 10.1007/978-90481-8716-4_4

Bertler, N. A. N., Mayewski, P. A., Aristarain, A., Barrett, P., Becagli, S., Bernardo, R., . . Zielinski, A. (2005). Snow Chemistry across Antarctica. Annals of Glaciology, 41, 167179.

Bertler, N. A. N., Mayewski, P. A., \& Carter, L. (2011). Cold conditions in Antarctica during the Little Ice Age - Implications for abrupt climate change mechanisms. Earth and Planetary Science Letters, 308(1-2), 41-51. doi: 10.1016/j.epsl.2011.05.021

Bertler, N. A. N., Naish, T. R., Mayewski, P. A., \& Barrett, P. (2006). Opposing oceanic and atmospheric ENSO influences in the Ross Sea Region, Antarctica. Advances in Geosciences, 6, 83-86.

Bigler, M., Svensson, A., Kettner, E., Vallelonga, P., Nielsen, M. E., \& Steffensen, J. P. (2011). Optimization of high-resolution continuous flow analysis for transient climate signals in ice cores. Environ Sci Technol, 45(10), 4483-4489. doi: 10.1021/es200118j

Bond, G. C., Showers, W., Elliot, M., Evans, M., Lotti, R., Hajdas, I., ... Johnson, S. (1999). The North Atlantic's 1-2 Kyr Climate Rhythm: Relation to Heinrich Events, Dansgaard/Oeschger Cycles and the Little Ice Age. In P. U. Clark, Webb, R.S., \& L.D. Keigwin (Ed.), Mechanisms of Global Climate Change at Millennial Time Scales. Washington D.C.: American Geophysical Union.

Bradwell, T., Dugmore, A., \& Sugden, D. (2006). The Little Ice Age glacier maximum in Iceland and the North Atlantic Oscillation: evidence from Lambatungnajökull, southeast Iceland. Boreas, 35(1), 61-80. doi: 10.1080/03009480500359202

Broecker, W. S. (2000). Was a change in thermohaline circulation responsible for the Little Ice Age? Proceedings of the National Academy of Sciences, 97(4), 1339-1342.

Broecker, W. S., Sutherland, S., \& Peng, T.-H. (1999). A Possible 20th Century Slowdown of Southern Ocean Deep Water Formation. Science, 286, 1132-1135.

Bromwich, D., Rodgers, A. N., Kallberg, P., Cullather, R. I., White, J. W. C., \& Kreutz, K. (2000). ECMWF analyses and reanalyses depiction of ENSO signal in Antarctic precipitation. Journal of Climate, 13, 1406-1420. 
Brook, E. (2007). Ice core methods. Overview. In S. A. Elias (Ed.), Encyclopedia of Quaternary Science (pp. 1145-1156). Amsterdam: Elsevier.

Carrasco, J. F., \& Bromwich, D. (1994). Climatolgocal Aspects of Mesoscale Cyclogenesis over the Ross Sea and Ross Ice Shelf Regions of Antarctica. Monthly Weather Review, 122, 2405-2425.

Carrasco, J. F., Bromwich, D., \& Monaghan, A. J. (2003). Distribution and Characteristics of Mesocscale Cyclones in the Antarctica: Ross Sea Eastward to the Weddell Sea. Monthly Weather Review, 131(2), 289-301.

. Chromeleon 7.2 Chromatography Data System (CDS) Software. (2016): Thermo Fisher Scienfific.

Collins, M., An, S.-I., Cai, W., Ganachaud, A., Guilyardi, E., Jin, F.-F., . . Wittenberg, A. (2010). The impact of global warming on the tropical Pacific Ocean and El Niño. Nature Geoscience, 3(6), 391-397. doi: 10.1038/ngeo868

Crowley, T. J. (2000). Causes of climate change over the past 1000 years. Science, 289, 270277. doi: 10.1029/AR075p0135,doi:10.1029/AR075p0135,Ocean-atmosphere

10.1029/AR075p0135,Ocean-atmosphere

Cullather, R. I., Bromwich, D. H., \& Van Woert, M. L. (1996). Interannual variations in Antarctic precipitation related to El Niño-Southern Oscillation. Journal of Geophysical Research: Atmospheres, 101(D14), 19109-19118. doi: 10.1029/96jd01769

Curran, M., van Ommen, T., Morgan, V. I., Phillips, K. L., \& Palmer, A. S. (2003). Ice core evidence for Antarctic sea ice decline since the 1950s. Science, 302, 1203-1206.

Dansgaard, W. (1964). Stable Isotopes in precipitation. Tellus, 16(4), 436-468.

Delmonte, B., Petit, J. R., \& Maggi, V. (2002). Glacial to Holocene implications of the new 27,000-year dust record from the EPICA Dome C (East Antarctica) ice core. Climate Dynamics, 18, 647-660.

Dixon, D., Mayewski, P. A., Kaspari, S., Kreutz, K., Hamilton, G., Maasch, K., . . Handley, M. J. (2005). A 200 year sulfate record from 16 Antarctic ice cores and associations with Southern Ocean sea-ice extent. Annals of Glaciology, 41(1), 155-166.

Drucker, R., Martin, S., \& Kwok, R. (2011). Sea ice production and export from coastal polynyas in the Weddell and Ross Seas. Geophysical Research Letters, 38(17), n/a-n/a. doi: 10.1029/2011gl048668

Ekaykin, A. A., Lipenkov, V. Y., Kuzmina, I. N., Petit, J. R., Masson-Delmotte, V., \& Johnsen, S. J. (2004). The changes in isotope composition and accumulation of snow at Vostok station, East Antarctica, over the past 200 years. Annals of Glaciology, 39(1), 569-575. doi: 10.3189/172756404781814348

Emanuelson, D. (2016). High-Resolution Water Stable Isotope Ice-Core Record: Roosevelt Island, Antarctica. (Doctor of Philosophy (Geology)), Victoria University of Wellington, Wellington.

Emanuelsson, B. D., Baisden, W. T., Bertler, N. A. N., Keller, E. D., \& Gkinis, V. (2015). Highresolution continuous-flow analysis setup for water isotopic measurement from ice cores using laser spectroscopy. Atmospheric Measurement Techniques, 8(7), 28692883. doi: 10.5194/amt-8-2869-2015

Etheridge, D. M., Steele, L. P., Langenfelds, R. L., Francey, R. J., Barnola, J. M., \& Morgan, V. I. (1996). Natural and anthropogenic changes in atmospheric CO2over the last 1000 years from air in Antarctic ice and firn. Journal of Geophysical Research, 101(D2), 4115. doi: $10.1029 / 95 j d 03410$

Fogt, R. L., \& Bromwich, D. (2011). Understanding the SAM influence on the South Pacific ENSO teleconnection. Climate Dynamics, 36(7), 1555-1576.

Fogt, R. L., Wovrosh, A. J., Langen, R. A., \& Simmonds, I. (2012). The characteristic variability and connection to the underlying synoptic activity of the Amundsen-Bellingshausen Seas Low. Journal of Geophysical Research: Atmospheres, 117(D7), n/a-n/a. doi: 10.1029/2011jd017337 
Gillett, N. P., Kell, T. D., \& Jones, P. D. (2006). Regional climate impacts of the Southern Annular Mode. Geophysical Research Letters, 33(23). doi: 10.1029/2006gl027721

Grove, J. M. (1988). Little Ice Age. London: Methuen.

Hammer, $\varnothing$. (2016). PAST: Paleontological Statistics (Version 3.14). Univsersity of Oslo.

Haug, G. H., Hughen, K. A., Sigman, D. M., Peterson, L. C., \& Rohl, U. (2001). Southward Migration of the Intertropical Convergence Zone Through the Holocene. Science, 293(5533), 1304-1308.

Hosking, J. S., Orr, A., Marshall, G. J., Turner, J., \& Phillips, T. (2013). The Influence of the Amundsen-Bellingshausen Seas Low on the Climate of West Antarctica and Its Representation in Coupled Climate Model Simulations. Journal of Climate, 26(17), 6633-6648. doi: 10.1175/jcli-d-12-00813.1

Indermuhle, A., Stocker, T. F., Joos, F., Fischer, H., Smith, H. J., Wahlen, M., ... Stauffer, B. (1999). Holocene carbon-cycle dynamics based on $\mathrm{CO} 2$ trapped in ice at Taylor Dome, Antarctica. Nature, 398, 122-126.

Jouzel, J., \& Merlivat, L. (1984). Deuterium and oxygen 18 in precipitation: Modeling of the isotopic effects during snow formation. Journal of Geophysical Research, 89(D7), 11749-11757.

Jouzel, J., Waelbroeck, C., Malaize, B., Bender, M., Petit, J. R., Stievenard, M., . . Sowers, T. (1996). Climatic interpretation of the recently extended Vostok ice records. Climate Dynamics, 12, 513-521.

Kaspari, S., Mayewski, P. A., Dixon, D., Sneed, S. B., \& Handley, M. J. (2005). Sources and Transport Pathways of Marine Aerosol Species Into West Antarctica. Annals of Glaciology, 41, 1-20.

Keller, E. D., Basiden, W. T., Bertler, N., Emanuelson, D., \& team, R. (Submitted). Processing, calibration and uncertainity of RICE ice core Continuous Flow Analysis water isotope record.

King, J. C., \& Turner, J. (1997). Antarctic Meteorology and Climatology. New York, USA: Cambridge University Press.

Koch, J., \& Kilian, R. (2005). 'Little Ice Age' glacier fluctuations, Gran Campo Nevado, southernmost Chile. The Holocene, 15(1), 20-28. doi: 10.1191/0959683605hl780rp

Kreutz, K. J., Mayewski, P. A., Meeker, L. D., Twickler, M. S., Whitlow, S. I., \& Pittalwala, I. I. (1997). Bipolar Changes in Atmospheric Circulation During the Little Ice Age. Science, 277, 1294-1296.

Kreutz, K. J., Mayewski, P. A., Pittalwala, I. I., Meeker, L. D., Twickler, M. S., \& Whitlow, S. I. (2000). Sea level pressure variability in the Amundsen Sea region inferred from a West Antarctic glaciochemical record. Journal of Geophysical Research, 105(D3), 4047. doi: 10.1029/1999jd901069

Kushner, P. J., Held, I. M., \& Delworth, T. L. (2001). Southern Hemisphere Atmospheric Circulation Response to Global Warming. Journal of Climate, 14, 2238-2249.

Laj, P., Ghermandi, G., Cecchi, R., Maggi, V., Riontino, C., Hong, S., . . Boutron, C. (1997). Distribution of $\mathrm{Ca}, \mathrm{Fe}, \mathrm{K}$, and $\mathrm{S}$ between soluble and insoluble material in the Greenland Ice Core Project ice core. Journal of Geophysical Research: Oceans, 102(C12), 26615-26623. doi: 10.1029/96jc02660

Lavigne, F., Degeai, J. P., Komorowski, J. C., Guillet, S., Robert, V., Lahitte, P., . . . de Belizal, E. (2013). Source of the great A.D. 1257 mystery eruption unveiled, Samalas volcano, Rinjani Volcanic Complex, Indonesia. Proc Natl Acad Sci U S A, 110(42), 16742-16747. doi: $10.1073 /$ pnas.1307520110

Legrand, M., \& Delmas, R. J. (1984). The Ionic Balance of Antarctic Snow: A 10 Year Detailed Record. Atmospheric Environment, 18(9), 1867-1874.

Legrand, M., \& Delmas, R. J. (1986). Relative contributions of tropospheric and stratospheric sources to nitrate in Antarctic snow. Tellus, 38B, 236-249.

Legrand, M., \& Mayewski, P. A. (1997). Glaciochemistry of polar ice cores- A review. Reviews of Geophysics, 35(3), 219-243. 
Li, Y., Cole-Dai, J., \& Zhou, L. (2009). Glaciochemical evidence in an East Antarctica ice core of a recent (AD 1450-1850) neoglacial episode. Journal of Geophysical Research, 114(D8). doi: 10.1029/2008jd011091

Liu, Z., Lu, Z., Wen, X., Otto-Bliesner, B. L., Timmermann, A., \& Cobb, K. M. (2014). Evolution and forcing mechanisms of El Nino over the past 21,000years. Nature, 515, 550-553.

MacDonald, G. M. (2005). Variations in the Pacific Decadal Oscillation over the past millennium. Geophysical Research Letters, 32(8). doi: 10.1029/2005gl022478

Mann, M. E., Zhang, Z., Rutherford, S., Bradley, R. S., Hughes, M. K., Shindell, D., . . Ni, F. (2009). Global signatures and dynamical origins of the Little Ice Age and Medieval Climate Anomaly. Science, 326(5957), 1256-1260. doi: 10.1126/science.1177303

Mantua, N., \& Hare, S. R. (2002). The Pacific Decadal Oscillation. Journal of Oceanography, 58, 35-44.

Markle, B. R., Bertler, N. A. N., Sinclair, K. E., \& Sneed, S. B. (2012). Synoptic variability in the Ross Sea region, Antarctica, as seen from back-trajectory modeling and ice core analysis. Journal of Geophysical Research, 117(D2). doi: 10.1029/2011jd016437

Marshall, G. J. (2003). Trends in the Southern Annular Mode from Observations and Reanalyses. American Meteorology Society, 16, 4134-4143.

Martin, S., Yu, Y., \& Drucker, R. (1996). The temperature dependence of frost flower growth on laboratory sea ice and the effect of the flowers on infrared observations of the surface. Journal of Geophysical Research: Oceans, 101(C5), 12111-12125. doi: 10.1029/96jc00208

Massom, R. A., Stammerjohn, S. E., Lefebvre, W., Harangozo, S. A., Adams, N., Scambos, T. A., . .. Fowler, C. (2008). West Antarctic Peninsula sea ice in 2005: Extreme ice compaction and ice edge retreat due to strong anomaly with respect to climate. Journal of Geophysical Research, 113(C2). doi: 10.1029/2007jc004239

Mayewski, P. A., \& Maasch, K. (2006). Recent warming inconsistent with natural association between temperature and atmospheric circulation over the last 2000 years. Climate of the Past Discussions, 2, 327-355.

Mayewski, P. A., Maasch, K., White, J. W. C., Steig, E. J., Meyerson, E., Goodwin, I., . . Kreutz, K. (2004). A 700 year record of Southern Hemisphere Extratropical Climate Variability. Annals of Glaciology, 39(127-132).

McConnell, J. R., Aristarain, A. J., Banta, J. R., Edwards, P. R., \& Simoes, J. C. (2007). 20thCentury doubling in dust archived in an Antarctic Peninsula ice core parallels climate change and desertification in South America. Proc Natl Acad Sci U S A, 104(14), 57435748. doi: 10.1073/pnas.0607657104

Meredith, M. P., Murphy, E. J., Hawker, E. J., King, J. C., \& Wallace, M. I. (2008). On the interannual variability of ocean temperatures around South Georgia, Southern Ocean: Forcing by El Nino/Southern Oscillation and the Southern Annular Mode. Deep Sea Research Part II: Topical Studies in Oceanography, 55, 2007-2022.

Miller, G. H., Geirsdóttir, Á., Zhong, Y., Larsen, D. J., Otto-Bliesner, B. L., Holland, M. M., . . Thordarson, T. (2012). Abrupt onset of the Little Ice Age triggered by volcanism and sustained by sea-ice/ocean feedbacks. Geophysical Research Letters, 39(2), n/a-n/a. doi: 10.1029/2011gl050168

Morgan, V. I. (1997). Seasonality in late-Holocene climate from ice-core records. The Holocene, 7(3), 351-354.

Mosley-Thompson, E., \& Thompson, L. G. (1990). Little Ice Age (Neoglacial) Paleoenvironmental Conditions at Siple Station, Antarctica. Annals of Glaciology, 14, 199-204.

Murphy, B. F., \& Simmonds, I. (1993). An Analysis of Strong Wind Events Simulated in a GCM near Casey in the Antarctic. American Meteorology Society, 121, 522-534.

Neff, P. D., \& Bertler, N. A. N. (2015). Trajectory modeling of modern dust transport to the Southern Ocean and Antarctica. Journal of Geophysical Research, 120, 9303-9322. 
Newton, A., Thunell, R., \& Stott, L. (2006). Climate and hydrographic variability in the IndoPacific Warm Pool during the last millennium. Geophysical Research Letters, 33(19). doi: 10.1029/2006gl027234

NOAA-NCDC. (2016). Pacific Decadal Oscillation (PDO). from https://www.ncdc.noaa.gov/teleconnections/pdo/

NSIDC. (2016). All About Sea Ice: Arctic vs. Antarctic. from https://nsidc.org/cryosphere/seaice/characteristics/difference.html

Nylen, T., \& Fountain, A. (2004). Climatology of katabatic winds in the McMurdo dry valleys, southern Victoria Land, Antarctica. Journal of Geophysical Research, 109, 1-9.

Oppo, D. W., Rosenthal, Y., \& Linsley, B. K. (2009). 2,000-year-long temperature and hydrology reconstructions from the Indo-Pacific warm pool. Nature, 460(7259), 1113-1116. doi: $10.1038 /$ nature08233

Orsi, A. J., Cornuelle, B. D., \& Severinghaus, J. P. (2012). Little Ice Age cold interval in West Antarctica: Evidence from borehole temperature at the West Antarctic Ice Sheet (WAIS) Divide. Geophysical Research Letters, 39(9), 1-7. doi: 10.1029/2012gl051260

Painter, T. H., Flanner, M. G., Kaser, G., Marzeion, B., VanCuren, R. A., \& Abdalati, W. (2013). End of the Little Ice Age in the Alps forced by industrial black carbon. Proc Natl Acad Sci U S A, 110(38), 15216-15221. doi: 10.1073/pnas.1302570110

Parish, T. R., \& Bromwich, D. H. (1987). The surface windfield over the Antarctic ice sheets. Nature, 328(6125), 51-54.

Pasteur, E. C., Mulvaney, R., Peel, D. A., Saltzman, E., \& Whung, P.-Y. A. (1994). A 340 year record of biogenic sulphur from the Weddell sea area, Antarctica. Annals of Glaciology, 21, 169-174.

Putnam, A. E., Schaefer, J. M., Denton, G. H., Barrell, D. J. A., Finkel, R. C., Andersen, B. G., . . Doughty, A. M. (2012). Regional climate control of glaciers in New Zealand and Europe during the pre-industrial Holocene. Nature Geoscience, 5(9), 627-630. doi: $10.1038 /$ ngeo 1548

Rahaman, W., Thamban, M., \& Laluraj, C. (2016). Twentieth-century sea ice variability in the Weddell Sea and its effect on moisture transport: Evidence from a coastal East Antarctic ice core record. The Holocene, 26(3), 338-349. doi: 10.1177/0959683615609749

Rankin, A. M., Auld, V., \& Wolff, E. W. (2000). Frost flowers as a source of fractionated sea salt aerosol in the polar regions. Geophysical Research Letters, 27(21), 3469-3472. doi: 10.1029/2000gl011771

Rankin, A. M., Wolff, E., \& Martin, S. (2002). Frost flowers: implications for tropospheric chemistry and ice core interpretation. Journal of Geophysical Research, 107(D23), AAC 4-1-ACC 4-15.

Rankin, A. M., Wolff, E. W., \& Mulvaney, R. (2004). A reinterpretation of sea-salt records in Greenland and Antarctic ice cores? Annals of Glaciology, 39(276-282).

Raymond, B. $(2009,2014)$. The maximum extent of sea ice in the southern hemisphere by day and by winter season Australian Antarctic Data Centre. from http://data.aad.gov.au/aadc/metadata/metadata_redirect.cfm?md=/AMD/AU/sea ice_extent_winter.

Renwick, J., \& Thompson, D. W. J. (2006). The Southern Annular Mode and New Zealand Climate. Water and Atmosphere, 14(2), 24-25.

Rhodes, R. H., Bertler, N. A. N., Baker, J. A., Sneed, S. B., Oerter, H., \& Arrigo, K. R. (2009). Sea ice variability and primary productivity in the Ross Sea, Antarctica, from methylsulphonate snow record. Geophysical Research Letters, 36(10). doi: 10.1029/2009gl037311

Rhodes, R. H., Bertler, N. A. N., Baker, J. A., Steen-Larsen, H. C., Sneed, S. B., Morgenstern, U., \& Johnsen, S. J. (2012). Little Ice Age climate and oceanic conditions of the Ross Sea, Antarctica from a coastal ice core record. Climate of the Past, 8(4), 1223-1238. doi: 10.5194/cp-8-1223-2012 
Rouillard, A., Skrzypek, G., Turney, C., Dogramaci, S., Hua, Q., Zawadzki, A., ... Grierson, P. F. (2016). Evidence for extreme floods in arid subtropical northwest Australia during the Little Ice Age chronozone (CE 1400-1850). Quaternary Science Reviews, 144, 107-122. doi: 10.1016/j.quascirev.2016.05.004

Rustic, G. T., Koutavas, A., Marchitto, T. M., \& Linsley, B. K. (2015). Dynamical excitation of the tropical Pacfic Ocean and ENSO variability by Little Ice Age cooling. Science, 350(6267), 1537-1541.

Sachs, J. P., Sachse, D., Smittenberg, R. H., Zhang, Z., Battisti, D. S., \& Golubic, S. (2009). Southward movement of the Pacific intertropical convergence zone AD 1400-1850. Nature Geoscience, 2(7), 519-525. doi: 10.1038/ngeo554

Schaefer, J. M., Denton, G. H., Kaplan, M., Putnam, A., Finkel, R. C., Barrell, D. J., . . S Schluchter, C. (2009). High-frequency Holocene glacier fluctuations in New Zealand differ from the northern signature. Science, 324(5927), 622-625. doi: 10.1126/science.1169312

Schneider, D. P., Steig, E. J., van Ommen, T. D., Dixon, D. A., Mayewski, P. A., Jones, J. M., \& Bitz, C. M. (2006). Antarctic temperatures over the past two centuries from ice cores. Geophysical Research Letters, 33(16). doi: 10.1029/2006gl027057

Shulmeister, J., Goodwin, I., Renwick, J., Harle, K., Armand, L., McGlone, M. S., . . Curran, M. (2004). The Southern Hemisphere westerlies in the Australian sector over the last glacial cycle: a synthesis. Quaternary International, 118-119, 23-53.

Sinclair, K. E., Bertler, N. A. N., Bowen, M. M., \& Arrigo, K. R. (2014). Twentieth Century sea-ice trends in the Ross Sea from a high-resolution, coastal ice-core record. Geophysical Research Letters, 41, 1-7. doi: 10.1002/2014GL059821

Sinclair, K. E., Bertler, N. A. N., \& Trompetter, W. J. (2010). Synoptic controls on precipitation pathways and snow delivery to high-accumulation ice core sites in the Ross Sea region, Antarctica. Journal of Geophysical Research, 115(D22). doi: 10.1029/2010jd014383

Sinclair, K. E., Bertler, N. A. N., \& van Ommen, T. D. (2012). Twentieth-Century Surface Temperature Trends in the Western Ross Sea, Antarctica: Evidence from a HighResolution Ice Core. Journal of Climate, 25(10), 3629-3636. doi: 10.1175/jcli-d-1100496.1

Sommer, S., Wagenbach, D., Mulvaney, R., \& Fischer, H. (2000). Glacio-chemical study spanning the past 2 kyr on three ice cores from Dronning Maud Land, Antarctica: 2. Seasonally resolved chemical records. Journal of Geophysical Research: Atmospheres, 105(D24), 29423-29433. doi: 10.1029/2000jd900450

Stammerjohn, S. E., Massom, R., Rind, D., \& Martinson, D. G. (2012). Regions of rapid sea ice change: An inter-hemispheric seasonal comparison. Geophysical Research Letters, 39(6), n/a-n/a. doi: 10.1029/2012gl050874

Sun, J., Ren, J., \& Qin, D. (2002). 60 year record of biogenic sulfur from Lambert Glacier basin firn core, East Antarctica. Annals of Glaciology, 35(362-367).

Thompson, D. W. J., \& Mosley-Thompson, E. (1981). Temporal Variability of Microparticle Properties in Polar Ice sheets. Journal of Volcanology and Geothermal Research, 11, 11-27.

Traufetter, F., Oerter, H., Fischer, H., Weller, R., \& Miller, H. (2004). Spatio-temporal variability in volcanic sulphate deposition over the past $2 \mathrm{kyr}$ in snow pits and firn cores from Amundsenisen, Antarctica. Journal of Glaciology, 50, 137-146.

Trouet, V., Esper, J., Graham, N. E., Baker, A., Scourse, J. D., \& Frank, D. C. (2009). Persistent Positive North Atlantic Oscillation Mode Dominated the Medieval Climate Anomaly. Science, 324, 78-80.

Tuohy, A., Bertler, N. A. N., Neff, P. D., Edwards, R., Emanuelson, D., Beers, T., \& Mayewski, P. A. (2015). Transport and Deposition of heavy metals in the Ross Sea region, Antarctica. Journal of Geophysical Research, 120, 1-16.

Turner, J., Phillips, T., Hosking, J. S., Marshall, G. J., \& Orr, A. (2013). The Amundsen Sea Low. International Journal of Climatology, 33(7), 1818-1829.

UMaine. (2016). Climate Reanalyzer. from http://cci-reanalyzer.org 
Vaughan, D. G., Bamber, J. L., Giovinetto, M., Russell, J., \& Cooper, A. P. R. (1999). Reassessment of net surface mass balance in Antarctica. Journal of Climate, 12, 933946.

Villalba, R. (1994). Tree ring and glacial evidence for the Medieval Warm Epoch and the Little Ice Age in southern South America. Climate Change, 26, 183-197.

Welch, K. A., Mayewski, P. A., \& Whitlow, S. I. (1993). Methanesulphonic acid in coastal Antarctic snow related to sea-ice extent. Geophysical Research Letters, 20(6), 443-446.

Winstrup, M., Vallelonga, P., Kjaer, H. A., Fudge, T. J., Lee, J., Riis, M., . . W Waddington, E. D. (In prep). A 2800-year timescale and accumulation reconstruction for Roosevelt Island, West Antarctica. . For submission to Climate of the Past.

Wolff, E., Fischer, H., Fundel, F., Ruth, U., Twarloh, B., Littot, G. C., .. Gaspari, V. (2006). Southern Ocean sea-ice extent, productivity and iron flux over the past eight glacial cycles. Nature, 440(7083), 491-496. doi: 10.1038/nature04614

Wolff, E., Rankin, A. M., \& Röthlisberger, R. (2003). An ice core indicator of Antarctic sea ice production? Geophysical Research Letters, 30(22). doi: 10.1029/2003gl018454

Yuan, X., \& Martinson, D. G. (2001). The Antarctic dipole and its predictability. Geophysical Research Letters, 28(18), 3609-3612. doi: 10.1029/2001gl012969 